Portland State University

PDXScholar

$1-1-2010$

\title{
Music and Conflict Resolution: Exploring the Utilization of Music in Community Engagement
}

Mindy Kay Johnston

Portland State University

Follow this and additional works at: https://pdxscholar.library.pdx.edu/open_access_etds Let us know how access to this document benefits you.

\section{Recommended Citation}

Johnston, Mindy Kay, "Music and Conflict Resolution: Exploring the Utilization of Music in Community Engagement" (2010). Dissertations and Theses. Paper 437.

https://doi.org/10.15760/etd.437

This Thesis is brought to you for free and open access. It has been accepted for inclusion in Dissertations and Theses by an authorized administrator of PDXScholar. Please contact us if we can make this document more accessible: pdxscholar@pdx.edu. 


\title{
Music and Conflict Resolution:
}

Exploring the Utilization of Music in Community Engagement

by

Mindy Kay Johnston

A thesis submitted in partial fulfillment of the requirements for the degree of

\author{
Master of Science \\ in \\ Conflict Resolution
}

Thesis Committee:

Robert Gould, Chair

Rachel Hardesty

Amanda Smith Byron

Portland State University

(C)2010 


\begin{abstract}
This study is based on interviews conducted with twenty-two musician-activists in the Pacific Northwest region of the United States in 2009 to explore perspectives about the role of music in community engagement with the aim of considering how music might be used in the field of conflict resolution. The study followed the qualitative approach of constructivist grounded theory as designed by Charmaz (2000, 2002). Two themes, "Music for Self," and "Music for Society" emerged from interviews and comprise the internal and external meanings of music to the research informants. The results of the study indicate that the relationships people have with music make it a potentially powerful tool in conflict situations within the realms of both conflict resolution and conflict transformation. More extensive research exploring these benefits is recommended.
\end{abstract}


This work is dedicated to Tina Marie Weyland in her endless support of me through this process, and in the rest of life; for expanding my world in countless ways and helping me understand things are not always as they seem; for showing me it is worth every effort to learn a little more and approach life and the people we meet with as much sympathy and compassion as possible. 


\section{ACKNOWLEDGEMENTS}

There are many people to whom I am deeply indebted for their love and support as I went through this journey. I extend my deepest gratitude to Jesse Snyder for believing in me from the beginning and providing hours of conversation, technical assistance and friendship; Tina Weyland for her seemingly endless patience with my questions especially in my frantic moments, her smarts, and her willingness to be my editor; Joseph Eaton for the many needed distractions, for asking questions, providing insight, and being undisturbed by my grumpier moments; Emily Stone for constantly surprising me with herbs, art, books, and the deep well of wisdom and love that she endlessly offered up. Additional thanks to Trisha Rayne, Michelle Doiron, Albert Chimedza and Emily Fern Dayton for the frequent check-ins and encouragement, as well as Stephanie Helm for her editing and support in the final stages. I could not have done this without the love and encouragement from my amazing family: Henry Johnston, Vickie Gritzmacher, Camille Barraclough, and Adrienne Scott. I am also extremely grateful to my committee from the Conflict Resolution Department at Portland State University: Robert Gould for getting behind this and allowing it to happen; Amanda Smith Byron for planting the seed in the first place, for believing I could do it, and for her continual willingness to process with me; and Rachel Hardesty, whose constant guidance, wisdom, and encouragement pushed me through and got me to the end. Because of her, I am a better scholar. Finally, I must thank each of the informants who participated in this study. It was a great pleasure meeting with each of them and listening to their remarkable ideas and experiences. 
TABLE OF CONTENTS

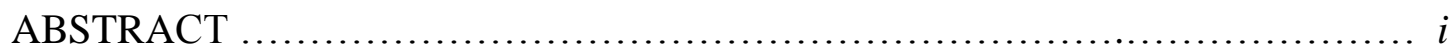

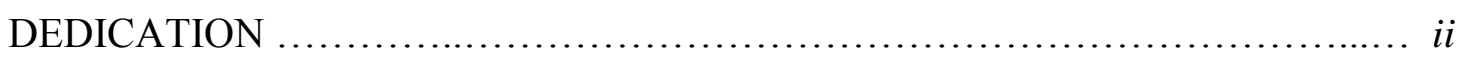

ACKNOWLEDGMENTS.............................................. $i i i$

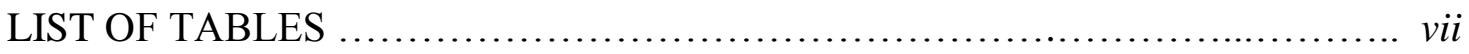

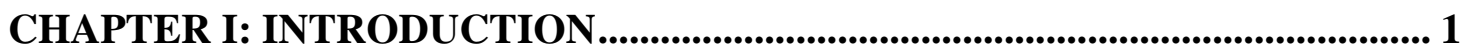

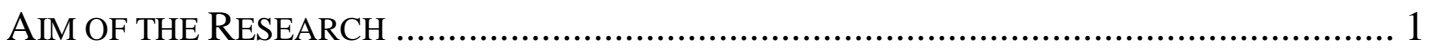

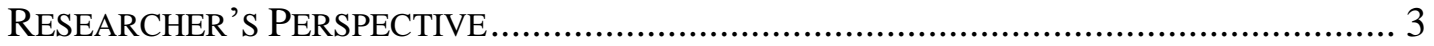

SIGNIFICANCE OF THE RESEARCH.................................................................... 5

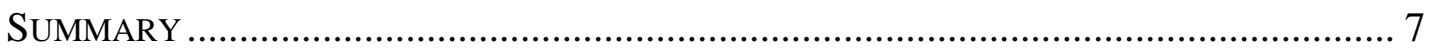

CHAPTER II: REVIEW OF THE LITERATURE ........................................... 8

CONFLICT RESOLUTION: BACKGROUND AND PSYCHOLOGY ........................................ 9

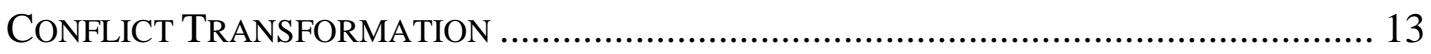

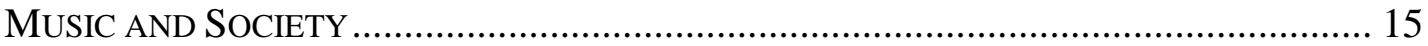

Music, Physiology, Language and Mind ............................................................. 16

Music, Expression and Emotions................................................................ 20

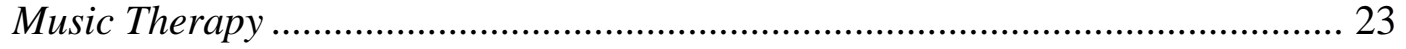

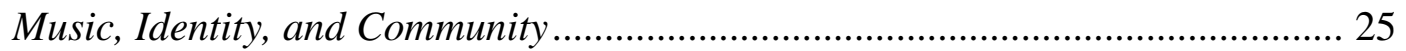

Music, Resistance, and Censorship .............................................................. 31

MusiC AS A CONFLICT RESOLUTION STRATEGY ................................................. 41

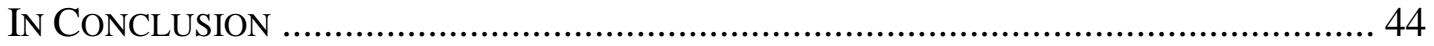

CHAPTER III: RESEARCH METHODOLOGY ................................................... 47

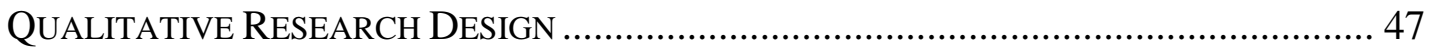

STRATEGY OF INQUiRY: GROUNDED THEORY HiSTORY AND PROCEDURES ............... 49

SELECTION OF INFORMANTS AND DATA COLLECTION............................................. 52

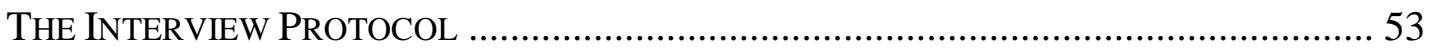

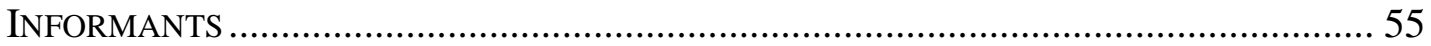




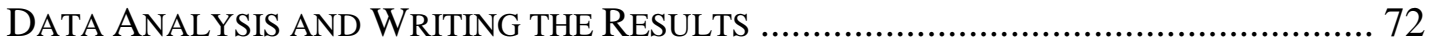

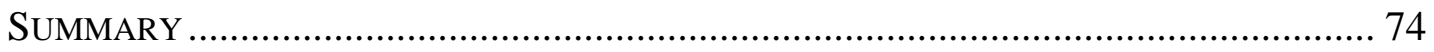

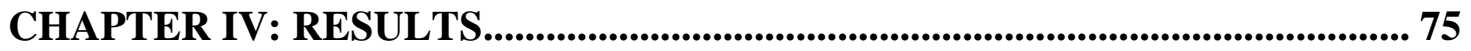

EXPERIENCES AND IDEAS RELATED TO MUSIC AND SOCIAL ENGAGEMENT................. 75

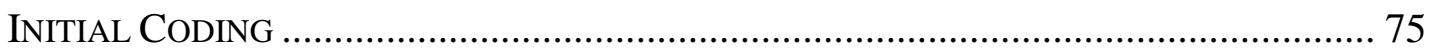

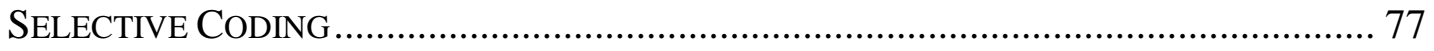

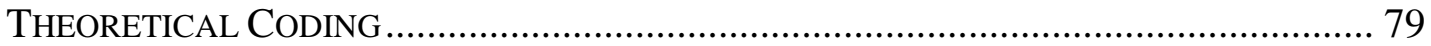

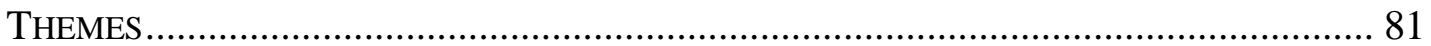

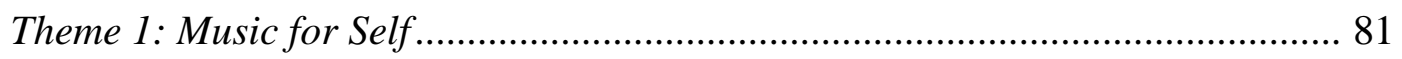

The meaning of music in the informants' lives .......................................... 82

Early memories of music: stories of parental influence .............................. 85

Music, identity and personal activism .................................................... 88

The perceived responsibility of musicians to participate in socially engaged

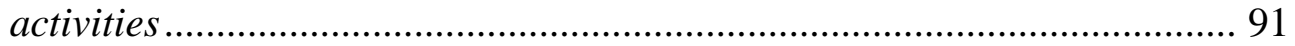

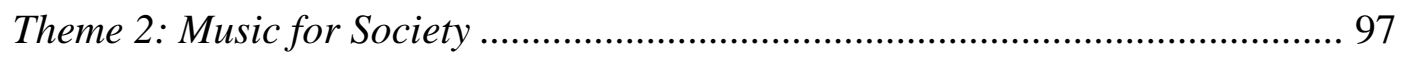

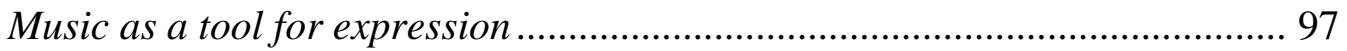

Music's relationship to emotions ................................................................ 101

Music, connection, and community building .......................................... 104

Music as social engagement: values, activities and activism ....................... 109

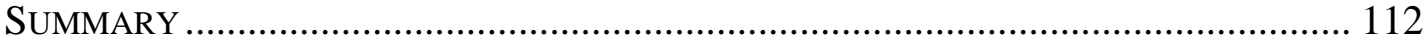

CHAPTER V: DISCUSSION .................................................................... 113

INTERPRETATION/IMPLICATION OF THE RESULTS .......................................... 113

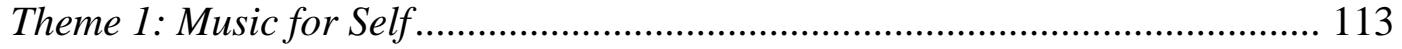

The meaning of music in the informants' lives ........................................... 114

Early memories of music: stories of parental influence ............................. 117

Music, identity, and personal activism .................................................... 118

The perceived responsibility of musicians to participate in socially engaged

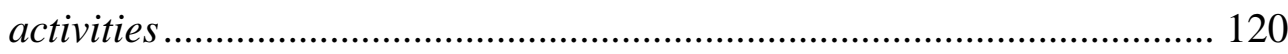


Theme 2: Music for Society ............................................................................. 125

Music as a tool for expression ................................................................ 125

Music's relationship to emotions ............................................................. 129

Music, connection, and community building ........................................... 133

Music as social engagement: values, activities and activism ...................... 138

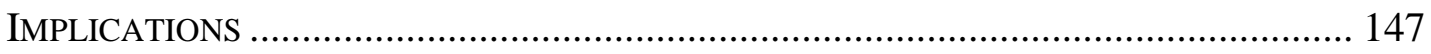

Problems With Music as a CONFLICt Resolution/Transformation TOOL .... 151

REFLECTION ON THE PROCESS - StUDY LIMITATIONS .......................................... 153

RECOMMENDATIONS FOR FUTURE RESEARCH.................................................. 155

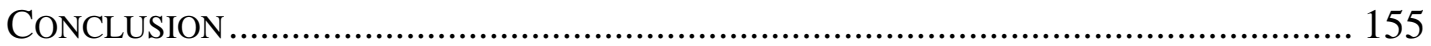

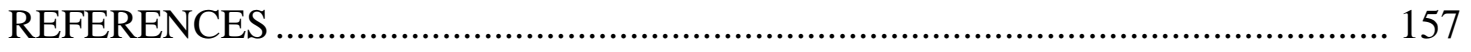

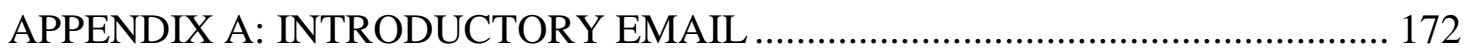

APPENDIX B: INTERVIEW QUESTIONS ................................................ 173

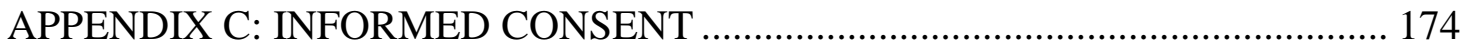

APPENDIX D: HUMAN SUBJECTS RESEARCH REVIEW APPLICAITON ..... 177 
LIST OF TABLES

TABLE

PAGE

1. Initial Coding ................................................. 76 


\section{CHAPTER I: INTRODUCTION}

“We attempt to satisfy our longing to belong” (David, 2004, p. 5).

\section{Aim of Research}

The object of this study is to explore attitudes and beliefs regarding how musician-activists perceive the role of music in community engagement. My research findings indicate that current approaches to conflict resolution will benefit from an increased awareness of how music can be used to foster healthy relations between individuals and within a community. These findings contribute to the aims of conflict resolution and promote a deeper knowledge of the activities being used by musicianactivists from a variety of backgrounds to create social change and transform community issues nonviolently with music. I believe the effects of both conflict and music are deeply powerful in shaping identity and giving meaning to people's lives and the intersection between the two should be explored more fully. The findings expose the benefits these two important disciplines can gain by doing more to consider one another in the work of conflict resolution, and as a result, the gain that the larger society will achieve by approaching conflict with more tools, skills and creativity. The more experts in the fields of music and conflict resolution draw on the advantages this union can offer, the more both fields can mutually benefit from the knowledge and traditions of one another and work to transform conflict situations and engage society in a positive manner. 
Twenty two musician-activists from the Pacific Northwest in the United States were interviewed to explore their values and ideas about the role of music in society and how this might impact conflict resolution. The study made use of constructivist grounded theory methodology with the aid of nineteen interview questions to explore musician-activists' perceptions about the relationship between music and community engagement. Fawcett and his colleagues (1995) have described community engagement as the process of working collaboratively with, and through, groups of people affiliated by geographic proximity, special interest, or similar situations, to address issues affecting the well-being of those people and to bring about environmental and behavioral changes that will improve the health of the community. I have made use of the term "musician-activist" to describe the informants of this study because of the nature of their activities with music to engage people around them on a deeper level, from music educators working with school children learning about different cultures to environmentalists teaching about sustainability issues, to a social worker utilizing music and story to address race issues. Grunig (1992) defines activism as a situation where an individual or group "organizes in order to influence another public or publics through action that may include education, compromise, persuasion, pressure, or tactics of force" (p. 504). In line with Grunig's definition, these musician-activists' activities "to influence another public or publics through action" provide examples that validate the benefits of music as a conflict resolution tool. However, the informants for this study did not necessarily identify themselves as being activists in the traditional sense, though all of them expressed a desire to utilize 
music to connect and teach people in their communities. Despite the fact that not all the informants identified themselves as activists, the term musician-activist will be used throughout the study to describe my initial intent in identifying a clear category of informants and will be further explored in Chapter V.

\section{Researcher's Perspective}

Throughout my life, through every adventure, joy and mishap, music has been a companion to help me reflect, grow and find meaning in my life. I grew up in an environment where music was highly valued; my mother encouraged piano lessons and orchestra while my dad cherished The Beatles and playing bagpipes and saxophone, all of which I also came to treasure. In time, I made my own connection to music that has continually challenged, fulfilled and expanded my experiences in life. In junior high and high school I played in school orchestras and community youth symphonies, an experience that connected me to wonderful and diverse groups of

people that I might not have been exposed to otherwise. Many of these people made a deep impression on me in their enthusiasm for life and compassion toward others and are still important in my life. They are some of the first people outside of my family who I felt saw and accepted me, and in their openness, exposed me to a world much larger than I could have imagined. In college I discovered the wonderful realm of "world music" and studied Irish fiddle, African marimba and Indonesian gamelan. These experiences opened doors and led to journeys I could not have imagined. I have no doubt that, because of music, my life has been enriched in incredible ways that 
have made me a more considerate person and given me a richer perspective in looking at the world. Without music, there would be a great emptiness to who I am.

Meanwhile, my career choices have always led me to social work. I have worked and volunteered with people with Cerebral Palsy, in literacy programs for K$3^{\text {rd }}$ grade students, in homeless shelters, with cancer camps for children and with "at risk" teenage boys and girls. Working with teenagers as a case manager in a residential treatment program had a great impact on me as I witnessed the deep suffering caused by abuse and neglect and the amazing resiliency of these youth. In many ways I felt helpless to make any real change and was motivated to return to school to seek skills I felt could help me be more effective in this work.

When I started my Master's degree at Portland State University, I had just returned from three years of studying Javanese gamelan in Indonesia. As I worked my way through school, I assumed that my studies in music had ended, and that the time had come to focus on the more "real" things in life, a different passion: conflict resolution. However, I quickly found that the role music had always played in my life felt even more potent as I learned about peace and conflict resolution studies and the motivating forces that sway people to take action or to reach out to others to find meaning and understanding. It seemed only natural to delve more deeply into the powerful place of music, not only in my own life, but also in the lives of other musicians and activists, to explore attitudes about music as a positive tool for change and how it has been utilized as a nonviolent tool for social activism around the world. 


\section{Significance of the Research}

Throughout the ages, music has been an important tool for social engagement. In the United States, music played a fundamental role in the civil rights movement and in protests against the Vietnam War (Whitehead, 2008). Music was a life-line for black South Africans during apartheid, helping the oppressed maintain a sense of hope and sending important coded messages throughout the black community (Gray, 2008). In the Israeli-Palestinian conflict, music has been used to question the status quo and explore ways the two societies might learn to coexist (Abi-Ezzi, 2008). Globally, big time musicians such as Angelique Kidjo, Billy Bragg, U2's Bono, Emmanuel Jal, the Blackeyed Peas, Pete Seeger, Bruce Springsteen and numerous others have brought attention to humanitarian crises throughout the world, spreading awareness, encouraging engagement and often raising large sums of money.

But what, might you ask, is the point of all this? What does music have to do with conflict resolution? Despite the increasingly interdisciplinary nature of conflict resolution, it has traditionally been rooted in negotiation, mediation, arbitration, and diplomacy. However, as the ideas around building positive relationships and honoring culture are increasingly identified within the field of conflict resolution as crucial elements in any conflict resolution setting, the field will benefit from expanding the tools it uses to build community; create emotional connections, especially empathy; and foster healthy relations. "Conflict is universal yet distinct in every culture; it is common to all persons yet experienced uniquely by every individual" (Augsburger, 1992, p. 18). Conflict is a part of human existence everywhere and is greatly 
influenced by cultural components. At the same time, music is a central component of every culture and for most of us has great power (Sacks, 2007). Because of this, with the right intention and awareness, music is a potentially powerful and transformative tool in conflict resolution.

Peter van den Dungen (2008) from the Department of Peace Studies at the University of Bradford states, "Of all the arts, music is undoubtedly the art form with the potential to affect people more immediately and more deeply than any other. It can stir the emotions as nothing else, inspire people to the loftiest thoughts and sentiments, and bring them together in indissoluble bonds" (p. xv). Sacks (2007) asserts through his studies in neurobiology that music is as much a part of being human as language, underscoring the powerful influence it has in shaping people's experiences, an influence that is under-acknowledged outside the specific disciplines of music, music therapy, ethnomusicology and, increasingly, neurobiology. Moreover, the potential power of music to transform individuals in conflict situations is under-examined in the field of conflict resolution (van den Dungen, 2008) and the potential transformative relationship between these two disciplines has not been understood or utilized enough in the general study of music. This has resulted in musical practices and traditions as a credible tool for nourishing empathy and building community nonviolently being overlooked by musicians, activists, and academics who miss creative opportunities to transform conflict on a broader scale. To emphasize this point, Reverend C.T. Vivian is quoted as saying: 
I don't see anyone having struggle separate from music. I would like to think that a movement without music would crumble. Music picks up people's spirits. Anytime you can get something that lifts your spirits and also speaks to the reality of your life, even the reality of oppression, and the same time is talking about how you can really overcome: that's terribly important stuff. (as cited in Whitehead, 2008, p. 81)

\section{Summary}

This introductory chapter has given the context for this research about how musician-activists perceive the role of music in community engagement and identified why this study is a valuable addition to the fields of both conflict resolution and music. My perspective has been given to help the reader understand a little more about why this topic is important to me, as well as to give transparency to the connection I have with music and my belief in its significance. Definitions of terms used in this study have been given to provide clarity. The following chapter will give an overview of the field of conflict resolution as well as review the literature related to various aspects of music, such as physiology, language, neuroscience, expression, emotions, identity, community, and the field of music therapy and community-engaged arts practices. Chapter III will discuss the methodology used for this study. Chapters IV and $\mathrm{V}$ will present the results of the study and discuss the implications of this research. 


\section{CHAPTER II: REVIEW OF THE LITERATURE}

"Music is a moral law. It gives a soul to the universe, wings to the mind, flight to the imagination, a charm to sadness, gaiety and life to everything. it is the essence of order, and leads to all that is good, just, and beautiful, of which it is the invisible, but nevertheless, dazzling, passionate, and eternal form" (Plato as quoted in Bonny \&

$$
\text { Savary, 1973, p. 18). }
$$

In order to understand the significance of "How musician-activists perceive the role of music in community engagement" and how that relates to the field of conflict resolution it is important to explore and understand traditional practices in conflict resolution, as well as to investigate broader contexts of music related to musicology and ethnomusicology, psychology, sociology, neuroscience, philosophy, anthropology, and healing. Because music permeates our lives to such a great extent, there is an endless amount of literature in any one of these fields, though there is limited research that directly links music and the field of conflict resolution. It is important to touch on some of the key points related to these broader fields to provide a foundation of understanding that can highlight how music is in fact an important tool for consideration in conflict resolution. However, due to the scope of this study only a small percentage of the material will be included for review. As Olivier Urbain (2008) says in the preface of Music and Conflict Transformation, "It is high time for the human brain and heart to join forces to explore and apply the power of music for peaceful and effective conflict transformation" (p. xii). 
Before delving into the numerous components of music and why it might be useful in conflict resolution settings, it is first important to have a basic understanding of conflict resolution as a field. The following section gives a brief overview of the field before discussing the attributes of music that could make it useful in some conflict resolution settings.

\section{Conflict Resolution: Background and Psychology}

Conflict is an important part of growth and progress for individuals and societies, and it would be difficult to find social groups existing without "convergent and divergent currents" (Simmel, 1955, p. 15). Wilmot and Hocker (2001) describe conflict as stemming from the perception between people or groups that there are incompatible goals, scarce resources or interference from others in achieving their goals. As Augsburg (1992) explains in Conflict Mediation Across Cultures, "Conflict is essential to, ineradicable from, and inevitable in human life; and the source, cause, and process of conflict can be turned from life-destroying to life-building ends" (p. 5). Simmel (1955) goes so far as to declare that conflict is "a way of achieving some kind of unity, even if it be through the annihilation of one of the conflicting parties" (p.13). Conflict is something that has existed throughout history, with a plethora of cultural traditions to manage it. At times though, conflict is no longer constructive and it becomes desirable and necessary to eliminate the violent aspects of conflict (Bergh, 2006). 
The first recorded efforts to understand and avoid war were in response to the first recorded wars (Langholtz, 1998). "The ancient Greeks, wracked by perpetual war, were eager to investigate its causes. Thucydides, writing about war, sought its causes. He expected his history to be useful 'to those who wish to have a clear understanding both of events in the past and of those in the future which will, in all human likelihood, happen again in the same or similar way"" (Kagan, 1995, p. 5). Conflict resolution attempts to understand the underlying causes that lead to the inevitable disputes that will occur and works to find approaches that will lessen the negative impacts of conflict on individuals, in society and between nations. Hugh Miall (2004) describes conflict resolution as the way in which parties can move from zero-sum, destructive patterns of conflict to positive-sum constructive outcomes. He goes on to say the aim is to develop processes of conflict resolution that appear to be acceptable to parties in dispute, and effective in resolving conflict (p. 4).

Conflict resolution began as an interdisciplinary field with practitioners from a range of disciplines looking at conflict as a general phenomenon and applying tactics from management, industrial relations, social work, social psychology, international relations, communications and systems theory (Centre for Conflict Resolution, 2000). The foundation for this field was established after a variety of movements failed to prevent World War I and then World War II, and a handful of scholars were motivated to develop a "science of peace" (Centre for Conflict Resolution, 2000). Conflict resolution emerged further in the 1950s and 1960s during the Cold War and on into the 1970s and 1980s as more institutions and scholarly journals were established. 
Mary Parker Follett, Pitrim Sorokin, Lewis Fry Richardson, Quincy Wright, Gene Sharp, William James, Jonathan Dymond and Kenneth Boulding are just a few of the early scholars in the West that added to this field of study and laid the groundwork for further development of conflict resolution as a field (Centre for Conflict Resolution, 2000; Woodhouse, 1998).

Important tools in conflict resolution are the use of mediation, negotiation, arbitration and dialogue in working with two or more parties to resolve perceived incompatibilities and disputes and discover underlying needs and interests. Concepts such as impartiality, legitimacy, mutual respect, minimum force, credibility and transparency are all crucial components in utilizing the above mentioned tools and in making effective interventions (Woodhouse, 1998). The concept and use of nonviolence, inspired by the work of Mahatma Gandhi, is also an important component of conflict resolution. The aim of conflict resolution is not necessarily to alleviate conflicts, but to work creatively to contain destructive conflicts, and to provide clarity that can channel, alter and ultimately transform the relationship or facilitate mutually acceptable solutions (Augsburger, 1992; Lederach, 1995).

In order to understand and manage conflict, it is important to develop an understanding of the behavior that stems from human needs. Maslow (1943) was instrumental in developing what he called the "Hierarchy of Needs" and includes five sets of goals, or what he calls "basic needs" that include psychological health, safety, love/belonging, esteem and self-actualization. Maslow arranges these goals in order of importance for survival and states that they are related to one another. Paul Sites and 
Johan Galtung have both developed their own theories regarding what they consider to be basic needs (Burrowes, 1996). Sites (1973) describes eight needs that include the need for response, security, recognition, stimulation, distributive justice, meaning, rationality, and control. Galtung (1990) has identified four classes of needs: survival, well-being, identity and freedom.

The drive to fulfill human needs is so strong that individuals will endeavor to satisfy them "even at the cost of personal disorientation and social disruption" (Coate \& Rosati, 1988, p. 7). Sites adds, "the most fundamental component in individual and social life is that of control" (as quoted in Burrowes, 1996, p. 54). Sites' comment highlights how individuals seek to control their physical and social environment in an attempt to satisfy their needs, and gives some insight into how conflicts emerge when people feel they do not have the control they need to do this. According to Burrowes (1996), "It is the existence of needs in humans that makes society possible. Individuals' needs make it necessary for them to attempt to control their environment and, at the same time, to modify their behavior in response to the controls exercised by others" (p. 60). According to this view, at the heart of every conflict is a real or perceived obstacle preventing needs from being fulfilled; this leads to frustration and gives rise to psychological and social processes that make aggression more likely (Staub, 2003). On the flip side, when needs are fulfilled there is a sense of security and positive identity which results in an ability to care and feel empathic toward others, and an openness to others' needs is then more likely. 


\section{Conflict Transformation}

In the context of understanding how music might augment practices in conflict resolution, it is important to consider conflict transformation. Lederach (1995) points out that conflict resolution has come under some criticism for seeking to reduce conflict to create harmony, possibly at the expense of justice. He goes on to say that conflict resolution practices approach conflict as an undesirable situation that should be eliminated and therefore utilize the development of strategies and skills to resolve it. In contrast, Miall (2004) describes conflict transformation as "a process of engaging with and transforming the relationships, interest, discourses and, if necessary, the very constitution of society that supports the continuation of violent conflict" (p. 4). Instead of simply working toward an agreement and moving on with an impression that the conflict is over, conflict transformation seeks to dig deeper into the causes that resulted in a conflict in the first place and to transform the relationships involved.

In Bush and Folger's (2005) The Promise of Mediation: the Transformative Approach to Conflict, they discuss the importance of transformation in any process involving conflict. They state:

The importance of conflict transformation rests on the assumption that people are, by their essential nature, both separate and connected beings, who are distressed whenever negative interaction between them continues, even if their separate needs get satisfied. There is considerable evidence that the desire to change negative interaction is a primary motivator for parties in dealing with conflict. The benefit of conflict transformation responds to the parties' inherent 
sense of social or moral connection, a basic part of their nature as human beings that is not addressed by the other benefits of mediation. (p. 36)

This underscores the point that often the more meaningful intervention in any given conflict situation goes beyond the resolution of specific issues, although that might not be apparent initially. This requires practitioners to focus on not only the content or substance of the conflict, but to explore the less visible dimensions of the relationship (Lederach, 2003). As Henry Wadsworth Longfellow eloquently states, "If we could read the secret history of our enemies, we would find sorrow and suffering enough to dispel all hostility" (2008).

Retzinger and Scheff (2000) propose that it is not alienation or emotion alone that cause protracted conflict, but their denial by the participants. This further supports considering conflict transformation as a process that aims to delve into the underlying dynamics of a conflict, including the emotional responses and relationship dynamics beyond the content of a particular issue, in order to discover long-lasting solutions. Lederach states, "A transformational approach requires that we develop a capacity to see the immediate situation without being captivated, overwhelmed, or driven by the demands of presenting issues. It requires an ability to avoid the urgency that pushes for a quick solution and the anxieties that often accompany a system of relationships as conflict escalates" (2003, p. 48).

It is important to note there is not always a clear line separating how conflict resolution and conflict transformation are used in the literature and at times they are interchangeable, although as can be seen from the above, there are nuances separating 
the two, and many practitioners in the field prefer to think of the work they do as a transformational process. Music's role in society has the ability to address specific issues, as has been suggested is the aim of conflict resolution, but it is also able to give power and insight to less visible components of a person's life, which can lead to a deeper understanding of what is meaningful, as is the aim of conflict transformation. Consequently, it is helpful to have an understanding of both in order to inform what role music might play in specific conflict situations.

\section{Music and Society}

Like conflict, music can be found in every society around the world without exception (Levitin, 2006; Storr, 1992). It appears that making music is an innate human trait that dates back to the beginning of civilization and knows no limits in its reach to this day. The beat and melody might vary from one place to another, but regardless of these variations, music plays part in some of the most important customs and ceremonies of life across cultures, including weddings, funerals, recreational events and important holidays. Due to advances in technology, music is more accessible around the world than it has been at any other time in history (Music Experience and Behavior in Young People, 2008). Fischlin (2003) writes, "Musical sounds are interwoven into the warp and weft of virtually everything. They mediate the world as we know it through being linked in astonishingly diverse ways with images, words, and the formation of community" (p. 15). Music is something that nearly every person on earth is involved in at some level, as listeners and performers, 
in ritual and religion and for fun and relaxation. Lopéz-Vinader (2008) goes so far as to say "our own bodies are made of a huge combination of vibrations, and we could say that we are not matter, nor energy, but 'music'” (p. 153), highlighting how fundamental music is to simply being alive.

\section{Music, Physiology, Language and Mind}

Research has shown that in the earliest experiences of life, infants begin to categorize and differentiate between tones, notice changes in tempo and rhythm and can recognize a melody even if it is played in a different key (Weinberger, 2004). Because of advances in neuroscience and the ability to do brain scans, we now know music processing is distributed throughout the brain and engages nearly every identified region of the brain (Levitin, 2006; Sacks, 2007). Music engages numerous brain functions, including the "reptilian brain" (the cerebellum), involved in motor control and emotion; the hippocampus or memory center; the frontal lobe, responsible for planning and reward; and the amygdala, the "seat of emotions." It is remarkable to consider that from our earliest experiences of life our brains process and identify music, and for the rest of our lives most of us often have music running in our heads, or can recall a favorite piece of music in an instant, further showing how intrinsic music is in constructing and acknowledging our experiences and how it literally is part of us (Sacks, 2007).

Studies conducted with four and five year old children have shown that the more music skills a child has, the greater the child's phonological awareness and reading development (Sousa, 2006a). In addition, listening to music appears to 
stimulate and improve spatial thinking, memory recall, verbal memory and visual imagery with long lasting effects (Sousa, 2006b). Studies have shown that young people who have been given music instruction have performed better academically in reading and math than their peers who were not given the same opportunity, as well as showing a positive effect on the self-esteem and self-discipline of students (2006b). It is important to highlight these benefits of music when thinking about why music is beneficial in any setting, let alone a conflict resolution setting. That the positive attributes of music can better self-esteem and enhance learning increases the potential benefits of using music in conflict resolution, particularly, but not exclusively, in work done with children.

In addition to the positive correlations between music and learning, music affects us physiologically. Depending on the nature of a piece, whether it is happy, sad or expresses some kind of tension, the body reacts accordingly as shown through heart rate, blood pressure, respiration and other physiological measures (Krumhansl, 2003). Music has also been shown to be a powerful tool for people who have had brain injuries or illness impacting brain function (Sacks, 2007). Individuals suffering from Alzheimer's disease and victims of strokes, tumors, or other brain trauma who may have lost the ability to recognize or recall previously known information can still sing songs they learned as children, showing the ingrained and long lasting hold of music (Levitin, 2008). A study at the Yale School of Medicine showed that patients who listened to music of their choice on headphones during surgery required much less sedation, showed a more positive general frame of mind and were less likely to be 
depressed or confused than the control group that did not listen to music. These studies have also shown that surgeons perform better while listening to music (Live Science, 2005).

There has been great debate through the centuries and continuing to this day as to which came first: music or language. We are both a musical and a linguistic species and both require articulation and phonetic mechanisms (Sacks, 2007). Each hemisphere of the brain contains regions that respond both to music and language that are difficult to separate in the first year of life (Sousa, 2006b). Anton Ehrenzweig (1975), a psychoanalyst and musician, wrote:

It is not unreasonable to speculate that speech and music have descended from a common origin in a primitive language which was neither speaking nor singing, but something of both. Later this primeval language would have split into different branches; music would have retained the articulation mainly by pitch (scale) and duration (rhythm), while language chose the articulation mainly by tone colour (vowel and consonants). Language moreover happened to become the vehicle of rational thought and so underwent further influences. Music has become a symbolic language of the unconscious mind whose symbolism we shall never be able to fathom. (p. 164-165)

Darwin (1874) believed that music preceded speech and was an instinctively used mechanism in mating rituals to charm the potential mate and display physical and mental fitness. John Blacking (1987), a British enthnomusicologist and anthropologist, claims that music and dancing preceded language. He says, "There is evidence that 
early human species were able to dance and sing several hundred thousand years before homo sapiens sapiens emerged with the capacity for speech as we now know it” (p. 22). Levitin (2006) suggests that the role of music in human evolution promoted cognitive development through singing and instrumental activities, refining motor skills necessary for speech. Regardless of whether music or language came first, it is clear that music is much more than a superfluous extra-curricular activity. It is one of the tools we use to make sense of the world and it helps us express the meaning we create from our experiences.

It is important to draw attention to the impact and benefits of music when thinking about why music is valuable in any setting, let alone a conflict resolution setting. Music impacts our bodies; it influences our brain and it can enhance our process of learning. Skyllstad (2008) reports that certain musical activities, especially in social settings, lower the concentration of the hormone which induces aggressiveness (testosterone) in men, acting to prevent conflict. It has also been found that music lowers the concentration of the stress hormone cortisone in both men and women, and some tests have shown an increase in the production of oxytocin, a hormone that strengthens social bonding between men and women and ensures greater group cohesion (Bicknell, 2009; Skyllstad, 2008, p. 176). That music can influence so many aspects of our bodies alone is a testament to the importance of music in our lives and the potential power it holds to create change and transformation if used in the right way. If music can help calm a mind and body during surgery, strengthen bonds and 
lower hormones related to aggression it seems an obvious tool to consider during stressful situations of conflict.

\section{Music, Expression, and Emotions}

Music is a powerful vehicle for expression and for the arousal of emotions. Music is used to express ideas and emotions related to all the layers that make up life, and it can have great poignancy for people who hear it or play it. David claims, "Music and emotions are so similar that it is difficult to distinguish where one starts and the other leaves off' (as quoted in Jordanger, 2008, p. 140). Even instrumental music can be a vehicle of ideas and is "revelatory of the world"; it should not be underestimated as it extends beyond the limitations of language to provide meaning (Bicknell, 2009, p. 44). It is important to note that not all music has this power; music often serves only as background noise or worse yet, becomes an irritant. Philosopher Immanuel Kant (1951) disdainfully compared music to perfume in the way they are both able to extend their influence further than desired, highlighting how the presence of music is not always appreciated. However, "once in a while, or often if we are fortunate, we hear music that inspires awe, transfixes us, even stops us in our tracks" (Bicknell, 2009, p. 16). At these moments we might experience chills or possibly be brought to tears because the music has touched something deep in us and tapped into our emotional selves. It is in this place that music holds such potency and power.

In addition to music's role as a powerful form of expression, it is also a conduit for empathy and compassion, a critical element in its importance as a tool in the field of conflict resolution. In "Music and Empathy," Laurence (2008) states: 
Music is often seen to unite us, and also to promote our self-awareness and self-esteem, mutual tolerance, sense of spirituality, intercultural understanding, ability to cooperate, healing - to name but a few. Above all, there is a recurrent conjecture that music can enable people, somehow, to 'get inside' each other's minds, feel each other's suffereing and recognize each other's shared humanity - that is, in common understanding, to have empathy for each other. (p. 13-14) The process of empathizing with another can be powerful in creating a feeling of connection by extending beyond the self and imagining what another is feeling.

Edith Stein (1989), a philosopher who explored empathic experiences, claimed that empathy is not a single event or action but instead is a process occurring over time with many stages. Laurence elaborates on this:

In empathizing, we, while retaining fully the sense of our own distinct consciousness, enter actively and imaginatively into others' inner states to understand how they experience their world and how they are feeling, reaching out to what we perceive as similar while accepting difference, and experiencing upon reflection our own resulting feelings, appropriate to our own situation as empathic observer, which may be virtually the same feelings or different but sympathetic to theirs, within a context in which we care to respect and acknowledge their human dignity and our shared humanity. (2008, p. 24)

Without emapthy, particularly in conflict situations, positions become cemented and in some cases acts of dehumanization and oppression run rampant, ultimately leading to 
extreme violence. Urbain (2008) claims that without empathy peaceful solutions to conflict cannot be guaranteed. Because of music's power to access empathy, it can create a sense of connection with the other and interrupt the "us and them" thinking that often results in further alienation between individuals or groups.

This can be illustrated in Daran Kravanh's powerful story about how music helped him survive life during the violent regime of the Khmer Rouge in Cambodia from 1975-1979. He said:

Yes, music, the power within my accordion's voice, saved my life and, in turn, he lives of others. How can I explain this to you? It is strange, this power beyond myself that made itself known to me when I was only a child. This thing with the ability to touch every human being came through music and through myself. It came through my parents, through strangers, and, in the end, through those who sought to kill me and could not. (as cited in Lafreniere, 2000, p. 3)

Kravahn further said:

Playing music together made us brothers...I thought to myself "Why do people come to listen to this music when they barely have strength to stand? Why don't they go looking for a potato or a few leaves to eat?” And I wondered, why did I not do the same? It seemed I was finding my strength in the music. I came to understand that playing music recreated everything that I had lost: my mother, my farm, my peace, the closeness of brothers. These things were 
sometimes more important than food to sustaining me. So I played my music and survived one more day. (p. 98)

\section{Music Therapy}

Music therapists have utilized the power of music as a healing tool in numerous settings and the field is continually growing. The World Federation of Music Therapy describes music therapy as:

The use of music and/or its musical elements (sound, rhythm, melody and harmony) by a qualified music therapist with a client or group of clients in a process designed to facilitate and promote communication, relationships, learning, mobilization, expression, organization and other relevant therapeutic objectives, in order to meet physical, emotional, mental, social, cognitive and spiritual needs. Music therapy aims to develop potentials and/or restore functions that sometimes cannot be reached through other means of expression. In this way the individual can develop better intrapersonal or interpersonal integration and consequently, a better quality of life through prevention, rehabilitation or treatment. (Petersen, 2005, II 5)

Although the utilization of music as a healing tool can be seen throughout history, music therapy was first developed as a profession after World War I and gained steam after WWII at veterans hospitals in the United States as an intervention to address traumatic war injuries (History of Music Therapy, 2010). These days, music therapists are not only found in veterans hospitals, but also psychiatric hospitals, rehabilitative facilities, medical hospitals, outpatient clinics, day care treatment centers, agencies 
serving developmentally disabled persons, community mental health centers, drug and alcohol programs, senior centers, nursing homes, hospice programs, correctional facilities, halfway houses, and schools (Frequently Asked Questions About Music Therapy, 1999; Lopéz-Vinader, 2008). Music therapist and international director of Music Therapists for Peace, Maria Elena Lopéz-Vinader (2008), asserts that "A person who can feel and express his/her self through music, is better equipped to respond with strength to adversity" (p. 151).

Inspired by the work of Viktor Frankl, a Holocaust survivor, neurologist and psychiatrist, Lopéz-Vinader connects the ideas of Frankl's Logotherapy (logos spirit/meaning) with the practices of music therapy. Logotherapy is a psychotherapy which helps people to find meaning in their lives and to take responsibility for their actions (Frankl, 2000; Lopéz-Vinader, 2008). Logotherapy focuses on responsibility, freedom, values and self-transcendence. Lopéz-Vinader made the connection between Logotherapy, music and her work as a music therapist. This is just one example of the possibilities that exist within the field of music therapy to combine music with other healing practices and the work being done in conflict resolution. She says she uses music to "awaken inner possibilities for growth and inner peace" because music can "bypass" the mind and go straight to the heart (2008, p. 153). Music therapists are important advocates and potential partners in the work being done by conflict resolution speicalists and peace practitioners. 


\section{Music, Identity, and Community}

Music plays an important part in shaping identity and forming community that can result in shared meaning between people. Identity can be understood as an individual's psychological relationship to particular social category systems and memberships, together with a set of personal meanings and experiences related to those systems/memberships, such as gender, religion, class, nationality, race, ethnicity and age (Deaux, 1993; Frable, 1997). Communities are defined by a set of common characteristics, and the identity of a particular community is defined by the specific character of its commonalties. For example, communities are defined by specific common traits of political identity, political commitment, memory, history, tradition, and culture; by variations in their degree of openness; and in their size and scope (Mattern, 1998). Mattern explains, “As a sign of community, music reveals constituent elements such as beliefs, assumptions, and commitments that define the character and shape of the community" (p. 15). This can be seen in a wide range of examples, from the slaves who brought their music to the Americas to the use of national anthems to unify people in a nation, music used in church to express faith, or specific genres of music such as punk or country. Specific instances of music's role in community can be seen in the powerful use of music against apartheid in South Africa, the "singing revolution" in the Balkans where 300,000 singers gathered to sing and demand independence, and the prominent place of music in the Civil Rights and anti-Vietnam War movements in the United States. Music helps shape individual identity within a 
society, and helps to form group identity based on culture, values, religious beliefs, or class. Mattern clarifies:

Music expresses common experiences and, by playing and listening to it, people reexperience its sentiments and forms, which reflects back on the identity of the participants. This, in turn, may contribute to the development of community as individuals acquire and maintain an awareness of common experiences, memories, beliefs, and commitments. If the musician succeeds in integrating common experiences into a piece of music and making it comprehensible to others, he or she clarifies and reinforces the meaning of group life, bringing it into focus. The musician helps the audience recognize a relatedness that may not have existed before. (p. 19)

It is important to add that the musician him/herself might not understand or intend to reinforce group life, but simply by playing music, group life is created in that moment as the individual is part of something bigger than him/herself, resulting in a sense of commonality and belonging.

A powerful example of the community that can be created through music can be seen in the Christmas Truce that took place during World War I in 1914 between German and British/French troops. As the story goes, on Christmas Eve German troops began lighting candles along the trenches and started singing Christmas carols (Brown D. , 2004). Albert Moren from the Second Queens Regiment recalled the scene: "It was a beautiful moonlit night, frost on the ground, white almost everywhere; and about 7 or 8 in the evening there was a lot of commotion in the German trenches 
and there were these lights - I don't know what they were. And then they sang 'Silent Night' - 'Stille Nacht.' I shall never forget it; it was one of the highlights of my life. I thought, what a beautiful tune" (as quoted in Vinciguerra, 2005, II 7). The British and French troops responded with their own Christmas carols and the fighting stopped between the enemies, in many places until Boxing Day. It is estimated that over 100,000 troops participated in the truce, and the spark that started it was the act of singing. The war did continue on, but the singing that happened in the trenches stopped the horror for a short time and must have been a great relief to the troops. The singing of Christmas carols created space for enemies to cross the line without killing or being killed, to exchange gifts, play some soccer and to bury and honor the dead. Pablo Casals says, "Music must serve a purpose; it must be a part of something larger than itself, a part of humanity" (as cited in Lopéz-Vinader, 2008, p. 158). During those few days of the war, music was certainly part of something larger than itself, and as one British soldier said about the Christmas Truce, "The fact is that we did it, and I then came to the conclusion that I have held very firmly ever since, that if we had been left to ourselves there would never have been another shot fired" (Brown D. , 2004, p. 4).

Music is social and it functions to create and reinforce bonds between individuals and communities. Bicknell (2009) states, "When we are moved by music and want to share the music and the feeling with others, this can be the foundation of a deeper relationship" (p. 111). Music creates a means by which people recognize identities and places (which is especially important for diaspora communities), and it 
also acts to reinforce boundaries that separate people (Stokes, 1997). Music creates an environment where a sense of identity "may or may not fit the way we are placed by other social facts" (Frith, 1987, p. 149). Mattern (1998) explains:

Music maintains the differences between different groups even as it solidifies a common identity within them. In other words, the Irish are Irish in part because of the distinctiveness of their musical expression. The way they express themselves musically helps mark them off as a distinctive people. Their music contributes to a universe of shared meanings, memories, and selfunderstanding that differs from the universe of other groups. (p. 21)

Through music, we can feel our own experiences are acknowledged when we find they are shared by others - thus helping to shape our own individual identity - and common interests and concerns can be brought to light. Music making provides an opportunity for bringing people together to engage in activities with others they may not normally interact with, and it can influence how individuals think about their own values and beliefs in relation to others. Depending on the setting, music can confine us within a group or setting, or it can "leap across boundaries and put into play unexpected and expanding possibilities" (Stokes, 1997, p. 24).

Does the meaning of music change depending on our role in the musical activity, whether as a composer, a performer or a listener? Chris Small (1995) has explored this question in his writing about the meaning of music in life. He claims that the central experience of music is in the action of performance, pointing to the central role of the performer, as no performance can happen without a performer. He asserts 
that the performer mediates between the intention of the composer and the desires of the audience. He describes a performance broadly, saying, "It is an encounter between human beings that is mediated by nonverbal organized sounds. All those present, listeners as well as performers, are engaging in the encounter, and all are contributing to the nature of the encounter through the human relationships that together they bring into existence during the performance" (Small, 1995, ๆ 10). Small emphasizes that musical performance is an action that involves everyone whose presence affects the nature of the event, from the performers to the listeners to the dancers to the people organizing the ticket sales, and has coined the term "musicking" to describe this activity. Small goes on to say that finding the meaning that music has in life is directly related to the "act of musicking" because "whatever it is that is being done, we are all doing it together" (II 14).

Small's (1995) perspective is significant in exploring the role of music in giving meaning to human experience because it is inclusive of everyone in society, not just a few gifted members, and the focal point is on the action of "musicking" that brings people together. He says:

The act of musicking brings into existence among those present a set of relationships, at it is in those relationships that the meaning of the act of musicking lies. It lies not only in the relationships between the humanly organized sounds that are conventionally thought of as the stuff of music, but also in the relationships that are established between person and person within the performance space. These sets of relationships stand in turn for 
relationships in the larger world outside the performance space, relationships between person and person, between individual and society, humanity and the natural world and even the supernatural world, as they are imagined to be by those taking part in the performance.... The musicking empowers us to experience the actual structure of our universe, and in experiencing it we learn, not just intellectually, but in the very depths of our existence, what our place is within it and how we relate, and ought to relate, to it. We explore those relationships, we affirm them and we celebrate them, every time we take part in a musical performance. (I 19-20)

According to Small, musical performances are rituals that reflect relationships in society and allow people to explore, celebrate, resist and affirm them in a process of giving and receiving information that links us together. For Small, this is a condition of being alive and a necessary component of our existence that helps define who we are and our place in relation to others.

It must also be noted that music has a dark side and is not always a positive component in people's lives or in society. Music has been used in propaganda, to control groups and to torture people. War also requires creating a sense of unity within a group and music has certainly been used to celebrate war, viciousness, hate, and humiliation. It has been used as a tool to rally troops against an adversary in preparation for killing (Kent, 2008). Explaining how music can be negative or hateful, Kent states, "Hateful music strengthens ties between the collaborators, but at someone else's expense. Thus, a racist ditty sends a message of fellowship to fellow racists. 
[This message of fellowship] is more important than the message communicated to the targets of the racism" (p. 109). An example of this is the role music plays in the white supremacist movement in the United States and Europe, with songs titled "Time for War," "Hurt the Homeless," and "Some Niggers Never Die (They Just Smell That Way)" (White Power MP3s, 2007). However, music's negative influence might not always be so blatant, and understanding circumstances and relationships is a critical component in knowing what impact it might have.

\section{Music, Resistance, and Censorship}

Music can transform a space and strengthen social identity groups which either support the dominant power paradigm or push against it, forming alternative realities and pictures of truth. Abi-Ezzi (2008) succinctly describes music and resistance: "Music as a form of resistance addresses fixed, dominant structures which through their hegemony constitute the status quo" (p. 99). In Gray's (2008) research about the powerful influence of music in South Africa, she highlights the role of music and identity for black South Africans who were oppressed through apartheid. She says:

With regard to the identity and experiential world of black South Africans, music is one of the most important tools for creating an authentic picture of the past. This is mainly due to the fact that music rather than politics provided a voice for black South Africans until the 1990s because there were no other channels open to protest. Steve Biko, the black activist who died in detention, spoke about the fact that any suffering experienced was made more real by 
song and rhythm and "is responsible for the restoration of our faith in ourselves and offers a hope in the direction we are taking from here.” (p. 64)

Miriam Makeba, the famous South African singer and civil rights activist, drives the point home: "In our struggle, songs are not simply entertainment for us. They are the way we communicate. The press, radio and TV are all censored by the government. We cannot believe what they say. So we make up songs to tell us about events" (as cited in Gray, 2008, p. 64). In this way, music in South Africa worked as a crucial component in creating unity and inspiration. It provided a means of accessing information within the black community that otherwise would have been nonexistent or limited at best, resulting in people being extremely isolated. Stokes' (1997) research also supports this notion. He claims, "Just as musical performance enacts and embodies dominant communal values, it can also enact in a powerful, affective way, rival principles of social organization" (p. 13). Music is a dynamic force that by its very nature resists or supports cultural memory and highlights power structures within society, and can ultimately transform individuals' and communities' perceptions.

When oppressed people are being censored by individuals, organizations or governments and have little power within that system, music can be a powerful tool to spread messages, inspire unity, enlist sympathy and inform outsiders about the course of events. Those in power clearly tend to be concerned by this influence, as illustrated by lists of banned music throughout history (for more detailed information see Freemusepedia's list of censored music at http://www.freemuse.org/sw15917.asp). According to the creators of the website Freemuse: 
Music is a free expression of the ideas, traditions and emotions of individuals and of peoples. It may express musicians' hopes and aspirations, their joys and sorrows, their very identity as a culture. Yet these expressions may conflict with those of people in power. The ideas themselves may simply be unpopular or outside the current thinking or practices of a regime or special interest group. For there are those the world over who are threatened by the very nature of a free exchange of ideas. There are those who will stop at nothing to stifle them. (Freemuse: What is Music Censorship?, 2001, II 6)

Music has been cencored by governments, religious groups, mainstream media, families, and educational systems. Governmental censorship of music violates international conventions on human rights such as Article 19: Freedom of Expression, Article 22: Freedom of Association and Article 27: the Right to Participate in Cultural Life (Freemuse: What is Music Censorship?, 2001; The Universal Declaration on Human Rights, 2010).

It is also necessary to acknowledge the power of those who disseminate music (Fischlin, 2003). When independent voices are not allowed to exist under particular governments or in a system of corporate control, cycles of violence and structural oppression continue unabated. Hitler's control of musical life in Germany after 1933 is an obvious example. "Everything modern in musical style was condemned. The new dissonances, especially atonality, as well as jazz or jazz-influenced works, were censured: They smelled of revolution, of independent thinking; they were not Aryan" (Perris, 1985, p. 55). Not only were rules established and enforced, but Jewish 
musicians were banned from performing and their musical works were prohibited from being performed.

The use of music as a means of resistance may be overt, for example, Zimbabwe's Thomas Mapfumo in his efforts toward the independence struggle in the 1970s, Carlos and Luis Enrique Mejia Godoy of Nicaragua in their support of the Sandinistas before 1979, Violeta Parra and Victor Jara of Chile in their support of the citizens and human rights in the 1950s and 60s and Nigeria's Fela Kuti, an avid critic of the Nigerian government and a passionate supporter of human rights, in the 1970s (Fischlin, 2003; Nandorfy, 2003). At other times however, music as a means of resistance or a means of expressing societal dynamics might not be so obvious. Peter Gabriel's WOMAD festivals are an example, bringing musicians from around the world together to celebrate and honor the rich diversity that exists. In talking about the festival, Gabriel says, "The festivals have allowed many different audiences to gain an insight into cultures other than their own through the enjoyment of music. Music is a universal language; it draws people together and proves, as well as anything, the stupidity of racism" (Gabriel, 2010, II 4). The WOMAD festivals celebrate the diversity and creativity of musicians and audiences around the world, although there is no specific regime being targetted.

Overt resistance can present great risk to musicians, many of whom have been harassed, threatened, banned, censored, jailed, tortured or killed (Fischlin, 2003). Fischlin states, "Music focuses community. And that power is to be feared by those who are threatened by it, and celebrated by those who use it to resist oppression and 
liberate expression” (p. 30). According to Orris (2003) and Puterbaugh (2004), the lack of politically motivated music on mainstream radio, such as Clear Channel Communications, the largest media conglomerate of AM, FM and shortwave radio stations in the United States, is just one example of the corporate structure limiting the freedom of musicians to express dissent against the status quo. They assert that this corporate ownership structure distracts the public from citizen involvement because it would not benefit the corporate structure.

Examples that less overtly criticize the status quo and established power structures are benefit concerts like the No Nukes concert in 1979, or the Live Aid, Farm Aid and 'We Are the World' benefit performances in the 1980s, as well as Live 8 in 2005, which focused on poverty. Although benefit concerts are not always overtly critical of the oppression or power abuses behind problems such as poverty, war, and the spread of disease, they help to educate people about situations the public might not otherwise know about and they may encourage people to act. Mattern (1998) explains: Music may help people see worlds that they did not know existed. Like other art forms, it is a vehicle for communicating with other people from other communities. If music expresses the experiences, history, and identity of a people, then it opens the possibility for sharing experiences, understanding the interests and identities of others, and communicating better in general. People are challenged to rethink assumptions about themselves and their lives as they encounter new horizons. (p. 22-23) 
Benefit concerts have successfully raised substantial monetary aid. The Live Aid concerts in 1985 raised more than $£ 150$ million (\$245.4 million). Over 150,000 people attended the concerts and 1.5 billion viewers in 100 countries watched the live broadcasts, the largest satellite and TV broadcasts of the time (Live Aid, 2010). Live 8 , preceding the G8 conference and summit in 2005 , was similarly ambitious and far reaching, with 150 bands at ten venues around the world and over three billion people watching the broadcast. The aim was to create awareness about global poverty and pressure the G8 leaders to fulfill their promises to address that poverty (Live 8: The Story So Far, 2010). These events expose millions of people to humanitarian and environmental issues, raise millions of dollars to support these causes and present a challenge to world leaders. Despite some skepticism about the actual effects of these hugely publicized events, and even claims that money from these events can end up in the hands of rebel groups funding the purchase of weapons, they cannot be easily dismissed precisely because of the power they have in exposing an issue, creating shared experiences and generating opportunity for "encountering new horizons." Resistance and efforts to create positive change within communities through the use of music has also been significant in the arena of community or socially engaged art. Davis (2009) describes community-engaged art as:

A form of art that seeks to undermine the elitism of artistic production and reception. Modernist paradigms have determined who has access to the arts, as a producer and as a consumer, and this has been limited to those with the wealth, education and leisure to be able to "fully appreciate" the difficulty of 
the avant-garde. Following François Matarasso's conviction that access to arts is key to our ability to participate autonomously in democratic society, community-engaged art brings political art practices into the content, methods, processes, and institutions that define and create art. Community-engaged art practices orient themselves to disenfranchised, marginalized groups, in the hope that this will enable art to become more democratic, and for these creative ways of working to open up new political possibilities. (II 3) Naidus (2009) adds that this form of art connects people with their feelings, their pasts, their dreams, and each other and addresses social issues that affect the lives of individuals and communities. She explains the distinction between community/socially engaged art and activism. She says, "Socially engaged work can be done in isolation or within community but usually activist art explicitly or implicitly aligns itself with a social movement of some sort" (p. 4). Naidus further explains that this distinction is vital in understanding that works of art created to incite change in a community do not need to "beat people over the head" or be aligned with a specific movement; their value is ultimately determined by the communities in which the art is found.

Community/socially engaged arts practices are in line with many of the goals of conflict resolution in terms of providing a means of empowerment, and they are a growing area of focus within the arts community. The terms "community-engaged art" and "socially-engaged art" are used interchangeably in the literature and are defined by Davis (2009) as a "form of art that seeks to undermine the elitism of artistic 
production and reception. Community engaged art practices orient themselves to disenfranchised, marginalized groups, in the hope that this will enable art to become more democratic, and that creative ways of working will open up new political possibilities” (\ 4). Naidus (2009) describes the various intentions in which community/socially engaged art is made. They are:

- $\quad$ to process or document something that the artists have experienced or witnessed

- $\quad$ to offer questions about, or solutions to, particular problems

- $\quad$ to foster dialogue between polarized groups

- $\quad$ to awaken those who are numb or in denial

- $\quad$ to compensate for social amnesia

- $\quad$ to heal the maker

- $\quad$ to make the invisible visible

- $\quad$ to express outrage, alert and alarm

- $\quad$ to stretch the mind

- $\quad$ to develop positive images of the future and to envision a different reality

- $\quad$ to find others of like minds

- to make what is most compelling and beautiful in image, object, word, motion and sound (p. 5)

The above list could be inserted into the agenda of any conflict resolution practitioner and nothing would be out of place. Naidus explains, "Bringing socially engaged art 
practice to communities in a way that can be non-threatening and inviting might be one of the most crucial pieces necessary for social change" (p. 4). Conflict resolution and community/socially-engaged arts practitioners are both working to create change, and creating partnerships with greater awareness of the common goals, talents and skills each can provide has great potential for making positive change happen.

There is little research related to why musicians become involved in humanitarian issues or activism and politics. One must assume there is an assortment of explanations that align with people's interests and passions. In Beverly Naidus' (2009) book on community/socially-engaged art, Arts for Change, she says the motivations are guided by multiple desires. She explains:

Some see themselves as cultural or community animators, artists who facilitate a create process within the community rather than as artists making pieces for communities or directing the communities to make works based on the artists' vision. Some artists are driven by a desire to find connection with their neighbors or people who share a life experience like a serious illness or prejudice. For other artists the inclination that draws them to this work is learning about a community that will give them a wider perspective on their world. (p. 44)

Reeves-Smith (2007) adds that the genre of music tends to influence this involvement. In his study of entertainers who get involved in the political process, he describes why some musicians might get involved more than others. He says, "Pop and easy listening entertainers do not tend to develop political relationships with fans, while folk, rock, 
hip-hop and country musicians do develop these relationships. While the later types of music are not inherently political, they frequently deal with daily issues of life. These musicians can become political because of the context of their music and their role in society as troubadours and truth bearers" (Reeves-Smith, 2007, p. 27).

Street (2004) points out that the media often focuses on the political stand of entertainers, which results in an audience that supports the same issues. Reeves-Smith (2007) highlights entertainers' important position as leaders in society and adds that people generally respond to this. However, Marks and Fischer (2002) indicate that Americans do not give celebrity activists much credibility, while they do give time, attention, and financial contributions to celebrity politicians and their causes. This is important in noting that the approach a musician takes in his/her involvement with the community, regardless of whether or not there are similar outcomes and interests, impacts how this engagement is received and consequently supported by members of the community. While this contradiction is helpful in understanding why celebrity musicians might get involved politically, it does not fully address why musicians who are not famous get involved, nor does it address realms of involvement that are less overtly political, such as humanitarian and environmental causes. Understanding more about why and how celebrity musicians engage politically warrants more research, as there is potential for a significant impact on the process and outcomes related to community involvement and support. 


\section{Music as a Conflict Resolution Strategy}

As described above, music is part of our very beings, aiding in expressing emotions, helping us heal, creating a sense of unity and connecting community. Music helps to shape identity and culture, and is extremely important for providing our lives with inspiration. It can help us find our voice to fight against injustice. For these reasons, music can be a powerful tool in the field of conflict resolution. As stated by van den Dungen (2008):

It is imperative that attempts to halt and reverse the cycle of violence draw on the widest possible range of peacemaking instruments and mechanisms. In this context, the potential contribution of the arts has traditionally been ignored or marginalized, and also today is insufficiently appreciated. Of all the arts, music is undoubtedly the art form with the potential to affect people more immediately and more deeply than any other. It can stir the emotions as nothing else, inspire people to the loftiest thoughts and sentiments, and bring them together in indissoluble bonds. These remarkable and unique attributes of music have long been recognized - not least in the forging of armies, with military bands boosting unity and morale. The potential of music for peacemaking rather than war-making has been little explored and is in need of more research. (p. xv)

This utilization of music can vary, from structured listening exercises to hands-on music making activities with an aim to heal and overcome barriers that divide peoples (Cohen, 2008). Bergh (2006) sees music playing a role in conflict transformation in 
the small scale projects that follow protracted social conflicts, in conjunction with dialogue or other appropriate tactics for reconciliation and community building. The role of music can range from one time structured workshops to ongoing community music making opportunities (choral and instrumental groups, community singing, and related music festivals) (Dunn B. , 2008a).

In examining what needs to happen for peace-building after a conflict between former adversaries, Cohen (2008) highlights several important points of the reconciliation process that involve learning more deeply about the communities involved. Her list reflects that of Naidus, above. This process includes:

- appreciating each other's humanity and respecting each other's culture

- telling and listening to each other's stories, and developing more complex narratives and nuanced understandings of identity

- acknowledging harms, telling truths, and mourning losses

- empathizing with each other's suffering

- acknowledging and redressing injustices

- expressing remorse, repenting, apologizing, letting go of bitterness, forgiving

- imagining and substantiating a new future, including agreements about how future conflicts will be engaged constructively. (Cohen, 2008. p. 50) Music can be used to address each of these elements, helping adversarial groups understand each other's frame of reference, background, identity and visions for the future. Jordanger (2008) states: 
Given the right circumstances, music can be very efficient in activating or enhancing the degree of shared content of consciousness. A high degree of shared content of consciousness is potentially very useful as it creates a basis for coherent thinking, ease of communication, common understanding, trust, and a new common identity. All this may unfold, nevertheless, only if the group is in accordance at an emotional level. (p. 142)

This highlights one of music's most significant functions in the work of conflict resolution and conflict transformation: helping people balance their thoughts and become aware of their emotions.

William Zartman's (2003) theory of “political ripening” is also useful to consider, with respect to music's place in conflict resolution. As opposed to other conflict resolution theories which rely on the notion that the success or failure of a peace negotiation is based on the substance of the proposal and the willingness of the parties involved, Zartman's theory states that “the parties' perception of a mutually hurting stalemate is a necessary condition for the opening of negotiations to end a conflict” ( $\mid 1$ ). The status quo and the possibility of escalation must be seen by both parties as no longer acceptable so that the hurting stalemate turns into an "enticing opportunity" (Wallensteen, 2007, p. 43). In order for a conflict to reach resolution, or for the atmosphere to be "ripe," there must be a convergence of events that precede it in order to facilitate a successful peace agreement. This could be another critical place for the use of music in seeking resolution/transformation, by giving the different parties new ideas and perspectives that will "shake them up" or simply by providing a 
break from the stress of the conflict, a break that can bring the common humanity back into focus (Lederach J. P., 2005; Zartman, 2003, II 6). As Reuben M. Koroma says in the documentary film about his band, Sierra Leone's Refugee All Stars, "We are refugees and we know your problems. But the only contribution we have is to detraumatize the people. We want to disoccupy the people from the worries they have. That's why we suggest music" (White \& Niles, 2005).

\section{In Conclusion}

In 1992 during the Siege of Sarajevo, at one of the remaining bread shops that still opened for a few hours a day to provide a much needed staple to residents, snipers took advantage of the fact that people were lined up and a dropped a mortar shell, killing 22 men, women and children. Local resident and world renowned cellist Vedran Smailovic recounts his experience:

Filled with sorrow, I eventually fell asleep at dawn, and was awakened by new explosions and the shouts of my neighbors, who were carrying children and blankets to shelters. I went to the shelter myself and returned home after the shelling was over. I washed my face and hands, shaved, and without thinking, put on my white shirt, black evening suit and white bow tie, took my cello and left home. Looking at the new ruins, I arrived at the place of the massacre. It was adorned with flowers, wreaths and peace messages; there were posters on local shops saying who had been killed. On a nearby table was a solemn book of condolences, which people were signing. I opened my cello case and sat 
down, not knowing what I would play. Full of sadness and grief, I lifted my bow and spontaneously made music. (as quoted in Lederach, 2005, p. 156) Friends and other people from the neighborhood expressed how meaningful his act was for them and how much hopeful the music made them feel (Lederach, 2005). Smailovic showed up every day to play his cello in the rubble and debris of violence to honor those who had been killed. Smailovic said, "I understood then that Albinoni's Adagio is healing music, that music heals, and that this was no longer a purely personal issue" (as quoted in Lederach, 2005, p. 156). During this time a TV reporter approached Smailovic and asked, “Aren’t you crazy for playing music while they are shelling Sarajevo?" He responded, "Playing music is not crazy. Why don't you go ask those people if they are not crazy, shelling Sarajevo while I sit here playing my cello" (as quoted in Lederach, 2005, p. 156).

Although Smailovic's music did not stop the shelling of Sarajevo, it did uplift the spirits of those who heard his music, and must have given Smailovic himself a sense of purpose and control, as he watched day after day as his city was destroyed and his friends and neighbors killed. Smailovic said, "I never stopped playing music throughout the siege. My weapon was my cello" (Sharrock, 2008, ๆ 16). He was not able to stop the violence but he could respond to it with his music, and he became a national symbol of peace in Bosnia. Around the world this story was heard, and there was an outpouring of creative responses to Smailovic's cello playing.

Was this response by Vedran Smailovic conflict resolution? I would say it was, whether that was his intention or not. Each step made to rejuvenate and invigorate our 
common humanity is an indispensable step toward reconciliation and peace. As we continue to discover these powerful acts of humanity stemming from conflict, the things that can create strength, community and aid people in healing will be revealed in the fabric of society and can be seen in the activities and relationships people engage in. Lederach (2005) asks in his book The Moral Imagination, "How, when, and why did politics and developing responses to needed social change come to be seen as something separate from the whole of human experience?" (p. 153). We know music is a powerful force in our lives, in various capacities, and as we continue to use it, we need to continue to study it and share our results. We must keep trying creative approaches in partnership with other techniques in the work of conflict resolution and building peace, and perhaps in these attempts we will find the "ripe" moment where transitions from violent to peaceful management of conflict can happen. As Confucius, who believed music held hidden significance and therefore was one of the most important things in life, said, "The superior man tries to promote music as a means to the perfection of human cultures. When such music prevails, and people's minds are led towards the right ideals and aspirations, we may see the appearance of a great nation" (as cited in Bonny \& Savary, 1973, p. 21; Tame, 1984). To extend this further into the context of the modern world, if music can help lead people's minds to the ideals and aspirations that help to end violence and create healthy connections between us, we may see the appearance of a more harmonious world. 


\section{CHAPTER III: RESEARCH METHODOLOGY}

"Music sets an atmosphere for reason to occur in conjunction with passion" (Stephen

Stills as quoted in Crosby \& Bender, 2000, p.141)

\section{Qualitative Research Design}

Qualitative research was chosen to address my research topic of "How musician-activists perceive the role of music in community engagement." This study was unique because it sought to initiate a discussion of music's role in community toward creating positive change from the viewpoint of those who have done it, primarily musicians and activists. Qualitative research allows for a deep and broad range of data collection methods that are appropriate for understanding this topic from a variety of angles. There is much to be explored and discovered through a deeper understanding of the role of music in people's lives and how that might augment or better practices in conflict resolution settings.

As Pinnegar and Daynes (2007) point out, qualitative research is not about prediction and control, but about understanding. Another key component of qualitative research is a recognition that meaning is socially constructed by individuals and the interactions they have (Merriam, 2002). By utilizing qualitative methodology, I was able to gain a deeper understanding of how different individuals perceive music in relationship to conflict and how they feel about music in their lives, and to consider how music might be utilized more in conflict resolution settings. Qualitative research captures the nuance of informants' experiences and beliefs regarding how both 
conflict and music impact their lives, and how they have used music as a tool to create positive transformations within conflict or potential conflict situations.

This qualitative study employs a grounded theory approach through the utilization of phenomenological interviews to explore this theme with the aim of giving a comprehensive analysis of how individual musicians view the relationship between music and conflict. The use of phenomenological interviews to explore this topic allowed for a broad exploration of informants' thoughts and feelings about the role of music in their lives and in the larger society. As stated by Van Der Mescht (1999), the researcher's task is to "enter that dialogue, and eavesdrop, as it were; to listen in, and capture the essence of what is perceived by the subject" (p. 3). In the retelling of these ideas and experiences, I have employed a narrative writing style, using the informants' voices as much as possible. Utilizing the phenomenological lens, this subject has been explored with the aim of finding its essence from the perspectives of those who have experienced it (Merriam, 2002).

Qualitative research with grounded theory provides deeper validity to this topic and will add to the body of literature on the relationship between conflict resolution and the use of music to create connections between people. I worked with the informants in capturing their opinions and ideas related to music and conflict, and developed a creatively designed interview tool that kept me closely engaged with the topic and the informants in the study. All of these factors support the qualitative framework with grounded theory as the most appropriate research design for this topic. 
My research applied a narrative format through interviews to explore the ideas of Portland area activists and musicians. I was most interested in the lived experiences of those involved in music who have used their art to make a statement or engage the community to address community issues. I believe music has played an important role for many people in providing comfort, creating community and generally giving more depth to our lives, creating enriching experiences that help us make sense of the world. This study has certainly been shaped by my beliefs, though by framing the research with a narrative interview approach I hope to tell this story not in my voice, but in the words of the twenty-two informants who spoke with me. In this study I have explored the way Portland area activists and musicians have used musical expression as conflict resolution and community building. I did not expect to find just one answer about what the role of music should be in the field of conflict resolution, but a variety of potential approaches and opinions that can be considered within the constraints and realities of particular situations.

\section{Strategy of Inquiry: Grounded Theory History and Procedures}

Grounded theory was developed by sociologists Glaser and Strauss in 1967 as described in their book titled The Discovery of Grounded Theory: Strategies for Qualitative Research (Bernard \& Ryan, 2010). Grounded theory research uses varied forms of data collection with the aim that "We researchers will see the basic social process in the field through our respondents' telling us what is significant" (Charmaz, 2000, p. 514). Grounded theory studies portray moments in time, slices of social life. 
They foster the identification of connections between events and, significantly, remain open to refinement (Charmaz, 2000; Creswell, 2009).

This study's primary source of data collection within grounded theory comes from interviews exploring informants' experiences and the social conditions that influence those experiences, which are then used to build theoretical frameworks to explain the data. As Charmaz (2002) explains, interviews are utilized to "explore, not to interrogate" (p. 679) informants, and meaning is derived from their lived experiences. As Bernard and Ryan (2010) explain, "Informants and researchers create data together, interactively, during the interview" (p. 270). Charmaz (2000) highlights that an important aspect of grounded theory is its durability because it accounts for variation and researchers can make ongoing modifications to their analysis. According to Bernard and Ryan, grounded theory is the most widely used research method across the social sciences for collecting and analyzing data about how people experience the world.

Since its inception in 1967, grounded theory has been contested and Glaser and Strauss (with his co-author Corbin) have taken the method in different and sometimes conflicting directions (Charmaz, 2000). The primary differentiation that has emerged is that Glaser's grounded theory dictates that theory emerges from data alone and any preconceived notions by the researcher are excluded from analysis. Strauss and Corbin's grounded theory allows for greater involvement of the researcher's insight into the topic being explored and the theories that emerge. Their theory recognizes art as well as science in the analytic product and process (Dunn, 2008b; Charmaz, 2000). 
This research study is in line with Strauss and Corbin's philosophy of grounded theory.

Charmaz (2000) developed grounded theory even further with constructivist grounded theory. Charmaz states, "Constructivism assumes the relativism of multiple social realities, recognizes the mutual creation of knowledge by the viewer and the viewed, and aims toward interpretive understanding of subjects' meanings" (p. 510). The researcher that makes use of constructivist grounded theory looks at phenomena in society and tries to show how they are socially created through action, intention, and routine while acknowledging they are not totally external from it (Charmaz, 2000).

A primary component of grounded theory research in identifying a theory is coding the data (Bernard \& Ryan, 2010). Coding data is a way to interact with the material in a way that helps identify common themes, gain new perspectives and focus further data collection (Charmaz, 2000). This research, in line with grounded theory, used three steps in the coding process: 1) initial coding, 2) selective coding, and 3) theoretical coding. Initial coding is a process used to filter through the data and identify key words or phrases from the data. Selective coding identifies common themes that emerged from the data, in this case, across interviews. Finally, theoretical coding links the themes in order to explore the relationships between them and situate them in relationship to this study. An important tool in grounded theory is the researcher's practice of keeping running notes throughout each of these coding phases, called "memoing." Memoing is an important tool for noting observations and insights 
about the topic being explored, refining categories and helping to solidify theories related to the research. My use of memoing included taking notes about recurring topics in an interview, body language, the length of the interview and repetition of themes that were brought up in other interviews. The results of this study, in line with constructivist grounded theory, will be reported and explored in chapters IV and V.

\section{Selection of Informants and Data Collection}

I began this process by examining Portland based projects such as Voices for Silent Disasters, the Aurora Chorus, Rock and Roll Camp for Girls and the Portland Peace Choir. After this initial search, I contacted potential musician-activists with an introductory email (see Appendix A) or with a phone call to request and set up an interview. As I conducted interviews, informants suggested other musicians or activists (snowball sampling) who have made use of music in a way that stretches beyond the scope of mere entertainment, such as musicians who perform benefit concerts or work with school children to explore diversity through music (Bernard \& Ryan, 2010). Within a few weeks I had a pool of thirty five possible research informants. Between August and November 2009, I conducted twenty one interviews in person and one over the phone. These interviews included a range of activists and musicians, from professional to hobby, in the Portland area (including two from Seattle) who responded to my request for an interview. All the musician-activists interviewed have used music as a means for addressing conflict or have developed music as a tool for engaging the community in social/community issues. The activities 
of the informants will be described in more detail later in this chapter. Each interview was recorded with a minidisc player, with the consent of the informants, and later transcribed word for word. I also made use of memoing as described above, writing my own notes and observations about each of the interviews conducted.

My goal was to connect with a substantial sample of Portland area musicianactivists who have engaged in the process of using music as a tool for community engagement, in order to find out more about the process and understand the beliefs behind these activities. I wanted to more deeply understand how this engagement has affected the informants' lives as well as the communities in which they have lived and worked. I made an effort to balance gender, race and age in this study because it was important to have a broad range of perspectives, which are certainly influenced by these factors, in order to have a variety of experiences and ideas to consider. The primary methodological tool used in this study was coding of the data (interviews) in line with grounded theory methodology in order to develop themes and categories that will be discussed further in chapters four and five.

\section{The Interview Protocol}

The data collection tool consisted of nineteen open ended questions formatted in a circle (see Appendix B), with the aim of allowing the most flexibility possible so that the informants could express their knowledge and experiences without having to follow any particular order in responding to the questions. The interview questions were sent to the informants with the introductory email so they could have time to 
look them over before the interview. I talked with people from a wide range of backgrounds and careers and with varying degrees of involvement in music, which necessitated a level of broadness in the questions. The questions were based on the literature reviewed and my own experiences, with the hope of allowing as much room as possible for the diversity and creativity of the informants to be expressed and explored.

In addition to employing a circular interview instrument with broad, openended questions, I color coded the questions into three categories to aid in my own coding process. The three categories were: 1) personal stories related to this topic (blue), 2) application related to music and community engagement (green) and 3) theory/philosophy related to the perceptions of the power of music (red). The colors chosen to represent these categories were arbitrary and were simply used to create a clear visual grouping of the categories. The color coding did not seem to impact the interview process or the way informants answered questions, as some informants answered each question presented while others chose only those questions that were most interesting to him/her. In future studies of this nature, a follow up survey would be useful in determining this for sure. During the interview process not all questions were addressed at each interview, though every informant answered two questions that I thought were especially important in exploring this topic. These questions were: 1) “Do you consider yourself an activist? Why or why not?" and 2) "Please explain any activities you have been involved in that utilize music as a tool for raising awareness about something in your community." I took an 11x17 copy of the instrument tool to 
each interview. Many of the informants had already printed out their own copy of the instrument and had made notes around the circle to remind them of things they wanted to be sure to address during the interview.

\section{Informants}

As mentioned above, I conducted twenty two interviews with musicianactivists in the Portland area to explore "How musician-activists perceive the role of music in community engagement." Thirteen men and nine women between the ages of 28 and 69 were interviewed. Four of the informants were born in a country other than the United States. Because the stories and experiences of the informants are really the heart of this study, it is important to describe a little about each. This section will give a brief outline and background of each of the informants' activities in order to provide a snapshot of each individual.

It is important to note that some of the informants of this study are high profile musicians often in the public light, while others are hobby musicians and are not necessarily well known for their activities related to music. I have used musical pseudonyms in place of real names in order to freely explore and analyze the material gathered without focusing too much on any one participant's status in the broader society. It is my belief that all the opinions and experiences expressed are equally important to consider.

I chose pseudonyms that either reflect some aspect of my time with the informant or describe my own interpretation of some aspect of their personality that I 
observed during our meeting, evoking another layer of information to be considered in the process of analysis. Pseudonyms are helpful because the aim of this study is to get at the heart of beliefs related to music and community engagement without being distracted by social status or anyone's particular identity. The use of pseudonyms also protects the integrity of the interviews and the privacy of the informants. The following summaries are by no means a complete picture of who they are or what they do, but simply a glimpse into who they are and why I was interested in speaking with them for this study.

- Acceso (ignited, on fire): Acceso is a man who grew up in several Western African countries and eventually ended up in Portland, where he has pursued his Master's degree in Conflict Resolution. He has been passionate about music since his youth and recently released his first $\mathrm{CD}$, something he was visibly very proud of as we spoke. He has done performance workshops with middle and high school students utilizing music and story to share his experiences about structural oppression and "coming from what the West calls a third world country." Acceso told me, "My experience with music is really the highlight of pretty much my life, if I can put it that way." Acceso and I met in a coffee shop and talked for an hour and a half. As we talked, his guitar leaned against the wall behind him, helping to frame the mood of the discussion.

- Aleatory (chance music; from the Latin word "alea," meaning dice. This is music in which some element is left to chance and/or an element of the 
composition is left to the performer to decide): Aleatory is a woman now in her mid forties who grew up with a grandfather who played organ and a mother who was a music teacher, who now finds that she enjoys singing and being part of a band. She works locally and internationally as a trainer, coach, facilitator and consultant and has her own business doing this work. Her graduate work focused on transformational learning, systems theory and change management and resulted in a degree in Organizational Psychology. When asked what her relationship with music is she answered, "I use it in my work to help people obtain, define, refine, develop their voice in everything that they do. So to me it's - music is now a venue for empowering people and teaching them so that we have a common thread that we can talk about that isn't personal but is deeply personal." I met Aleatory at her office, a beautiful place surrounded by trees, where her dog was by her side and at times influenced parts of our discussion. We talked for over an hour with Indonesian music playing softly in the background and hot tea at our side.

- Aliquot (after Aliquot strings: piano strings placed above normal piano strings resulting in an unusual resonating sound when strings are struck by the piano hammers): Aliquot is a middle aged man who is deeply involved in the arts scene in Portland. He is a jazz musician/composer and conceptual artist. He has been a culture writer for local newspapers and currently works at a local theater where he is responsible for community programs, partnerships and outreach. A mutual acquaintance once described him as "one of the most 
engaged and knowledgeable artists in Portland." His list of activities and his apparent connection to every other artist in Portland are proof of this. On his website he says he is "fascinated by the slim corridors running between art, utility, entertainment, and civic engagement." I was interested in talking with him about my research topic because of his broad range of interests and activities. As we talked about what he does he said, "I think especially with the performing arts, you're naturally convening groups of people around ideas. I look at that as an incredible opportunity to dig a little deeper and to ask some good questions." We met at his place of work and talked for just under an hour (due to time constraints).

- Alzate Sordini (lift or raise the mute/expose the brighter sound of the instrument): Alzate Sordini is a middle aged woman who has worked as an educator, activist, program director, and philanthropist. She has consulted locally and in Uganda and is currently pursuing a business in life coaching. After dealing with a serious illness she got involved with music and is now playing in a successful band that just released their first CD. Alzate Sordini was one of the first people I met with for this study and I feel I owe her a tremendous amount in igniting my motivation and excitement to delve more deeply into this topic and to be fully present and aware during the time I spent with the other informants of this study. We met in a coffee shop and talked for three hours. Early in our time together she said to me, "The ripple effect is profound and wide." 
- Ardore (with love and warmth): Ardore has a degree in Speech and Human Sciences and worked in a classroom with children living with special needs for a decade. She has played music since she was a child and is now working on her career as a singer-songwriter. She has played in bands since high school and has released numerous albums of her music. Ardore realized that by being a musician she was in a good position "where I can do something because of music" and started playing benefit concerts. She was inspired to get involved with a local nongovernmental organization (NGO) to help raise money for projects they are involved with around the world. She was able to travel to Uganda and during our meeting shared wonderful stories about the impact of this journey on her life. When she returned to the Northwest her idea of doing a house concert to raise a few thousand dollars turned into a huge event that included hundreds of musicians, several venues and months of preparation time, and resulted in raising $\$ 69,000$ for projects in Uganda. When talking about this huge accomplishment Ardore said, "The seed for all of that was music. Everybody is already together for music, so it's the perfect thing to just weave in the act of...the raising money part." Ardore and I met at a tea house on a bright sunny day. She was easy to talk to and very down to earth despite her many accomplishments. We talked for a little over an hour.

- Ballad (a narrative poem, often of folk origin and intended to be sung): Ballad grew up with parents who loved music and along with her siblings started learning piano at a young age; she eventually also taught herself guitar. She is 
now an accomplished composer and conductor and has received prestigious awards and fellowships for her work. She currently leads an all women's chorus with over 100 women participants. The mission of the chorus is "to inspire and reflect the universal yearning for peace by giving voice to women" and members have participated in numerous community outreach events. Ballad enjoys collaborating with a variety of performers; her music has been performed by dozens of choral groups around the United States and will soon appear on a benefit CD supporting AIDS education in Africa. As we explored this topic together Ballad said, "Singing, the act of singing, I believe, just opens you up. It just opens your heart up. It does that." We met at her home office, catching the last rays of summer sun, while we drank coffee and talked for about two hours.

- Bruscamente (brusquely): Bruscamente is a singer-songwriter and composer who has released several CDs and started her own record label. She has helped organize a local non-profit that works to build girls' self-esteem through music creation and performance and encourage social change and the development of life skills. She has played in hundreds of benefit concerts to "engage people about issues." When we talked about the idea of activism, Bruscamente said, "I think that music is a really important and useful way to appeal to people's emotional lives and manipulate them...convince them of things. Convince them of ways of feeling." She teaches in a Women's Studies Department at a local university and works with homeless teens in an urban setting. She is also 
an advocate of the gay rights movement. The day Bruscamente and I met at a coffee shop she was not feeling well and our interview only lasted about twenty five minutes. My interview questions/tool did not seem to "click" with her and she felt that several of the questions were repetitive. However, the feedback I got from her has been very important to my process of exploring this topic.

- Colia Voce (with the voice) and Con Larghezza (with broadness): Colia Voce and Con Larghezza are part of a group of seven people who started a local choir with a mission of peace. The choir website expresses their philosophy as follows:

Singing in a Peace Choir is about much more than making music. It's a radical act of optimism - knowing that what we do makes a difference. It's engaging in activism. It builds community. We who sing in this choir believe in what we are singing. We see our music as a path to creating more peace not only in our own lives, but for our families, our neighbors, our nations and the world. We sing to lessen our own isolation. We sing to feel connection, to belong and to feel joy. We sing to learn new languages, to honor sacred traditions, to heal our wounds. We sing because someone once told us that we couldn't. Both Colia Voce and Con Larghezza are healers in their own right, outside of the time they spend singing with this community choir. Colia Voce works as a massage therapist and has been and is currently involved with other musical 
activities in the area, including a choir for "women singing peace," the local group of Dances of Universal Peace and the Portland Revels. Colia Voce led me to think about the importance of making music with your own voice and the power this can have. Con Larghezza is finishing his $\mathrm{PhD}$ in counseling and has spent time working with and supporting men who have been perpetrators of violence. Con Larghezza was also instrumental in inspiring me to think about the categories and labels I have used in my examination of this topic. I met them at their home where we drank tea and talked at the dining room table for a little over an hour.

- Con Moto (with motion): is a professional singer-songwriter and grassroots political activist in his early 40s. Con Moto grew up with parents who played classical music and started playing classical music himself at an early age. In his teens he discovered artists like The Grateful Dead and Phil Ochs, further fueling an interest in music that eventually led him to learn guitar and write his own songs. He has released numerous CDs and has travelled internationally singing songs against war and globalization and advocating social justice. He has made his recorded music freely available as downloadable mp3 files and encourages free distribution of his music by non-profits to spread political messages. As we talked about Con Moto's music and activism he said, "I've tried in my song writing to address conflicts in sometimes a funny way and sometimes in a serious way so that people can laugh at themselves and so that they can hopefully come to a deeper understanding of each other." Con Moto 
and I talked on the phone for 40 minutes while he was driving between gigs on the East Coast.

- Devoto (religiously): Devoto is a 58 year old woman originally from the Southern Appalachian region of the United States. She grew up around music and is now a semi-professional musician (singer) who uses song and story in an attempt to educate people about communities and individuals different from themselves (most of her work is done in small white communities near Portland). She has a Doctorate of Ministry with a focus on spirituality as a healing element in mental health and African American resiliency. She has worked for years with a small grassroots organization in Portland as a program director for various programs ranging from work with "at-risk" children and African American youth to workshops and trainings about diversity. She commented, "I love... I love the fact that I turned my music into part of the methodology of making peace, you know, of doing what I feel God would have me do." My interview with Devoto took place in a café with an excellent salad bar and Hungarian mushroom soup. We talked for two hours.

- Esuberante (exuberant): Esuberante plays guitar, piano, lap dulcimer, autoharp and harmonica. She studied music in Vienna, Austria and received a B.A. in Music from Stanford University and a Music Teaching Credential from San Jose State University. She is a music educator, performer and peer mentor coach with a well established arts and education organization with a mission of enhancing children's learning with creative resources from the arts community. 
She has received numerous awards for her work with youth and has released two CDs of music that are being used in classrooms in the United States and Canada. She has appeared internationally in concerts, arts festivals, schools, and on television and radio. As Esuberante and I sat in a coffee shop talking about her experiences in an educational setting she said, "I think the arts, music being my specialty, but the other ones too - it's a cliché, but they truly are a common language. I think they open up that possibility of connection nonverbally, on the emotional level." Our time together passed quickly and I wished I could listen to more of Esuberante's stories about her work and vast knowledge in this field.

- Fan-Bei (Buddhist music, said to have floated down from the heavens to be heard by Emperor Wei Wen-di in 225 CE): Fan-Bei is a world renowned composer whose compositions have been played and recorded by dozens of orchestras around the world. He wrote a major orchestral piece after George Bush invaded Iraq, a piece he calls a "warning signal"; he wrote it in anger over the "stupidity of war" and greed. Fan-Bei himself was born in Eastern Europe during a period of Nazi occupation. He lost his twin brother when he was an infant. Eventually his family fled to the United States. Fan-Bei started playing piano when he was three years old and decided to become a composer when he was seven years old. Now in his late 60s, he has an impressive list of accomplishments, including his tenure at a local university and the many compositions he has written that have been performed around the world. When 
I asked Fan-Bei about the work he does as a composer and what it means to him in his life he said, "Sometime I have tears, when I'm having some sketch which is very deep and emotional. I think these are the most beautiful tears that I have. It's the...these are tears of beauty. They are very intimate, I'm even not sharing with anybody, and then actually (laughs) those tears are giving you a very happy day because you feel like you accomplished something really good, you know." We met at his home, where he was pruning the grapevine when I arrived. When we discussed demographic information and I asked him what his ethnicity is, he responded with a laugh that he's "Buddhist." We talked easily and laughed often, despite his having told me when I first arrived that he almost felt like he was going to the dentist, he so dislikes interviews. We talked for over an hour and then he played some of his compositions for me before I left.

- Festivamente (cheerfully/celebratory): Festivamente is a middle aged man with an impressive background in classical and jazz music. He has played piano since he was seven years old, and music was an important part of his upbringing. In addition to being a professional musician as a performer and composer, he is a music professor at a local university. He has released several CDs and has been involved in dozens of recordings as a performer or producer. He organized and performed in a May 2009 concert before a speech about reconciliation by the honored Bishop Desmond Tutu. Several times in our meeting the idea of using music to "serve the people" or "heal the people" 
came up as an important component of being a musician. Festivamente expressed the importance of understanding the communities he performs in and said he uses local history and stories to help shape his concerts.

Festivamente was cheerful throughout our meeting and seemed very open about sharing his experiences. At one point he said to me, "I feel like I've had a charmed life, for no particular reason. I'm not like, I deserved it or anything, but I mean, it's just like, as I'm getting older, when I tell this story again and again, I realize like, things fell into place an uncanny amount to me.”

Festivamente and I met at a local university campus in a classroom and talked for an hour and a half.

- Insistendo (insistently, deliberate): Insistendo is 43 years old and works in the field of sustainability. Growing up on the East Coast, he studied guitar as a child and in high school ended up playing in a band that then played together throughout college. Insistendo eventually created a musical persona based on sustainability and since 2004 has performed with his band at festivals and schools. He performs in 50-70 shows a year in addition to working full time and being a father. In the last five to six years Insistendo and his band have performed for over 130,000 children in the Pacific Northwest, imparting a message of environmental sustainability. In talking about his environmental/musical persona, Insistendo said, "I am kind of a mild mannered guy and I'm not naturally someone who just wants to be a comedian or an actor, but when I put on the suit and you get in front of people, there is no 
other option. So you just rise to the occasion, which I can do." We met at a local environmentally-focused nonprofit organization for just under one hour. Insistendo was in the middle of his work day so our time was somewhat rushed, though we covered considerable territory related to his experiences and this study.

- Libero (freely): Libero's family moved from Utah to Washington D.C. when his father became the press secretary for a U.S. congressman. His early memories include his mother's "world class voice, an amazingly beautiful voice," as well as listening to CDs from Broadway musicals that his parents would buy on excursions to New York City. He started playing piano when he was four and has been involved with music since. He is now in his early 50s, conducts a gay men's choir and has a $\mathrm{PhD}$ in Music History. When talking about his role as a conductor Libero said, “I've never felt like achieving some great musical outcome is worth the expense of ruining everybody's self esteem along the way, so I think it's always been important to me to achieve that balance of really getting a great product but also making everybody feel good about their participation." Libero and I met at a coffee shop and talked for just over an hour. After we did our introductions the first thing he said to me was, "Ask whatever you want." Throughout the interview, Libero was open and immediately easy and comfortable to talk to.

- Moderato (moderate): Moderato has been a professional musician for over three decades and has released dozens of CDs, several of which have been at 
the top of the Smooth Jazz charts. He grew up in a musical family and began playing various instruments at a young age. He has toured internationally and been featured on TV programs. In addition to performing music, he has also composed for TV and film. He has played for numerous charity events in the area, helping non-profits raise money and attract attention. He is also interested in politics. Many of my questions were not well fitted to Moderato's experience and it was my impression that he was uncomfortable, possibly feeling as though he was being put under the microscope by an outsider regarding a subject he didn't necessarily identify with. Nevertheless, his experiences and opinions added to the rich perspectives of this study and were important in my own process of examining this topic. Toward the end of our 45 minute interview, as we discussed the many benefit concerts Moderato has been involved with, he said, "Well, there is a lot of power in music and musicians, so usually everybody does it for a while who has any measure of success or even not; just those who like to give end up doing these things [benefits] because it's - I don't know, it's kind of a healing thing to do just personally."

- Narrante (narratingly) and Espressivo (expressively): Narrante and Espressivo both graduated from Reed College, where they were first introduced to folk music and eventually were responsible for organizing musician appearances at the college. This was only the beginning of their engagement with folk music and musicians. After moving to Seattle they became involved in establishing 
the Seattle Folklore Society, a volunteer organization that has survived for over 40 years and which stages the Northwest Folklife Festival. Narrante and Espressivo ran a booking agency that was responsible for bringing Mississippi Fred McDowell and Mance Lipscomb, Queen Ida, Jackie Torrence, Elizabeth Cotton, Boys of the Lough, Doc Watson, the New Lost City Ramblers, Bukka White, Bill Monroe, and dozens of other important musicians to the Northwest. As we talked about Narrante and Espressivo's unique knowledge of folk musicians and their work as booking agents, Espressivo said, "I think what we were about was bringing people who had led really exemplary lives, and bringing them before audiences that had no idea of the cultures that these people had come from and the uniqueness of their sound. Our era was bringing all these hidden treasures that were found in our country through roots and all the popular music and then finding the really - the best proponents who could also relate to their audiences. And that was our work, bringing them forward and giving them a decent venue where they would be treated properly and where they would be presented properly and in context." Now in their mid sixties, Narrante and Espressivo were open and generous, inviting me to their home in Seattle, feeding me crab and talking with me for well over three hours. The stories and knowledge they shared with me have been an invaluable contribution to this study.

- Nocturne (piece of music written for the night): Nocturne grew up in Ireland during "the Troubles" and is currently in his early $50 \mathrm{~s}$. He is a semi- 
professional musician and story teller, and identifies strongly as an activist. Nocturne and I started our interview around 9:30 pm, sitting in an old cemetery, drinking Guinness and talking about Madonna. We then went for a drive along the Willamette River and finished the interview on a dark, quiet road, with the occasional semi-truck zooming by. As our adventure continued into the night, Nocturne seemed to open up more and ideas that at first seemed hard for him to express flowed more freely. As we talked about the idea of activism Nocturne said, “The Irish are - and I don't think they are any different than anyone else, and we already acclaim ourselves to be - activists. You know, our whole thing is about talking. You know, we do a lot of war, we do a lot of war, but we're great fucking talkers, which I'm glad of." Our interview lasted about two and a half hours.

- Penseroso (thoughtfully/meditatively): Penseroso, 29, was among the youngest of the informants I spoke with. He plays saxophone in a successful jazz band and has a beautiful garden. For Penseroso's undergraduate thesis he went to Nicaragua twice to interview prominent musicians who were influential during the Sandinista Revolution. At times, Penseroso seemed to have difficulty finding the right words to talk about his thoughts and feelings related to this subject, but always had meaningful insight into my questions and this topic generally. He summed it up simply: "I think something that can be really powerful about music is it's a way for - well, to connect. Anything that we can do to help people, myself included, connect with ourselves is really good." We 
met at Penseroso's home for a little over an hour, sitting at the dining room table to talk. I left with a bag full of fresh tomatoes from his garden.

- Segue (now follows, go on or proceed with what follows) is in his mid 60s and has been a professional peace activist and hobby musician for over 30 years. He remembers learning folk songs at school as young as the age of five, and once Pete Seeger actually visited his school and taught and sang folk songs, which made a deep impression on Segue. He grew up around music and remembers being drawn to African-American spirituals rather than the classical music his father was playing at home. As he grew up he became very involved in the anti-war movement of the 60s and has been involved as a professional activist in many movements since, such as the anti-nukes movement that began in the 70 s and more recent anti-war movements. He is an original member of a thirty-year-old performance group which uses political satire to deliver messages about peace, justice and the environment. He is the executive director for a non-profit, grassroots organization that works to educate and organize people to work for peace, justice and environmental sustainability. During our meeting we talked at length about the role of music in past movements, as well as the current climate of activism and how music is (or is not) utilized. He said, "You know, it provides a bond that's not easily broken. The strength of the bonds that are created through the musical connection, which have nothing to do with what else is going on, you know. People may or may not find each other really compatible, but if they're 
musically compatible, that's a big bond... a big bond." We met at his office and talked for two hours.

\section{Data Analysis and Writing the Results}

After each interview was transcribed I categorized narratives from the transcriptions into broad themes such as emotions, community, activities, early memories and culture. Initially, I had more than twenty themes taken from over 300 pages of transcriptions, too many to be at all useful, so I repeated the coding process several more times to fine-tune the themes, resulting in two major themes. The first theme is "Music for Self" with the subthemes 1) the meaning of music in the informants' lives, 2) early memories of music: stories of parental influence, 3) music, identity, and personal activism, and 4) the perceived responsibility of musicians to participate in socially engaged activities. The second theme, "Music for Society" includes the subthemes, 1) music as a tool for expression, 2) music's relationship to emotions, 3) music, connection and community building, and 4) music's relationship to social engagement.

The data collected from informant interviews was rich and expansive. It often went in tangential directions, and instead of following a linear path, was circular with ideas and experiences overlapping, which often made the process of coding very difficult. In response to my research inquiry, the informants of this study expressed multiple realities and numerous viewpoints within these realities. As Charmaz (2000) explains with constructivist grounded theory, "Researchers' attention to detail in the 
constructivist approach sensitizes them to multiple realities and the multiple viewpoints within them; it does not represent a quest to capture a single reality" (p. 523). Exploring the "multiple realities" related to this study is one of the aspects that has made this work so interesting, and hopefully will also make it useful to practitioners coming from various perspectives in the field of Conflict Resolution.

My own experience as a musician helped me connect to the stories people told and identify important themes for this paper, not in an attempt to create the reality, but in an attempt to explore $a$ reality, as heard in the perspectives of the informants. Charmaz (2000) further explains, “The constructivist approach does not seek truth single, universal, and lasting. Still, it remains realist because it addresses human realities and assumes the existence of real worlds" (p. 523). Utilizing informant voices has been a key component in the design of this study and in addressing my research question, and because of this I have used the informants' narratives as much as possible in writing about the themes that emerged. Certainly my own experiences and perceptions have influenced how I have categorized what I have heard, though hopefully my own bias has been minimized by utilizing informant voices as much as possible. Because the breadth and range of topics discussed far excede the scope of this study, I selected the data that most closely responded to my research question, "How do musicians and activists perceive the role of music in community engagement?" 


\section{Summary}

In this chapter I have discussed the research method I utilized, given a snapshot of the informants and provided an overview of my own process in analyzing and digesting the information that was gathered. By utilizing a qualitative research design I have been able to listen to, collect and explore the experiences of twenty two informants through their voices, their words about music and community engagement. Grounded theory has allowed me to capture slices of the informants' experiences and portray moments that I then consider in relation to the field of Conflict Resolution. In the following chapter, I introduce the results of this research and discuss the themes that emerged. 


\section{CHAPTER IV: RESULTS}

"We are the music makers, and we are the dreamers of dreams" (Arthur W. O’Shaughnessy as quoted in Bonny \& Savary, 1973, p. 20).

\section{Experiences and Ideas Related to Music and Social Engagement}

In this chapter, the results of the research are presented by the themes that emerged from the interviews: Music for Self and Music for Society. The purpose of this research was to explore attitudes and activities of musician-activists related to the relationship between music and engagement in social issues. Data were collected from the transcribed interviews conducted with twenty two informants who have participated in and led musical activities to engage participants in their communities. In line with grounded theory methodology, this research followed the three phases of 1) initial coding, 2) selective coding, and 3) theoretical coding for examining the data.

\section{Initial Coding}

As the starting point for this data analysis, I used initial coding, which was done after all of the interviews were transcribed. I simply noted key words and phrases from each interview, which resulted in dozens of key words for each transcribed interview. I also expanded my field notes, noting particular nuances and reactions expressed by the informants during the interview process. I began noting broad themes and repeated phrases or words within each interview and then across interviews. This process of initial coding allowed me to look broadly at the informants' perspectives 
and aided me in organizing the data in relation to my research question. An example of this process is illustrated in Table 1, with selected passages taken from the transcribed interviews. Passages are shown on the left, with the corresponding codes on the right side of the table.

\section{Table 1: Initial Coding}

Preliminary coding taken from transcribed interviews

\begin{tabular}{ll}
\hline \multicolumn{1}{c}{ Informant Comments } & \multicolumn{1}{c}{ Initial Codes } \\
\hline Music just pulls everybody in the same; it always levels the & pulls everybody \\
playing field. So when a big, giant group of people come & giant group \\
together and they are protesting something, music can & protesting something \\
calm everybody into the same place, which is why I love & calm everybody \\
that. I know when I've been at concerts and I'm singing a & concerts, singing \\
lot, like they want us to sing along, just no matter who's & sing along \\
around me I'm like, we 're in this together, that feeling - we & in this together \\
can do it! And you sing along as a group, you're a group. & sing along \\
It makes you a group. -Ardore & a group \\
People really want to draft you if you have something to & draft you \\
offer. And so I feel...that's a really awkward thing for me & really awkward \\
and I think that's one thing that sort of steers me away & steers me away \\
from idea of activism. -Festivamente & idea of activism
\end{tabular}


War is ugly stuff. It just...you're trying to convince something which politically sometimes is questionable, you know. So that was - those two pieces you may say could be somewhat connected with activism, being an activist. But being in downtown and being a loud person, I'm not that type, you know. -Fan-Bei

Music is just a tool, you know, and just like any tool, it's really how you use it and who's using and when they're using it. It's - yeah, that's the way I look at it. It's a powerful tool, and if you know how to use and you're using it right and at the right time, you can have amazing results. If you're not using it right, you can cause some damage too, right? That's my outlook on it. Music is just an additional conduit that adds to a movement. It is not indispensable; it just comes as a supporting agent to a process. -Acceso war, trying to convince politically, questionable connected with activism loud person not that type

tool how you use it powerful tool, using it right, right time results damage, outlook additional conduit not indispensable

\section{Selective Coding}

After the initial coding process, I then began the procedure of selective coding, which helped fine-tune the themes and find commonalities among the informants. The following broad themes emerged during the selective coding process:

- Perceived responsibility to address community issues as musicians 
- Activism without music isn't as powerful

- Interest in a community's issues

- Thoughts/reactions to "activism"

- Perceptions of how music is used now compared to past movements

- Corporate involvement in promoting or limiting "engaged" music

- Obstacles for musicians in engaging in community issues

- Music that socially engages is not always explicit

- Music is a powerful tool

- The role of music in conflict situations

- Personal meaning/experiences with music and community engagement

- Personal identity and labels: "musician," "activist"; -researcher perceptions and participant perceptions

- First memories of music/parental involvement in music

- Emotions, particularly empathy

- Culture as expressed through music

- Connection of music to gay, lesbian, bisexual movements

- Awareness of community issues related to circumstances of the time

- Music as a community building tool

- Specific informant activities

- Music education/music in schools

- Career choices related to musical involvement 
- Music as a cultural bridge between groups

- Music and potential: informants' visions of possibilities through music Once each of the interviews had undergone the process of initial and selective coding, phrases were taken from each interview and placed in the broad categories listed above.

\section{Theoretical Coding}

With the vast range of topics discussed by informants and the inability to address everything here, theoretical coding was used to fine-tune the emerging themes. Themes that emerged from the selective coding process were grouped into more succinct categories that are applicable in illuminating the informants' perspectives regarding this research study. Two overarching themes and several sub-themes emerged from the theoretical coding process and are as follows:

A. Music for Self

1. The meaning of music in the informants' lives

2. Early memories of music: stories of parental influence

3. Music, identity and personal activism

4. The perceived responsibility of musicians to participate in socially engaged activities

B. Music for Society:

1. Music as a tool for expression

2. Music's relationship to emotions 
3. Music, connection, and community building

4. Music's relationship to social engagement

The first theme, Music for Self, discusses the broad range of meaning music provides in the lives of the informants on a more internal level, from first memories, current activities, personal activism and informant perspectives on their responsibility to engage in community issues. The second theme, Music for Society, reflects informant perspectives about the role of music externally, related to culture, expression, community building and social engagement.

These two themes and the related sub-themes form the framework for the presentation of findings of this study. Illuminating these themes with narrative from the interviews is in line with grounded theory methodology and supports my intention of gathering and sharing information about these beliefs directly through the informants' voices. At times, the themes that emerged from this study were overlapping and interrelated, making it difficult to assign them to tidy categories. With the aim of more deeply understanding the meaning of music in the informants' lives, I have made every attempt to present the results in line with these themes, with the understanding that my own life experiences and perspectives have shaped this process of categorization and that another researcher might have grouped things differently.

It is my goal to give voice to the opinions and experiences of the informants in order to more deeply understand the possible significance music can have in a conflict resolution setting. As Charmaz (2000) states, "We must try to find what research participants define as real and where their definitions of reality take them" (p. 523). In 
the following section the themes and related subthemes will be presented through the voices of the informants. The significance of these perspectives and the relationship to the research question will be discussed in Chapter V.

\section{Themes}

The following section presents the data related to the two overarching themes, Music for Self and Music for Society, with the related subthemes mentioned above. The themes are presented through the voices of the informants, taken from the data collected during the interview process.

\section{Theme 1: Music for Self}

Music for Self describes the first overarching theme that emerged from this data. All of the informants had a lot to say about the meaning of music to them personally and the various ways it has an impact on their lives. Some of the informants struggled to find the right words to talk about music while others were able to more easily discuss music and the meaning it has in their lives; some conversations became quite philosophical in nature. Many of the informants told about their experiences through stories, which often led to the recollection of more memories and more stories about the place of music in their lives. This presentation of Music for Self will recount some of these stories and ideas and their significance will be further discussed in Chapter V. The subthemes are the building blocks of the overarching theme and will be presented as follows: 1) the meaning of music in the informants' lives, 2) early memories of music: stories of parental influence, 3) music, identity and personal 
activism, and 4) the perceived responsibility of musicians to participate in socially engaged activities.

\section{The meaning of music in the informants' lives.}

Several of the informants spoke about how meaningful music is in their lives and how it helps them in various ways. For example, informants talked about how music helps them express themselves or find their "inner child"; it's a way they care for themselves and it connects them to God. Acceso passionately talked about his relationship to music and how it shapes his identity. He said, "My experience with music is really the highlight of pretty much my life, if I can put it that way. I always saw myself through music, and the tool almost became the master, if I can put it that way. It is the very tool in my life that I have learned some of the deepest lessons, you know. Music is my friend. With music I journey and experience God and the world. Music is my friend. We are friends." It is interesting to note that Acceso referred to his relationship with music almost as if it were a person, saying it is his "friend," and further stating that it is so powerful it is how he experiences God.

Ballad also spoke about music in terms of it being a relationship and a spiritual practice. She explained:

Today my relationship to music is a - it's a partnership, you know. I don't know if I consider it like this now, but for a long time I think I kind of considered it my spiritual practice in a way. Music is how I feel connected to source. That's how - and when I was younger it was very important - how I knew that I was okay, it's how I knew that I was loved because of this really 
extraordinary thing. So again, it's a multifaceted relationship, you know. I feel like I'm a conduit. So my relationship with music also is a collaborative thing, you know. Choices I make with music are really about opening people's hearts, you know.

Libero also talked about his involvement with music as something that helps him feel like he belongs to something. He talked about his early involvement in choir. He said, "There was always something about singing in choir that was wonderful for me. It was a safety net, for one. There's an internal thing. There's a meaning that's always going on, there's that deep personal connection." These examples highlight how music provides meaning and shapes identity, internally. For these musicians, music provides a container where meaning and belonging are rooted.

Other informants also commented about music's ability to connect them to God and how it is a healing force in their lives. For example, Devoto commented, "Music is such a huge piece of how I care for myself that it just happens. It just happens. Music is - music is probably the most important way that I take care of myself. I meditate with my music. Music - me singing - is my umbilical cord to God." Aliquot also spoke about the role music plays as a meditative activity in his life where he is able to be present in the moment and turn off the chatter of his mind. He commented:

It's one of the few times that I can actually not think about anything. I don't think about anything. I mean it's the closest thing to meditation I know of. But at the same time I'm very, very aware of the energy in the room, so it's sort of 
like you feel that washing over you and making it okay for you not to have to think. Because the minute you start thinking about things, that's when everything tightens up. Being able to just let that exist, that's an exceptional thing.

The words Devoto and Aliquot have used to describe this aspect of music in their lives are slightly different; however, the function is the same. For them, music slows things down and connects them to a higher power, and as Aliquot described, it allows him to be present in the moment with people that otherwise his busy mind might not notice.

Several informants also spoke about how music is a healing element in their lives. Alzate Sordini shared her story about finding out she had adrenal fatigue; she began engaging in more creative activities to help her find balance between work responsibilities and her health and wellness. Music became one of these activities and, as she explains, was crucial in her process of healing. She said:

You play. Your kid comes out. Yeah. And it's healing. I found that every time I played music I was energized and I felt better, no matter how exhausted I was. So there was something about what was happening with music that was very healing. This music thing was helping me show up in a new way and I was getting more intuitive - I was becoming more whole.

She added, "Music helps me a lot. In fact that's one of the key places for music for me, and for other people I see, is helping them settle down.” Alzate Sordini's comment draws attention to the fact that there seems to be something distinctive about music - playing or listening - that can be energizing and healing. She also adds that 
music helps people "settle down," mirroring Devoto and Aliquot's comments above about how music helps them feel more grounded in their busy and demanding lives and how for some, this settling down helps them quiet the chatter and connects them to God.

These comments illustrate the various ways music helps the informants care for themselves, feel centered and connected to a higher power, and therefore demonstrate the significant meaning music has in people's internal lives. For these informants, music is a central way they manage their hectic lives in order to feel whole, grounded and healthy.

\section{Early memories of music: stories of parental influence.}

This subtheme primarily emerged from the question, "What is your first memory of music?" I was curious to find out when informants consciously became involved with music, and to explore the activities in their lives that allowed that to happen. Nearly all of the informants had a lot to say about their early involvement with music and I was surprised at how many of the memories were very vivid, though they occurred when the informants were quite young. It also became apparent throughout the stories that their parents' involvement in and attitudes about music significantly impacted the experiences the informants had with music. Most of the informants said music was very important to their parents, even if they did not play music themselves. Colia Voce talked about her mother's relationship with music and how that impacted her own involvement. She explained her first memories of music: 
It was very early for me. Neither of my parents played instruments, but they loved music, my dad in particular. I grew up listening to folk music. My mother, unfortunately, was one of those kids who was given the message, "oh you can't sing, stand in the back of the room." It really affected her. She never got through that. So she didn't want that to happen to her children and we all grew up playing instruments. So music was a big part of our lives. I remember, you know, listening to records as early as I can. And started my own collection. My siblings and I passed time listening to music together. I sang in church choirs, I sang in high school choirs, I played piano, guitar and recorder and flute. It was very important.

Colia Voce stressed that her parents didn't play music but it was an important part of their lives regardless, and they highly valued listening to music as a family. It became a family pastime that eventually led Colia Voce to participate in making music, not only on her own but in community ensembles that she continues to be part of today.

Although Fan-Bei's first experience with music is not one he can remember, it was a powerful experience nonetheless and it gives a little insight into his parents' connection to music, as well as the significance music had in shaping the rest of FanBei's life. Here is his story:

Well, I'll tell you one thing. We were escaping from Nazi occupation. See I was born in Paris from twins. And my one hour older brother died when he was three weeks. So I cannot remember him. And I was almost dying too. I was hungry, my mom had tuberculosis, I was unable to be fed from her, so 
they were just using these milks stuff and I was not good. The beginning I was losing weight and when I was crying at night because of the condition, my dad, who was already musician, did one experiment. He put the Mozart Eine Kleine Nachtmusik, you know on those fast speed records, you know. Every time he did, I stopped crying. So he said, "Well this guy is sensitive for music." So they had a nice sleep, there was Mozart playing and I shut up myself. So that was the beginning of it. Obviously, I loved that song but I cannot remember it today because I was too young for that. I was like one month old or something like that. But that was beginning of it. When we settled in Boston during the Second World War for five years, he showed me notation and in three years I started to play piano. I loved key signatures [at] that time, you know. I was dreaming about a hundred sharps, or dancing fifty flats. I still remember that like today, because like 5 flats was my favorite shape of that. And I saw fifty of them, it was so much fun. I remember that. And even today if I force my mind and I close my eyes I could see shadow of it a little bit, still. Because I loved it so much, you know. You keep sometimes that image.

Fan-Bei's story is a remarkable testament to the soothing qualities music can provide in the most desperate of situations. Music not only touched him, as he explained, but must have provided great relief to his parents as they dealt with the perils of a world war, the loss of a child and the difficulty of keeping him alive.

These examples of first memories of music highlight how early the influence of music began to provide meaning in the informants' lives, and how the involvement 
and encouragement of parents was a significant component of sparking this relationship the informants later had with music.

\section{Music, identity and personal activism.}

All of the informants in this study were chosen because of activities that they have participated in, using music to engage the community about social problems or to encourage personal growth and development in the people they work with (see the biography section in Chapter III for more details). Each of the informants talked about how their activities with music align with their beliefs and identity and the role they then play within their communities and with their audiences. Out of this came numerous conversations about activism and whether or not the informants considered themselves to be activists based on these activities. Several informants returned to this question later in the conversation, after processing other ideas. Other informants were able to respond right away. This section will include comments the informants made about their desires and agendas with regard to music, as well as what they had to say about the idea of being identified as activists or not.

Acceso clearly identified himself as an activist and talked throughout the interview about how music must have a purpose. He commented, 'I'm really particular with music. I always have an agenda with what I'm trying to do with it. I have a vision for it. I don't just like making music for the sake of making music. I think it's like anything: it has to have a purpose and a direction." When asked how he identifies himself he said: 
Yes, yes, totally, I am an activist. What kind of activism? I am all over the spectrum. All over it. Definitely the bigger umbrella would be social liberation. I've been influenced by music like reggae music, um, hip hop music, gospel music. Those are my main sources of influences. But now I listen to a lot of stuff. Man, I just love music. I love to share it and I have to share it, you know. That's why I am never going to stop playing music until I die. I'm excited about this stuff. I have my set of experiences and my convictions. When I attack an issue, you know, it's just this is what I believe will help the human race from my humble perspective and I just share that. Yeah, I'm excited. During the interview, Acceso also commented that in his view music is never simply entertainment and that even if it goes unnoticed by some, music is always making some kind of statement. For Acceso, music is a way he can communicate his ideals and he finds it is a powerful means of shaping his identity as an activist.

Similarly, Con Moto discussed the way he uses music to deliver messages that align with his views and desires to engage people in community and global issues. He said:

I definitely use [music] to engage people in important community issues and in terms of using it as a means of resolving a conflict, I mean, yes, in a sense. It's a subtle kind of thing but I would say yeah. I've tried in my songwriting to address conflicts - sometimes in a funny way and sometimes in a serious way so that people can laugh at themselves and so that they can hopefully come to a deeper understanding of each other. So I'd say I've tried to use music that way. 
I don't know to what extent that has had success because these things are very hard to measure. I can definitely tell you that I get emails from people every day that are - they tell me that my music changed their life and my music made them realize that they need to become activists, or my music - whatever, - you can fill in the blank. I think there's - if you can believe your emails then I'm having an effect on people.

Con Moto pointed out that engagement in community issues through music can be difficult to measure and that the primary feedback he receives about the impact his music has on others is through personal contact at events and the emails he receives from his fans. Con Moto also pointed out that an important part of how he makes use of music to engage in community issues is by drawing on a variety of approaches, including humor, in order to educate and inform.

Ballad spoke about the way she uses music as an extension of her identity and purpose in life; she believes that any "activist" leanings are a by-product of her need to be "true to her calling." She explained:

For myself I think it's important that I am true to my calling. You know. And for me - and again, I'm old enough now and I've been doing music for 30 years and have some perspective, I can see - in looking back it is very clear to me that what I do, I'm doing out of a calling to open people's hearts, to bring them to what is - true. I can maybe be trying to direct people to what I think is true. And good. As an individual, I have this yearning for good. And I think 
that my music expresses that yearning for good. I am expressing myself, I'm expressing my own yearnings, is what I'm doing.

In other words, Ballad's expression through music is an extension of her own desires to "open people's hearts" and find commonality and shared interests, and this desire is deeply connected to how she sees herself. She spoke about her relationship to music and the way she uses music to reach others in a way that almost seemed as if she felt she has no choice, as though it were the only way she could use and relate to the music she writes, and how as a result of that she is able to be true to herself.

\section{The perceived responsibility of musicians to participate in socially}

\section{engaged activities.}

The final theme in Music for Self arose out of one of the interview questions, "Is it important for musicians to be activists or to be politically involved?" It is interesting to note that some informants like Con Moto focused on being politically involved while others like Ardore commented about musicians' responsibility to be engaged in activism. The interview question asked about both of these elements of engagement, though most informants commented on only one or the other. After the initial interview question there were numerous lengthy discussions about how the informants felt about their responsibility to become involved with social problems in general because of their relationship to music. Some informants felt that musicians have a responsibility to address social issues because of their position in society as musicians. Others felt that being a musician had no bearing on if or how they should be engaged socially, that everyone has the same responsibility, and furthermore, one 
informant felt that musicians do not have a responsibility to be politically engaged. This section will show the range of opinions that emerged related to this theme.

When asked the question "Is it important for musicians to be activists or to be politically involved?" Festivamente expressed clearly that he believes musicians do have a responsibility to be engaged in social issues and to be politically aware. He said:

I think it's important for musicians to be politically aware. One argument that you could make is that by virtue of being a musician, you as a human being transcend the sort of typical duality of political conversation, the typical sort of polarizing thing. I think it's important for musicians to be politically aware and I think it's good for them to be - it's good for us to be aware of the power of what we do. That we can make change. But then we get to think about what change do we want to make, you know. If, you know, if art is truly powerful then you have an ethical responsibility, you know. If it's not powerful then, you know, you don't. You can't - I feel like you can't really have it both ways. Either you are really powerful and you have an incredible ethical and moral responsibility to think about the effects of what you do, what you're about to do, just as anybody, just as a scientist should or a doctor or somebody like that, you know. Or if you don't have power then you really shouldn't expect to be part of the conversation. I want the musicians I train, anyway - my students to feel like they're important to society and they have something valuable to offer. So then they can actually be agents for change. In Burma if you know 
that if you do some kind of cartoon, they'll kill your family and your friends, you think about stuff like that. I think that if you're going to take it that seriously there, then why not take it that seriously here? Otherwise, what are we doing?

Festivamente's comment draws attention to the ambiguity that exists within society and among musicians about music's power to influence, but it goes on to express his conviction that the work musicians do is important to society and that musicians can and should be "agents for change."

Several informants expressed the opinion that everyone has the same responsibility to engage in their communities -through activism, politics or other means of social engagement - and that musicians in particular do not have more responsibility than anyone else does. Libero commented, "I don't think [musicians] have any, bear any more responsibility than the rest of the world and I don't believe that they're probably any more moral on that issue. There's a lot of responsibility out there and I don't know that musicians hold any more than any other." Con Moto also reflected the opinion that everyone should be involved politically, and that musicians are no more responsible than anyone else is. He said, "I think it's important for everybody to be politically involved, but I don't think musicians have any kind of special responsibility to be more politically involved than other people." Ardore commented about engagement in activism. She said, "It's important for everybody to be activists, I don't know about - I mean, maybe. Maybe musicians are in a good position - and that's why I did it. I felt like, you know, I'm in the perfect position to 
pull something together." Ardore seemed to struggle with the idea of there being a specific responsibility placed on musicians. Although Ardore commented that everyone should be engaged as activists, she also acknowledged, like Festivamente above, that musicians are in a unique position to get a message across and bring people together.

Unlike the above informants, Acceso commented that engagement in community issues is not a choice at all, and that by default everyone contributes in some way to the community around them. He said:

There is a general belief that there is such a thing as a neutral state. I disagree. All humans, whether consciously or unconsciously, advocate for something: one is either part of the problem or part of the solution. One's ignorance or apathy to an issue is not a neutral stand; it is activism in support of the problem. Hence, when writing music the artist is advocating for something. The question is what?

Acceso's comment highlights the view that regardless of whether or not a musician is explicit or even aware of his/her involvement or position, the messages expressed through music affect the community and there is a ripple effect. Acceso advocated for musicians to be aware of this and to engage with awareness and purpose with their music.

Insistendo, in talking about environmental issues such as climate change and efforts toward sustainability, spoke about how everyone should be involved in some 
way to work toward reducing harm to the environment but that these actions should be specific to each person's interests and talents. He commented:

I think everyone needs to look at what talents they have, and if it's a musical talent or if it's an organizing talent or a computer talent, whatever it is today, people should be using those talents to help promote the earth. It's gotten to the point - it doesn't matter if you're right or left or anything - we just need to join together and help one another. So yeah, I mean, if you're a musician and you have audiences and a way to get words out there, then I think it's an important piece.

Insistendo says here that musicians should be engaged in environmental issues, but points out that people who aren't musicians still have the ability to impact change through their own talents and interests; what is crucial is coming together to work toward common causes.

Despite Fan-Bei's own engagement in social issues with his compositions addressing environmental concerns and engagement in war, he was clear in his disagreement with the idea that musicians have a responsibility to be politically involved. He said, "No. Musicians don't have to be politically involved. As a matter of fact, they may hurt themselves (laughing). You know (more laughing). No, no, definitely not. Musicians, including myself, we don't like to be involved with political scandals or whatever you call it." I then pointed out that he wrote a major symphony composition against war; his program notes for the piece state, "Yes, [this piece] is a 
political statement." The program notes go on to provide insight into Fan-Bei's process in expressing his anger over war. They ask:

Can we ask nature to continue to provide all the gifts we are receiving? Can we afford to continue clutching to our accustomed comforts with mounting costs to our environment? Any decent and civilized nation is aware of [the nuclear bomb's] complete destructive potential and consequently carefully avoids major military conflicts with other nuclear nations. But how will we control radicals with their goal of revenge?

Despite his stated opinion that musicians have no particular responsibility to be politically involved, his comments and writings mirror Acceso's sentiment that there is no "neutral state." Fan-Bei's skepticism about involvement in politics and "political scandals" did not dissuade him from using music to make a statement to address the "mess and chaos we are experiencing," and that statement was consequently heard by thousands.

These above selections express how informants felt about the responsibility of musicians to be engaged in their communities, politically or as activists with a focus on specific issues. There was a broad range of ideas expressed, going beyond the original interview question which asked if musicians have a responsibility to engage as activists or to be politically involved in their communities. The informants reflected on their own experiences with music as a tool for engagement and expressed opinions that at times contradicted their activities. 
The theme Music for Self has covered the broad range of topics discussed by the informants and shows the variety of meaning and uses informants have found in their internal connection to music. The significance of this will be further explored in Chapter V. The next section, Music for Society, will explore the opinions of informants related to music's function externally.

\section{Theme 2: Music for Society}

Music for Society addresses the role music plays in society from the perspective of the informants. This section will explore 1) music as a tool for expression, 2) music's relationship to emotions, 3) music, connection and community building and 4) music's relationship to social engagement. Understanding informants' attitudes about music's place in society is a key ingredient in understanding whether music can be useful in the specific context of conflict resolution. Both music and conflict are embedded in the society in which they are found, and their relationship to society can potentially give us cues about the values and interests of the people and communities involved. Music is expressive of these values, while conflict highlights perceived incompatible goals connected to the values.

\section{Music as a tool for expression.}

In exploring the meaning music can have in society and between people, the way it is used as a tool for expression and the way it represents culture should be examined. Several informants talked about this function of music within society, describing it as one of music's most important strengths because of the way it can 
open people up. This first section will present the opinions informants expressed regarding music's relationship to expression and how that can be a window into the pulse of a society.

In discussing how music reflects what is happening in a community, Ardore elaborated on the relationship between music and expression, particularly related to anger or conflict. She explained:

Music is just a reflection of what's going on in the community. So [if that] community is in conflict then the music's going to reflect that. And if the community is in turmoil then the music's going to reflect that. I think it's just going to reflect. It's a good place to get the heartbeat of the community, is with the music. Music is just as much part of any community, conflict or not conflict; I just think that conflict is going to be expressed in the music. Music just means more because you need it more. I think music is a really healthy way to get out what could turn into violence. Even violent songs that are about violence and are angry and intense and dark, it's a healthy way to get that out, you know. It's a good way to do it. And so pent up energy, you know, music is a good way to express stuff that could otherwise come out, show up in different aspects. I think that music has a lot to do with nonviolence because, you know, to me violence itself - this is kind of philosophical, but I think it comes from - well, anger and mismanagement of anger and kind of feeling stuck and being pent up in that way - and so violence is a way of taking control or being in control. So maybe music is a better way to use that energy. 
Ardore talked about music as a tool for expression, particularly if there is a conflict within a community, or as a means to express anger in a healthy way. She pointed out that using music as a means of expression can lead to a sense of control and provide an outlet where otherwise there might not be one.

Esuberante also spoke about music's role in expression and the way it can result in a deeper understanding between people. She commented:

I think [music] is an innate part of us whether we recognize it or not. I think that it, again, expresses - it reaches our soul; it reaches a part of us that not verbally can always be reached. It's also fun. So in terms of working with children and teaching, if we can have fun and learn about the letters, or if we can learn about a different culture through the music, I mean really, whether it's a common history or it's culture, we gain deeper understanding of who these people are through their music and their arts.

Devoto put this simply when she stated, "[Music's] a better connecter than language." Several informants spoke about how music is often more effective than language in creating connection and understanding between people because it also accesses emotions. Ballad commented on the way she sees music opening people up. She said, "People can hear things in a musical context in a different way, in a more powerful way. Or even just hear it at all. Music can really illuminate what's being said." She added,

Music is a very, very powerful thing. Yeah, it's scary powerful, meaning it's kind of awe inspiring and yet it's this thing that people just kind of take for 
granted, you know. Singing, the act of singing, I believe, just opens you up. It just opens your heart up. It does that.

Music's ability to "just open your heart up," communicate ideas, and reflect people's experiences were identified by the informants as central components of what makes music so powerful. But as Ballad pointed out, this aspect is often taken for granted.

Aleatory spoke about the influential place music holds in the work she does in a coaching environment and how this creative influence can have dramatic effects in people's lives and in the way they communicate. I asked her how she uses music in her coaching sessions and why she sees this as beneficial in the work she does. She explained:

We do anything from karaoke to writing lyrics to composing music. And it's really designed to build courage. And to build that ability to have something to say and a vehicle to say it. So [this is for] the people that are everyday people or leaders of some sort that have an area of influence who are not confident. The ultimate goal for me is for people to trust in themselves and to step out and do something that scares them to pieces. I had one of my clients recently work on the piano just to develop a melody and that was helping him learn how to speak with other people. I think music comes out as a way to create hope. When things are not working - to me it brings a connection to something that you can do.

Aleatory talked about the long term benefits of having the opportunity to be creative and how she feels that by offering this experience she can help her clients be better 
leaders in their communities. She expressed concern that the workshops she provides which focus on creative skills such as music are not taken as seriously as other skillbuilding workshops; she sees this as a detriment to society as a whole. The significance of using music as a tool for expression will be further explored in Chapter V.

\section{Music's relationship to emotions.}

The second subtheme in Music for Society is informant perspectives on music's connection to our emotional lives, especially in response to the question, "What do you think music has to do with empathy?" Informants clearly believed that music's ability to tap into emotions is a key function of music's power.

Con Moto discussed how he believes music can access empathy and as a result help us connect with people that are otherwise very unfamiliar. He commented, Music is sort of intrinsically an emotional form of communication and so it's very infinitely linked with empathy. That's why music is so powerful, is because it can elicit an empathic response from people who are there paying attention. It can, if it's good, you know, you can empathize with a character that is otherwise really unfamiliar. I have found you can help - you can briefly, and at least with some real degree, you can get a white middle class person from the suburbs of New York to empathize with a Palestinian child who blows himself up on a bus. You can do that. It can be done. These people are not so separate from each other that they can't identify with each other. But I think a song is something that is - unless that white middle class person from 
the suburbs goes to Gaza and sees what life is like there, you know, the only other thing, one of the other things that is likely to reach them on an emotional level so they really do empathize with somebody who is in such a different situation than them, is music.

Con Moto’s remark, along with Esuberante's comment from the above subtheme about how music is important in expression, highlights how music's power in expressing emotions is inextricably entangled with its ability to help us access emotions. Con Moto also points out that music can be an important tool in accessing emotional responses to horrific situations that otherwise are so distant they allow people to check out or remain apathetic.

Segue talked at length about music's ability to access empathy; he adds to Con Moto's comment from above, stating:

[Music] has everything to do with empathy because it's got that power that art has. That's really one of the things that art's about, is connecting with people without going through their left brain. I mean, I'm surprised all the time by the power that music has to bring me to tears, or right to the verge of them by just putting somebody's experience in front of me in a really moving kind of way. It's not necessarily a tragedy by any means, you know, it can be delight or it can be humor - but I'll be like right on the edge of tears and very emotional in ways that hardly anything else does that to me. It has a lot of power in that respect. 
Segue went on to explain how music's ability to access emotions can be very useful in what he calls "movements," such as the anti-nuclear weapons movement or the environmental movement, and that organizations that don't understand music's power and as a result don't use it as part of their method of outreach are missing an important opportunity.

In talking about her work with communities in Uganda, Alzate Sordini reflected on the role of music in engaging emotions, particularly empathy:

One of the things I had learned early on was that music played a key role in helping people to heal from trauma. Music is the primary way of educating the community [in Uganda]. It's powerful and it's fun, you know. And it gets across really sensitive topics, taboo topics. The youth would teach the community through their music, through their projects. To be able to bring music back into communities like this is a huge form of empathy and is a huge form of being able to do recovery and to start to thrive. There was a woman there who just said - one of the Acholi women, who said, "Sometimes we need music more than food to survive, because music feeds the soul. We may not have food for days, but when we have music we can live." It blew me away. Alzate Sordini's experience observing the magic of music in Uganda highlights not only music's ability to educate, but also to access emotions that can aid in healing.

This subtheme, "music's relationship to emotions" addresses informant perspectives about music's link to emotions and illustrates the wide range of uses it can have. All of the informants spoke about music as a powerful means to access 
emotions and how this can aid in communication and provide a window into the experiences of a community.

\section{Music, connection, and community building.}

The capacity for music to build and create community was a constant throughout the interviews conducted. It was the thread that had the most commonality among these informants from a variety of backgrounds and experiences. There is the very literal way music brings people into the same room to play, sing or listen together, but informants also discussed more philosophical aspects of music, such as the way it creates a sense of belonging to a larger community/nation/world/universe. Some informants spoke specifically about the personal impact of playing music, while others seemed to feel that music was equally important as a component of building community regardless of whether one plays or is a participant in the audience, and regardless of any overt acknowledgement toward that purpose. With respect to personal relationships, several informants spoke about how when music is present it becomes a binding agent and can make it easier to share ideas or deal with conflict when it arises.

Insistendo talked about the role of music in society and the way it can act as a bridging agent between people from different communities. In talking about his own experiences going to rural communities to talk about environmental issues through music, he commented:

I think that one piece that is interesting in society is that music definitely ripples through all the communities. And so, you know, the timber community 
out in Amboy, Washington may not be interested in one type of music, or receptive to some approach, but I think they all respect the musicianship. So even if you show up and you can play guitar and they play guitar or they know someone who plays guitar or they listen to guitar, then it does cross over in that sense and they may listen to you a little bit closer. Or at least pay you some dues. So I think music can play a role and does play a role, but certainly could play a bigger role.

Esuberante added to this by emphasizing how central music is to our lives across cultures, and how it seems to be as important as other basic needs like food and shelter. She noted, "You know the whole idea is that we all have similarities and differences. Any place you go in the world you find music. You find people need food; they need clothing; they need shelter; and they seem to need music. So through the music you open up the possibilities." Both Insistendo and Esuberante's comments reflect the belief that music not only brings similar types of people together, but that it can bring very different people together and as a result "open up the possibilities." Bruscamente pointed out that music seems to inherently engage people and that as a result there is a sense of community amongst those who participate. She commented,

I think getting people in a room watching music is really important. That can be a way of organizing and building community. So putting on shows in a way that makes it accessible to people and encourage people's involvement with 
making music. You know, bringing people together to listen to music can do a lot of other things too, address a lot of issues.

She went on to say, "Every single thing I do with music is trying to engage people, not necessarily in social change always, but often." Bruscamente highlights that bringing people together through music is one way to build community and engage people, regardless of whether or not the intention is social engagement. Aliquot also commented on this, speculating that because everyone can contribute to music, because it is accessible to everyone, "It becomes a way to validate experience, I think, for a lot of people."

Ballad talked about her work conducting an all women's choir and the strong relationship she sees between music and community building. She shared this story: We have a range of women and it's great. How great for a young woman to have all these older women around, you know. So it's very cool in that regard. Yeah, it's community, for sure. And people join the group for various reasons. Some people join because they just want to do music; they just want to get back into singing. A lot of people find that this whole other thing happens to them. You know what I mean? (laughs) And the word for that is community. For some women, they don't go to church but they go to rehearsal every Thursday. It really is for them a spiritual thing too.

Ballad ended her story with the following comment:

Music is what makes people human and making your own music is a really powerful thing. It carries meaning and carries intention and carries - is about 
relationship, you know. Either it be the relationship to each other and the community we're playing, relationship to life cycle, relationship to God, I mean it's - yeah, it's what makes us human.

From Ballad's perspective, participating in a choir helps these women not only feel they belong to a choir, but also provides a place where they can feel connected to something higher than themselves, such as God. The reasons women join the choir vary, but regardless, it creates a community and pulls together a wide range of women from different backgrounds and for many of them becomes an important part of their lives for many years.

Penseroso also addressed the way music can connect people to one another while also helping them feel part of something larger than themselves. He observed: I think something that can be really powerful about music is it's a way for well, to connect. It's a lot about connection, I think. For the band, for a room of people to watch a band connecting with each other on a really deep level and then - but not just connecting with each other, but also connecting to something, to like a greater force that's around everywhere. And tapping into that, I think can bring the whole group of people that are there listening - it's all sort of helping everybody to tap into that energy which involves being connected to people and to this greater force around us. I think that can be so powerful. I think it affects things, not necessarily in a "political" way. A way that's like people - maybe helping people connect to themselves. Connect to a part of themselves and a part of human experience that they maybe haven't 
been in contact with as much. And I think any time, anything that we can do to help people, myself included, connect with ourselves is really good. I think everybody on a deep level is what is defined as an activist and so I think anything that helps people connect to their deeper self, I think is a really good force in society.

Like Ballad's comment above, Penseroso's remark reflects the way music is not only connecting people to one another in various capacities as listeners and performers, but also to a "greater force" and to people's "deeper selves."

People playing music together might not always realize how it can impact the larger community. It might simply be a creative outlet for themselves as individuals, to get away from the other demands of the world and create a sense of release. For Alzate Sordini, playing in a band was something she did with friends; a way for her to be creative and to help the healing process after being diagnosed with adrenal fatigue, without any intention of necessarily connecting to the larger community. However, she was surprised to discover that playing music did connect her to the larger community, and the group did not stay insular for long. She tells her story:

The band - we're realizing that this is creating profound levels of healing and change for us. The band was starting to succeed at levels we hadn't anticipated, and so it expanded. It was amazing what was coming together. We also started seeing that the way we engaged with the community was engaging the community to play music with us. And so suddenly there was this ripple effect that we were more like a tribe, and not just the band, but the people in the 
community were connected. And so music became this link to help communicate with and build a larger tribe of very eclectic people. So now the band is in transformation and we're realizing music is a transformation tool, and a consciousness raising tool. And you know it's a means by which to help engage at a higher level. So we realize, oh my gosh, we've got this gift that we can share with other people. [Music] keeps us connecting; it keeps us sharing stories and ideas; it helps us to step into a higher form of ourselves, or it can. Alzate Sordini's story highlights the way music has potential to create community, even without much effort, because it brings people together in a joined experience, and through this experience of sharing stories and ideas transformation can occur not only on an individual level, but on a communal level as well.

This subtheme, "music, connection, and community building," has presented some of the comments the informants made about music's ability to create community and make connections, not only to others, but to what Ballad has called "God" and Penseroso has called a "greater force." The opinions the informants had about this subtheme were rich and expansive and reflect the most related ideas among a diverse range of experiences and means of engagement with music.

\section{Music as social engagement: values, activities and activism.}

The final subtheme, "music as social engagement," emerged during the interview process as informants considered the nature of their activities with music and how to label their particular style of engagement. As was described in Chapter III, the informants were chosen for this study because of their involvement in utilizing 
music to engage the community in a variety of interesting ways. While several informants did not consider their engagement through music a form of activism, they indicated throughout the interview what activism means to them, and talked about how their activities with music reflect their personal values, irrespective of the label that is put on those activities. Although informant opinions presented in this section are very internal in nature, representing core values and beliefs, they have been placed in Music for Society because of the engagement they represent with the community. This section will address some of those perspectives, and the significance will be discussed in Chapter V.

Festivamente, in talking about how he sees his activities with music and engaging other people, spoke of his own goals and identity compared to how he views activism. He said:

I've always done projects here that try to have some creative - to be sustaining, I guess. You know, have some creative markings, but also infusing them with meaning. You know, when I think about activism, I think about somebody who has a mission, somebody who has like - there is a particular vision they have of the world and they're trying to get there. And that's more important than whatever else. And I don't - that's why I don't see myself as an activist because I don't feel like I have that sort of overriding wrong that I'm trying to right, or if I have sort of a deep yearning, it's for people's lives to be better, you know. Just in general. And also for people to believe that good things can happen in life. I'm pretty much an optimist and I guess if I see myself fighting 
for anything, I see myself as fighting for an optimistic worldview, you know. And to use whatever means I have to give people that kind of hope and, you know, optimism. And so I guess I don't see that as the same as activism because I guess I see activist people as people who are sort of tirelessly, against all odds, fighting for some cause. You know, that's much more specific. On the same token I don't see myself purely as a musician. Music has always been a means to me. It has always been a tool for me for something greater. But it's not laser beam, that's how I think of activism.

Con Moto also talked about how he perceives his musical activities in relation to activism. He commented:

I guess I consider myself an activist. I would say more that I consider myself a musician who is part of this very, very old tradition of writing and performing songs that are about things that are happening in the world. I think it's really it's really vital that the importance of culture be recognized as a useful tool, just on a purely pragmatic level by organizers. Music is a tool that is, in terms of activism and in terms of the impact that music can have on people, music can inspire people to action. And music can foster a sense of community. You know, whether that action is a nonviolent action or a violent action, music can be and has been and often is central to keeping people on track in whatever it is they're trying to accomplish. Music could be potentially used to help embolden and seal the will of anybody, whether they're fascists, communists, pacifists, 
anarchists, whatever they're doing, nonviolent or violent. I think music is neutral in that argument.

Although many of the informants did identify themselves as being activists in their communities, the primary identity, as illustrated by Festivamente and Con Moto above, was first as a musician, and as musicians they believe they have access to a tool that can be used to "inspire people to action."

\section{Summary}

This chapter gave an overview of each of the coding processes used in grounded theory. It then presented the results of this research, exploring the attitudes and activities of these musician-activists with respect to the relationship between music and engagement in social issues. The themes presented in this chapter, Music for Self and Music for Society, emerged from the coded data taken directly from the narrative of the interviews and were presented by the corresponding subthemes. These major themes and the related subthemes will be further discussed and developed in Chapter V. 


\title{
CHAPTER V: DISCUSSION
}

\author{
“As in music, so in life" (Tame, 1984, p. 15).
}

The musician-activists I interviewed have not necessarily faced the same oppression as musicians like the Chilean group, Ortiga, or members of the Palestinian group, El Funoun, or Pete Seeger during the McCarthy years. However, they all had important experiences connected to music, and had a great deal to say about this topic and why music is so valuable to them as individuals and to society in general. Some of these experiences happened to be political in nature, though the majority were not. Each informant I talked with had a lifetime of stories to tell about the power of music, sometimes only affecting one or two people, and at other times affecting thousands. After listening for hours to these stories it seems clear that more people should be paying attention to music and the way it shapes meaning in our lives, particularly those working to transform and heal conflict. In this chapter I will further explore what the informants had to say through the framework of the two primary themes that emerged from the interviews I conducted and discuss the relevance of these themes. My own perspective will be reflected in the interpretation of the results.

\section{Interpretation/Implications of the Results}

\section{Theme 1: Music for Self}

Music for Self and its subthemes, 1) the space music occupies in the informants' lives, 2) early memories of music: stories of parental influence, 3) music, identity and personal activism, and 4) the perceived responsibility of musicians to 
participate in socially engaged activities, address the numerous ways informants' spoke about the meaning of music in their lives and consequently how their lives have more meaning because of their activities and relationships connected to music. This theme explores the variety of reasons music is important to the informants, and significant time was spent in each interview talking about the very personal connection the informants have with music.

\section{The meaning of music in the informants' lives.}

The first subtheme, "the space music occupies in the informants' lives," emerged as the informants discussed their perceptions of the role of music in augmenting their lives and providing meaning, through expressing themselves, finding their "inner child," self-care and their connection to what some called "God." Bicknell (2009) explains, "If it is plausible that music can represent non-auditory properties, objects and events, then there is potentially no limit to the things music might be said to represent" (p. 12). Meyer (1967) adds, "Music may be meaningful because it refers to things outside itself, evoking associations and connotations relative to the world of ideas, sentiments, and physical objects" (p. 6). Some informants went so far as to say music is their connection to God. For example, Devoto said, "Music for me, from the time I was little, was a part of the method by which I comforted myself; the method by which I expressed myself; the method by which I sought solace from the universe"; she later commented that music is her "umbilical cord to God." Other informants also expressed this sentiment, including Ballad, who explained that music is her 
"connection to source," and Acceso, who said music is how he "experiences God and the world."

In line with the experiences of the informants of this study, literature from around the world has contemplated the power of music and its connection to the divine throughout the ages. One early example in the United States is the influential music critic of the nineteenth century, John S. Dwight. Dwight lectured and published extensively on the power of music as a means of communication with the divine (Ginow-Hecht, 2009). To him, music was "the art and language of the feelings, the sentiments, the spiritual instincts of the soul; and so becomes a universal language, tending to unite and blend and harmonize all who may come within its sphere" (as quoted in Ginow-Hecht, 2009, p. 49). Ginow-Hecht goes on to explain Dwight's conviction in the power of music. She says, "Music, he believed, was the principle of the universe and of all things, the expression of the pure spirit, and the most intimate of languages because it created instant harmony between two people as well as two cultures (p. 50)." Music, Dwight believed, could penetrate the walls of time and space and, because of this power, was a connection to the divine. Sufi mystic al Ghazzali says, "The heart of man has been so constituted by the Almighty that, like a flint, it contains a hidden fire which is evoked by music and harmony, and renders man beside himself with ecstasy. These harmonies are echoes of that higher world of beauty which we call the world of spirits, they remind man of his relationship to that world, and produce in him an emotion so deep and strange that he himself is powerless to explain it" (Ghazzali, 1991, p. 57). And so it continues, music connecting people to a 
higher meaning and grounding them on the earth, which in turn allows them to engage more fully in life.

Judith Schulevitz (2010), author of The Sabbath World, discussed in an interview with Terry Gross her ideas about God. She said, "God is tradition, God is in ritual, God is this idea that we can be connected to the past and to our ancestors through these extraordinary gifts that get passed on, which are rituals, which are ways of shaping time and space and that have stories embedded in them that in the doing we understand." Music plays a vital part in the rituals of our lives, which possibly explains why for some informants it is equated with God and spirituality. Music functions to connect us to the past, our ancestors, it helps to shape time and space, and ultimately the more engaged we become in music, the more potential there is to understand our connections to one another through the communities we create. The informants certainly expressed a wide range of meaning in their lives through their connection to music and by being given a chance to tell these stories, I was given the gift of insight into the values, history, identity and means of self-integration and selfcare of the informants. Music occupies an extremely personal and meaningful realm in people's lives and an awareness of the relationship between music and spiritual meaning is significant in attempting to understand the experiences and beliefs that shape people's behavior. 


\section{Early memories of music: stories of parental influence.}

The second subtheme, "early memories of music: stories of parental influence" also provided a rich opportunity to gain a deeper understanding of the informants' experiences. It might not be surprising to note that most of the informants' early musical memories revolved around their parents' involvement with music. What was surprising to me was that most of the informants had at least one parent, if not both, who were musicians, something I had not anticipated. The parents who were not musicians were lovers of music and encouraged their children to play music. This parental involvement certainly affected their children's participation in music, and unlike many of the parental influences children sometimes try to shed, musical appreciation and participation was one thing that stayed with these informants, something they did not want to discard. Further, participating in musical activities is likely one of the ways these informants learned to engage with their families, and then the community around them. For example, Aleatory shared her early memories of music, stating, "We always had music in our family, and it was kind of at the center. We came around, my grandpa rocked out on his little organ. And we went to the Oregon Pizza Grinder... I can’t remember the exact name of it, but it had this huge organ, so we ate where there was this music. I think that was the way in which my family knew how to communicate." Festivamente's parents' relationship to music also clearly influenced his involvement with music and shaped his perceptions about its purpose, not only in his life, but also in his community. He said, "I think playing music well is definitely part of my parents'- my mom's - life. My parents were pretty 
religiously based, so there was definitely a service element to music. We did family concerts, my mom sang in nursing homes, I played, we played at church. Those kinds of things. So pretty early on it was clear. The way music was presented was like, you have a gift and you have a moral obligation to develop and use it, you know, for God." This subtheme only touches on the relationship between parents and their children's early experiences with music that then had an impact on later engagement with music. There are numerous aspects of this subtheme that would be interesting to explore further, such as how music can help a child integrate into a family, and then a community; how parents who involve their children in music see the role of music in their lives and why they feel their children should also engage in musical activities; and the long term perspectives of children who continue to play music versus those who do not continue playing music.

\section{Music, identity, and personal activism.}

"Music, identity and activism" is the third subtheme that emerged from the interviews. Here the informants shared how - or even if - they identify as activists. Although some of the informants have been musicians, some professionally, for many years, this seemed to be the first time some of them grappled with what exactly they do, particularly in relation to the musical activities aimed at engaging their communities around them. It is possible their reflections had to do with processing my terms "activist" and "social engagement," but certainly this part of our conversation led the informants to elaborate and clarify how they see themselves in relationship to what they do with music. For example, Esuberante commented: 
I don't label myself as an activist and yet based on all the different things I was looking at here, yeah, I am an activist. I think we all are in our own way. I see myself as subtle, gentle, surreptitious. My goal is to build community. My goal is to build awareness. My goal is to build the idea of possibility of different ideas and different ways of doing things. So it's not a hammer over the head type of thing, but just to create that space where things can happen.

Libero also considered his activities in relationship to activism. He said:

I don't know if I'm an activist, you know. Certainly not with a capital "A.” But that's probably just as much an age thing, you know. Activism changes, but I think you need to be happy in the pursuit because if you think about it, almost all of the great activists in history never lived to see the fruits of their work. So it's a process. I think as I get older it's a little more gentle.

These attitudes are important in understanding that the activities and beliefs people engage in with music to connect and build their communities are not always easily categorized and are not necessarily perceived in the same way from one person to the next. The informants all had their own way of thinking about their engagement with the world through music, and after processing their activities and beliefs many of them felt that what they are doing is activism, just not a "hammer over the head" kind of activism, as Esuberante pointed out. On the other hand, several informants could not identify as being an activist at all and simply saw their identity as being tied up in their relationship to music, as a musician, regardless of the activities they have participated in to engage community or raise awareness about issues such as war. 


\section{The perceived responsibility of musicians to participate in socially engaged activities.}

The final subtheme under the cluster "Music for Self" is "the perceived responsibility of musicians to be activists." This subtheme reflected the informants' feelings regarding the responsibility of musicians to intentionally be engaged in community issues and politics. Despite all of the informants' activities utilizing music to create and engage community, it is interesting to note that several of them did not feel that musicians have any more responsibility than anyone else to confront community problems, while others felt musicians do have a responsibility because of their status and position as leaders in relationship to a group of people; their audience. In addition, many informants expressed opinions that were contradictory to their own engagement in societal issues, as can be seen in Fan-Bei's firm belief, mentioned in Chapter IV, that musicians do not have a particular responsibility to engage in these issues contrasted with the symphony piece he wrote against war.

Ardore, the woman who, through a series of ten concerts that took a year of planning and raised $\$ 69,000$ for aid and relief for people in Uganda, struggled with this idea. She said:

The thing is, I don't like it when - and maybe this isn't fair for me, I might contradict myself here, but sometimes when someone's like, I have a responsibility with my - you know, I'm a famous person, I have a responsibility - maybe that is true. But what about just everyone has a 
responsibility? Why do you have more responsibility? But you know - if I was famous would I feel that same way? I don't know.

It is interesting to note that, although Ardore does not consider herself to be famous, she is making a career out of being a singer-songwriter and has many connections locally because of her position as a musician. Regardless of her level of fame, after participating in a benefit where someone said, "It just takes one person to start something," she decided she could make a difference, and as a result of this belief created an event that brought hundreds of musicians and audience members together in Portland to make a significant financial contribution to the humanitarian crisis in Uganda.

Festivamente spoke about how race can have profound influence on the way one feels about the responsibility of musicians to engage in community issues. He talked about his own history in thinking about this issue, saying:

You know, as an African American you sort of look at the history of civil rights and entertainment and there were a lot of people who were criticized for not using the power that they had as entertainers to be activists. Michael Jackson comes to mind. I mean, many, many other people. There were some people that did; Paul Robeson, Odetta, Harry Belafonte...very outspoken and then others like Sammy Davis who didn't. So that was something for me growing up that was very - I mean I read about that - I knew, I saw that conflict and it was a big question for me about what's the right thing to do? What would I do if I were in that situation? What should I do? Should I be the 
person that speaks out or be the person that works quietly in the back...change the system from the inside or scream about tearing down the system? I don't know that if I were not black, I don't know if I were not a person of color if those things would occur to me. They are because I saw people struggle with that and it was incumbent on me to deal with it because I had to deal with it, I couldn't ignore it. I had to have a position on that.

As discussed by the informants and shown in the literature, identity plays a significant role in one's relationship with music, regardless of whether the path chosen is a quiet one or screaming in order to "change the system." Stokes (1997) supports this attitude and says, "Music is socially meaningful not entirely but largely because it provides means by which people recognize identities and places, and the boundaries which separate them" (p. 5). Eyerman and Jamison (1998) add, "Like the clothes one wears or the slang one speaks, it is the music one plays and/or listens to that serves to define who one is" (p. 30).

Acceso shared a story that reflects the power of music in shaping his identity, while also making him more approachable to others who would possibly see him differently without his guitar. He explained:

I have in several instances, because I was carrying a guitar, experienced a change from antagonism to admiration and respect from groups of people who otherwise would have interpreted my eye contact with them as an aggression. When I carry my instrument, I feel safer. I'm telling you, I was downtown carrying my guitar but like a few days prior to that I was in the same 
neighborhood, I would make facial - eye contact, and a person would just totally look at it like I was being, like belligerent or something and I would have to avoid them. And then the next day or so, you know, I'm carrying the guitar, it's almost like an invitation. That's really what I've experienced. It's inviting. It's nonviolent. It's - yeah....I feel safe with my guitar, anywhere. I feel like I could go anywhere and be safe with my guitar. And I feel like I could cross any gender, any race with my instrument in my hands. I've experienced it, you know. There [are] times when in a group of people I start talking and they don't know anything about me, let's say, and then the second they find out I'm a musician, an artist, they warm up. They warm up. It's amazing.

Personal identity in conjunction with culture influences how musicians see themselves in relation to the dominant culture and can elicit responses that support the dominant culture or push against it. Culture also influences thought patterns (Rosaldo, 1984) and therefore will impact one's opinion about the responsibility and capacity one has as a musician for addressing community issues.

In connecting the significance of music to the field of conflict resolution, Music for Self provides numerous examples of how the informants of this study think about music in their lives, as well as how it represents identity and is used as a coping mechanism, so much so that several informants feel it connects them to God. This gives insight into the priceless position of music in these individuals' lives that likely is shared by many other people around the world. As has been exemplified in Music 
for Self, "Music provides numerous ways in which musical materials and practices can be used as a means for self-interpretation, self-presentation and for the expression of emotional states associated with the self”' (Sloboda \& O'Neill, 2001, p. 423). DeNora (1999) proposes that "music is a mirror that allows one to see one's self" (p. 51). In any attempt to alter and end conflict, these internal values and the practices people use to feel grounded and connected to something bigger than themselves through the use of music are noteworthy and could potentially be helpful in getting at the underlying needs and interests in a conflict. Dunn (2008a) explains, "This power of music to deeply affect someone is information that can be used to address a conflict through music. The facilitator can use cognizance of the effects of music to delve deeply into the conflict. Music can also be used to lighten up a situation with carefully selected music. Music has the ability to tap into deeply personal feelings and it has the power to influence people" (p. 75). Music can help center, affirm and nourish those who are receptive to it, and can create an important pause in thought and communication patterns that can lead to more productive conversations and interactions.

The first theme, Music for Self, has addressed a broad range of related topics discussed by the informants and has been supported by the literature. Music for Self reflects the variety of meaning and experiences the informants related regarding their connection to music on an internal level. The following section will look outward to explore opinions of the informants related to music's function externally, in Music for Society. 


\section{Theme 2: Music for Society}

Music for Society comprises a cluster of subthemes which encompass the external elements of music related to cultural expression, community building, and social engagement. Exploring informants' attitudes about the role of music in society, and integrating their perceptions with the literature, will show that the relationship between music and society is significant. This will be further explored in relationship to conflict resolution at the end of this chapter.

\section{Music as a tool for expression.}

The first subtheme to emerge in this cluster was how "music is a tool for expression." The informants expressed that because music is so meaningful to so many people, it has great power to create connection and provide a safe venue to articulate experiences. Music creates a space where people can tell their stories in an environment where they otherwise might not have a voice in the dominant culture or under a repressive government. This can be seen in numerous examples, from the Civil Rights Movement of the 1960s, to black music in apartheid South Africa in the last half of the twentieth century, to the Singing Revolution in Estonia in the late 1980s, to a very specific example such as the poignant Palestinian song, "Baladi, Baladi” (My Country, My Country). In talking about the music workshops she does in schools with large minority populations, Esuberante gave an example of the relationship between music and expression. She commented: "The stories come out. It gives [the children] a chance, a very safe place, very neutral place to say yeah, this is my situation. We don't make any judgments or anything like that; this is just the way 
it is. It also lets other people know, 'oh, maybe there is somebody like me,' or 'oh, maybe I have both parents but not everybody does.' That kind of thing. In that way I think it opens up awareness. And maybe through that comes a different way of feeling or accepting." She elaborated, "I think it allows the stories to be told in an accessible way. It tugs at your heart strings. Music is always more fun to listen to than bland prose or preaching. So I think it opens up a more accessible means of communication.” Esuberante observed that after her music workshops in the school setting, many children who had previously exhibited behavior problems or who seemed disengaged found a way to integrate themselves into the classroom culture and become leaders.

Expression through music is an opportunity to process and share information, emotions, intentions and meanings, and these can take place between those making music or those listening to it (Hargreaves, MacDonald, \& Miell, 2005). Colia Voce spoke about how music gives her opportunity to process information and emotions, and that a powerful connection to another person can result from the shared interaction with music. She said, 'If I'm in conflict with somebody, it's harder for me to think about singing with them. However, if I can break through that resistance, when I do sing I think it is more - it affects me more deeply. It creates a bond. It's a more powerful resolution or more powerful connection; a more powerful creation of music." Music involves action and interaction and is expressive of the life of individuals and societies, reflecting culture and values that help shape the meaning of experiences. Mattern (1998) states: 
Music provides a communicative medium that is not simply an alternative way to say the same things that humans say through speech. Music, like other art forms, can express meanings that are not accessible through words or express them in ways that give listeners more immediate access to emotions and ideas. (p. 17)

Sometimes music allows for the expression of strong emotion that might be too difficult to express with language alone, and in many places it allows the expression of dissent or challenges those in power (Kent, 2008). Expression through music can also be powerfully important when people see their own experiences and beliefs reflected in the music of others.

Several informants spoke specifically about how conflict influences expression through music. Con Moto commented on this:

I would say generally that conflict can create music. I mean, when there's conflict or contradictions within any element, any groups in society, big or small, it tends to create dramatic situations, lots of emotion, and then people doing a lot of things, and basically no matter what it's about, when you have people doing a lot of things and emotion and feeling a lot of things, you know, they are going to tend to express that musically. And certainly, undoubtedly as with any war that's ever happened, there's been lots of music created for both sides and certainly it's true of any kind of - any time people get together to do anything, especially when there's stress or conflict or lots of emotion involved, people are going to make more music. If everything is calm and nothing much 
is happening, people will still make music. It's probably not with the same kind of urgency though because they're not trying to communicate with their fellow people about something as urgently as they are when there's conflict. I think conflict tends to bring about - any time you're stirring the pot, that tends to produce more music, more art, more of all sorts of things.

Con Moto went on to say:

Music is powerful. Music and words together can really transport somebody to a place they've never been for a few minutes, if you do it right. And that's powerful. And other forms of communication can do that as well, certainly, but music does it very well. Something about that combination of words and music together in songs, it has the capacity to reach people on both the emotional and cerebral level at the same time. And it makes people feel good and people are inherently musical. I mean, we have been musical forever, and music...it's therapeutic, it has all kinds of important impact on people.

As Con Moto has articulated, music is powerful and its relationship to expression is significant. Tame (1984) adds, "No matter how one might try, it is impossible not to express in one's music the reality of one's own inner state of being, even if only in subtle ways. This affects others, the attainment or weaknesses of the performer or composer tending to become the attainment or weakness of the hearers" (p. 155). It becomes easy to imagine the rippling effects of music in a society that, with the aid of technology, can result in far reaching connections among a wide range of people. 


\section{Music's relationship to emotions.}

The second subtheme in the Music for Society cluster is "music's connection to emotions." The interview question was specifically related to the relationship between music and empathy, which resulted in that being the dominant emotion referred to in this section. According to Aristotle:

Emotions of any kind are produced by melody and rhythm; therefore by music a man becomes accustomed to feeling the right emotions; music has thus power to form character, and the various kinds of music based on the various modes, may be distinguished by their effects on character - one, for example, working in the direction of melancholy, another of effeminacy; one encouraging abandonment, another self-control, another enthusiasm, and so on through the series. (as quoted in Tame, 1984, p. 19).

Aliquot talked about about his experience being a musician and how emotional connections between band members extend to the audience. He said:

When you are playing with people and you are playing at an extremely high level, the empathy is palpable. And then I think implicit in that is the idea that you are sharing, you are sharing, it's a gift economy. You're sharing in - you are giving or you are receiving. And I think being able to reach that level of sensitivity has a lot to do with being able to communicate story and a lot of this is grounded in ideas. And with empathy, with this idea of communal, collaborative creation, I think we're building a sense of tolerance. 
This idea of giving and receiving helps clarify that there are relationships between people in any act of "musicking" (Small, 1995) and that meaning resides in the mutual relationships established at any given moment in time between the participants of a musical encounter (Becker, 2001).

Devoto talked about her experience working in white communities, talking about race, and how invaluable music is in this work of getting to an emotional level where people might be able to connect more easily with others. She explained:

I think music gives people time to have feelings and stay in feelings. People often say to me, "How in the world do you sing acappella?" It allows me to respond to the connection to my audience. And so, you know, like the Sunday when I did the concert, there was a gentleman there that will only come to church when I sing. And so when he started to cry, I knew that I needed to stay at that level of emotion for folks in that congregation or in that group of people. I think you have to do it in a non-confronted fashion. I want to work with white people. I want to work with white people and I want to be able to start the conversation by saying, "everybody in this room is a racist." And I... and I cannot kick their shins. I mean, if I poke buttons, I lose my welcome. And so somehow I have to get people first to empathize. And that's not hard, because most people are genuinely kind human beings.... Only way I think you can have a truly heartfelt, healing conversation is if people feel affinity and understanding for each other. And if I can create that sacred space with song and music and story, then, then I think I believe the spirit does the work. 
And if my music can allow that conversation to be a little more tender... music has taught me to listen for my heart. I mean, when I'm singing I'm doing everything I can do to be emotionally communicative. My goal, very simply, with my music, is to start a dialogue, to start a conversation with folks, to have folks ask questions, to have folks be willing to look at people who are different from them with some curiosity. And if I can do that, I think I've accomplished something.

Devoto explained that in her work it is important to get people to respond to one another on an emotional level before she can be effective in getting them to look at and possibly understand their biases. She expressed that music is a wonderful tool for getting people to that emotional place. As Sloboda and O’Neill (2001) explain:

Reliving past relationships, constructing identity, using music to 'siphon off' emotions that are not for public presentation: all of these depend on, and are used to negotiate and develop, the complex web of cognitions and behaviors that constitute social life. As such, music becomes part of the construction of emotional feelings and displays that are both reflective and communicative 'embodied' judgments used to accomplish particular social acts. In other words, musical emotions are a form of social representation, which is negotiated as an interaction between cultural/ideological values of a society, the values and beliefs operating in a social grouping or subculture in that society, and the individual's own social and personal experience. (p. 427) 
As illustrated by Devoto's activities with music to address race issues, cultural/ideological values are brought to a level of awareness through her music and storytelling where they can be negotiated and explored to create more understanding. For Devoto, the use of music creates a safe environment where negative stereotypes and biases can be explored, where language alone might fail.

Becker (2001) uses the concept of "structural coupling," taken from the field of biology, to explain how music and emotions ultimately extend beyond the individual to impact many other people. She explains:

"Structural coupling" describes the internal, structural changes that occur within an organism as a result of interaction with other organisms and with a world; changes of one's being or one's ontology. These changes become new domains of knowledge, knowledge gained through interactive behaviors, through doing. Music listeners as well as musicians undergo a learning process in which they imitate physical and mental gestures that ultimately transform both their inner structures as well as their relations to everything beyond the boundaries of their skins. Music and emotion are part of a larger processual event that includes many other people doing many other things while the whole event unfolds as a unity that has been organized and reorganized over time by small structural changes within the participants. (p. 152)

Becker's theory highlights the interconnectedness of individuals and communities that constantly influences the ways we think and behave, the interlocking activities in our lives that ultimately shape the society as a whole. Individuals cannot be considered 
without also thinking about their community, and community cannot be fully comprehended without understanding the individuals that make up the community. Music encompasses internal processes of reflection and association, and conversely immerses us in external activities such as dancing and preaching that help form culture and identity (Becker, Anthropological Perspectives on Music and Emotion, 2001). Becker adds, "We can begin to think of the music, the emotion, and every other aspect of the process [of structural coupling] as contributing to bringing forth the activities of each other, as bringing forth a world or a reality in which certain emotions and actions are expected and appropriate, and in which the reality brought forth by all is enacted by all” (p. 153). Becker's perspective is significant in understanding how the expression of emotion through musical engagement is a social function within a given society which helps to encode meaning in our lives.

\section{Music, connection, and community building.}

The third subtheme that emerged in Music for Society is the way "music can build and bind community." This theme ties together the ideas of informants from diverse backgrounds and experiences. Of all the potential ambiguities or differences of opinion about the realm of music and meaning in our lives, all of the informants affirmed music's significant relationship to community building and thus the role it has in society. Bicknell (2009) states, "Music's social character is evident in the role it plays in every culture, past and present, in creating and reinforcing social bonds, whether these are the bonds between caregivers and infants, adult partners, or among members of social groups and sub-groups (p. viiii). For Segue, the relationship 
between music and building community was obvious. He stated, "[Music is] a community building tool. It's a critical community building tool. It's hard to build community without music. Virtually all of my experiences, community has all had a very significant musical component and it just binds you together. The experience of making music together is always a binding kind of thing. I think it has an enormously important role in building the web of connections/community and shoring them up." Aliquot also expressed his belief that music is central to community and helps bind people together, sometimes in small, subtle ways that slip in to create connection and alter our outlook on any given day. He explained:

I think there is no better way to bring a roomful of people together and figure out what we have in common. You know, there isn't a person alive who can't clap their hands or stomp their feet. A great example of this: I was on the bus the other day and this woman was at the front of the bus. It was the most beautiful thing and we all for a second had to forget about ourselves. She turned around to the people on the bus and she said, "Well, people are going back to school. Summer is over and we's getting back to business." She said, "So what better time than now to sing a little song?" She said, "Now I'd like the right side of the bus to sing 'row, row, row your boat,' and then after that's happened three times I want the left side of the bus to go 'row, row...' and we'll do it in canon, okay?" She gave off this beautiful sense of joy and I was actually in a really bad mood when I walked on the bus, I was ' $g r r r$,' and she immediately disarmed me. And there were two little kids in the front, and they 
of course want to sing, and it was this thing that all of a sudden we all had come back to...we're all in third grade again, we all know it, we've all gone through it.

Aliquot's story highlights the flexibility and inclusiveness of music, how perfect strangers on a bus can sing a round of "Row, Row, Row Your Boat" and walk away feeling a little better than before. Mattern (1998) explains the significance of this. He says, "If music embodies common memories and meanings, then it is tied to public and objective social circumstances - to the shared experiences of people in an objective social and physical environment. The messages of music are thus publicly accessible, not merely elements of the musician's subjective and private world. This public, common quality gives music its communicative capacity, which, in turn, may support the development of community by enabling the sharing of experience" (p. 17). Although engaging people in music can be so simple, it takes an act of courage and confidence to stand up and prompt a bus full of strangers to sing together.

Playing music with others and in turn sharing that with an audience or other performers can lead to a profound sense of belonging and unity. Ardore noted:

Music just pulls everybody in the same, it always levels the playing field. Music can calm everybody into the same place. I know when I've been at concerts and they want us to sing along, no matter who's around me, I'm like we're in this together...that feeling: we can do it! And you sing along as a group; you're a group. It makes you a group. 
Several informants spoke about how this ability of music to create cohesion within a group has also helped them broach difficult topics, and how the relationships created through music form an opening where ideas can be discussed in a less divisive manner. Colia Voce talked about the purpose of the community music groups she has participated in and how these experiences have been helpful in dealing with relationships outside the ensemble. She commented:

The whole purpose was to gather people together in song to create community and I believe that form of creating community - you then establish connections that help you work through conflicts. In terms of my personal relationships, singing together has helped - just to forge the friendship - and also if there's a problem it's a way to work with the issues and arguments.

She added, "I think [music] touches people in that visceral, non-verbal place and not, you know, the [left] brain - whatever you want to call that place of us that's not so rational and logical and intellectual, where we do have more feelings and emotions and where empathy arises from. So it's a really effective bridge." Mattern (1998) explains:

Music may serve critical and visionary roles in making communities more open and tolerant to the experiences of others, helping members see themselves in a new light and expanding the horizons of the community. If music communicates meanings derived from the past and present everyday lives of a people, then each work of music embodies assumptions and beliefs that people hold about themselves and their lives. Music can make 
communities more open to differences by undermining the preconceptions and unconscious assumptions that sometimes underlie prejudice and intolerance. It increases the possibility of mutual recognition and respect of differences and encourages greater modesty in asserting universal moral and political ends and judgments that are hostile to differences. (p. 22)

Music can provide opportunities to connect with others by getting people out of their houses and exposing them to different kinds of people; this exposure in turn helps to inform identity. Considering all this, Ballad asks, "How can music not build community?"

It must be noted that music's ability to create community is not inherently positive, and the context in which it is used is important. Although none of the informants spoke about the potential exclusion from community that might occur, it should not be taken for granted that this won't happen during any group formation process. David (2004) notes, "Music is a way of bonding affectively, fulfilling the need to converge in harmony. Yet, it can also be a way that one group creates a boundary as a signal to other groups not to mess with what's inside their resonant chamber of shared values. Like any creative human endeavor, it can be made divisive as well as unitive" (p. 7). Nationalistic music or the bands at any sporting event illustrate David's point. Creating a sense of group affiliation and identity can be extremely positive, but particularly in the context of conflict resolution, extreme care should be taken to prevent an "us and them" mentality that further alienates individuals or entrenches negative stereotypes. As Kent (2008) explains, the meaning 
of music always depends on its context, but that meaning may be uncertain and therefore requires anyone wanting to use music as a tool to take care with the context in which it is to be used.

\section{Music as social engagement: values, activities and activism.}

The final subtheme is “music's relationship to social engagement: values, activities and activism." This subtheme reflects the integration of the informants' identity with the musical activities they engage in within their communities. Each informant was chosen for this study because of his or her involvement with using music to engage community, and each spoke about why these activities are significant.

Music has been used as a means of social engagement for centuries. Confucius believed that music contained hidden significance, making it one of the most important things in life, with great power for good or evil (Tame, 1984). Ancient civilizations from China to Greece and India "affirmed music to be a tangible force [sic] which could be applied in order to create change, for better or worse, within the character of individual man; and, what was more important, within society as a whole" (Tame, 1984, p. 17). In thinking about the role of music in social movements in his own lifetime, Con Larghezza commented:

As long as I remember music has been central to every last social protest and consciousness-raising in any kind of a conflict throughout the world. I can't think of one that doesn't, didn't have music carrying it in some way. I'm completely convinced that apartheid died on the back of the spirit of the South African songs that were sung. The civil rights movement certainly is that. 
Every war protest that I can remember has its own music. The whole labor movement had music to carry it, that we're all still singing. So I think it's impossible to separate them. I think that any kind of social activism that doesn't have music in it is probably sterile.

Eyerman and Jamison (1998) verify that music and song have been central in the formation and remembrance of social movements but point out that these elements of collective identity have not been examined enough. They do believe that the relationships between culture/politics and music/movements is significant as a collective learning process.

One of the interesting things that emerged from this theme was the way the informants saw their responses to social issues (such as war) in relation to activism. Some informants were clear that they are musicians as well as activists, while others did not identify with activism at all. Fan-Bei is a man who composed a symphony piece in opposition to the Iraq War, yet for him this effort had nothing to do with activism but was a way for him to express his own outrage at the situation. He explained:

I was never connected with activism. As a matter of fact, this [piece] is the second musical message to people which is somewhat political. Because you know, I am concerned the way how we treat our planet. I think our tragedy and our problem is that we are too much securing our comfort. Everybody wants to have a good life. And unfortunately, we're doing it by damaging our environment. We are constantly having some new ideas. And these new ideas 
are clogging the healthy environment and when I start to write this [piece], actually I approach it like an angry man, you know. Like being really upset. Extremely upset because I'm seeing the greediness, I'm seeing the selfishness, and bottom line is to have a good life. The question is, how much the next generation will still have good, healthy life, you know. So the [piece] is... really ends catastrophically. Mercilessly. That was my feeling, you know. Really, really angry. There is also a hidden warning on that, you know. Because I have my own belief why this war was, and I don't want to talk about it, it just - it was really - thousands and thousands of people simply died on that, and I'm talking about those Iraq people. And of course we perish too, I mean it's just - war is ugly stuff. It just - you're trying to convince something which politically sometimes is questionable, you know. So that was - those two pieces you may say could be somewhat connected with activism, being an activist. But being in down-town and being a loud person, I'm not that type, you know.

Fan-Bei's response illuminates an important paradox about social engagement: often those creating works of art or engaging in activities in response to societal problems are doing so simply because it is a way to help manage their own feelings and frustrations and not because they are setting out to capture the attention of others. The involvement begins as a personal response, and like Fan-Bei's piece, results in a public performance for hundreds - if not thousands - of others to hear and consider. 
Some informants also spoke about the problems associated with being categorized as an activist. For example, Festivamente talked throughout the interview about the service element of music that he learned very early on from his mother and his belief that music can create change, but how for him this is not in the same category as activism. He said:

I find that one of the problems with activism is that it is often polarizing because if you pick a narrow point of view then you - by definition you are excluding people [who don't have] that point of view. And that's a drag. I don't like to do that. If I, by putting my music behind a certain cause I then become linked to that cause and I have to exclude other people, I mean, that sucks for me. I'm not particularly interested in doing that.

Other informants also talked about the challenges of engaging publicly in what might be perceived as polarizing issues. Moderato pointed out:

If you're Bruce Springsteen it's easy to be an activist. Because you put yourself on the line, you know. A lot of your fans may not be progressive politically. But with somebody like Springsteen, [he] can afford to be - [he can afford to] put a lot of time into it because he's a megastar and he can afford to alienate a certain group of people because he can say, "I've got enough fans." I can't.

Penseroso also commented on the difficulties of activism, saying, "Activism as an identity is really different I think than changing - than like the idea of working to change systems that you think are not working well. I think sometimes one thing that 
can happen with activism is it becomes like an in-crowd kind of thing." These opinions about the way musical engagement is perceived and labeled are significant, especially in the context of conflict resolution. The power of music to help heal and connect people in conflict relies on the perceived differences and divisions being eliminated as much as possible by creating common ground and understanding; it should not exacerbate divisions with labels and categories.

Despite the hesitation some informants had in being identified as activists, other informants saw a clear connection between music and activism and did not see activism as a divisive element in community engagement. For example, Aleatory commented on the positive relationship she sees between music and activism. She said:

Music is about connecting people through a medium. Activism is about, in my viewpoint, connecting people through purpose. And so music to me is a vehicle of communication that can create a container that's safe for people. Music models the struggles that we have to conquer in ourselves to be able to communicate with that instrument, which is exactly what, to me, activism is about - being able to communicate beyond a struggle.

In Aleatory's view, activism is simply one way to communicate a purpose to another person or group of people; by utilizing music toward that purpose, a safe setting can be created where everyone can participate. In line with Aleatory's opinion, Peter Yarrow, a member of the folk band Peter, Paul and Mary, talked about why he got involved in activism as a musician. He said, "When you talk about people making a 
leap from music to activism, you first have to believe that people can change, that the times can change, and that you can have a part of that. That's why I became a folksinger, because I believed that" (as quoted in Crosby \& Bender, 2000, p. 25). Yarrow's remark expands on Aleatory's comment that not only is music something people from a variety of experiences can participate in, but that through that participation a belief is created that things can change.

In exploring how the desires and hopes for a more just society get translated into social codes of behavior, Ramos and Ochoa (2009) claim that music as a creative social force helps mediate those desires. Music calls attention to social relationships that are crucial for maintaining as well as for changing forms of community (Weintraub, 2009). A powerful example of the use of music to transform stereotypes, connect disparate communities and create outlets for expression is the work being done in Brazil by the AfroReggae Band and Cultural Group, a nongovernmental organization (NGO) started in 1993. The group was originally created in response to the massacre of twenty-one residents of the favelas (slums) of Rio de Janeiro by the police in an illegal operation (Ramos \& Ochoa, Music and Human Rights: The AfroReggae Cultural Group and the Youth from the Favelas as Responses to Violence in Brazil, 2009). Rio de Janeiro is a city where, according to UN statistics, nearly 50,000 people were shot between 1980 and 2000, four times as many people as have died in 50 years of conflict between Israelis and Palestinians (Parkins, 2007). Between 1997 and 2000, 20\% of these homicides were committed by the police force, with a disproportionate number occurring within the black population of the favelas (Ramos 
\& Ochoa, Music and Human Rights: The AfroReggae Cultural Group and the Youth from the Favelas as Responses to Violence in Brazil, 2009).

The AfroReggae Band and Cultural Group's objective is to "promote social inclusion and justice by using art, Afro-Brazilian culture and education as tools to create bridges that span differences and serve as pillars to sustain and exercise citizenship" (as quoted in Ramos \& Ochoa, 2009, p. 227). They participate in dozens of projects, from putting on concerts in the slums with popular Brazilian musicians to doing workshops with local police and teenagers from the slums. Ramos and Ochoa (2009) explain that the group "concentrates its efforts on racial and territorial affirmation, and produces a first-person discourse on behalf of the young and socially excluded who live in the slums and urban periphery" (p. 229). The group also works to create bridges between the middle class and the residents of the slums, acting as what Silvia Ramos (2009) labels a "new mediator" (p. 227) by working within the slums to bring them closer to the middle class and at the same time "presenting" the slums to the middle class. In my interview with Con Larghezza he also spoke about the ability of music to mediate and create empathy, mirroring the goals of the AfroReggae Cultural Group. He said:

I think music is the catalyst for empathy. Music is the mediator between us and our environment and we sing ourselves place to place, right. It's generalizable. So once we all have a sense of a particular injustice, I think music mediates that sense of injustice and it's - I believe it's a catalyst that creates an empathic response. 
Music not only accesses emotional responses and creates opportunity for mediation between people and groups, it provides healthy opportunities of engagement. Jose Junior, one of the members of the AfroReggae Cultural Group, explains, “Our major objective is that the youths of the favelas do not take the narcotraffickers as their idols any longer. Instead of guns, we offered musical instruments. Our power is not that of death, but that of life" (as cited in Ramos \& Ochoa, 2009, p. 233). Through the activities of this group, stereotypes have been altered and new images are being created in their place through the use of these "new mediators," showing that it is possible to combat violence through creative and peaceful means (2009).

It is useful here to return to William Zartman's (2003) theory of “political ripening." Several examples of community engagement discussed by the informants and in the literature occurred as a response to something that hit a limit of intolerability for them personally, such as Fan-Bei's example of writing music to express his anger about the Iraq War. The work being done by the AfroReggae Cultural Group and Band is another example of a response to a conflict within a community that could no longer be ignored, and for these individuals the expression and action they took came through music. Although Zartman's work is primarily focused on conflicts between nations in a political arena where negotiations are being conducted, it is also useful to consider in any context where there is conflict and a response to the conflict is desirable. A series of events generally happen before anyone decides to engage, and though the process might not be political, there is a ripening that occurs before someone will reach his/her breaking point and decide to get 
involved. Con Larghezza spoke about how for him music can provide a means to respond to injustice and can "lift up the individual," and as such can add to the process of "ripening." He said:

Our responses to injustice are dependent on our capacity to access our outrage against injustice, and for me music just - not only does it lift up the individual, but it creates a collective field of response. There is just no spirit in activism without music. That's my opinion. Activism floats on the spirit of music. Although it might be difficult to plan or prompt the ripening events that can alter a conflict situation toward transformation and resolution, music's influence internally and externally within society situates it where it can aid in the process of ripening and provide an outlet of expression. Festivamente asked:

Well what do you want to do? What would you do if you knew you could? What do you see? What kind of a world do you want? Then take a step towards it. If music is your way of doing it, then use your music to take a step towards it. And maybe you don't do anything but play the horn. Maybe you never say a word, but when you play the horn, you're going to play it with that in mind, to get to that dream. And that's cool. Nobody should be criticized for that if that's what works. I guess I'd prefer to think of it that way.

Music is flexible and sometimes amorphous in its various roles, but it is important to consider the potential that exists that it can be a "new mediator," as Ramos (2009) has suggested, in the process of ripening that provides opportunities to build peace. 
So far in this chapter the two themes of this study, Music for Self and Music for Society, have been discussed. I have analyzed and integrated the subthemes that emerged with the literature to show how music can shape identity, connect community and bring together a variety of emotions, memories, experiences and thoughts. "Music for Self' is important in the realm of conflict resolution for understanding the deeper layers of meaning in people's lives that result from their experiences with music, as the informants' stories show. "Music for Society" has highlighted music's strengths in society, paralleling many of the objectives in conflict resolution. The next section will elaborate on the implications of music's use in conflict resolution.

\section{Implications}

After considering the views of the informants and comparing them with the literature, it is clear that music has an important place in many people's lives and thus can be an important tool in conflict resolution settings. In conflict situations, especially protracted violent ones, learning how to live together peacefully can be one of the most difficult things to do, as can be seen in the Israeli/Palestinian conflict or the civil war in Somalia. In Eric Fromm's (1956) The Art of Loving, he says, “One does not begin to learn an art directly, but indirectly, as it were. One must learn a great number of other - and often seemingly disconnected things - before one starts with the art itself" (p. 92). In resolving conflict with the aim of long-lasting results, the process is also often indirect and sometimes it is in the seemingly disconnected things that opportunities can be found to create connection between adversaries and help heal divisions. In situations where a violent approach to conflict is the norm, music can 
play a critical role by creating a bridge from the past to a future without violence where communication and empathy are developed and differences are respected. In Dixon's (2002) work on music and human rights, he says:

The way that music-making reaches and draws out the essential humanity of the most unreachable people places it in direct opposition to political violence, which denies the humanity and individuality of its victims. Musical interaction draws attention to the uniqueness of each individual, and at the same time reveals the connections between us - our common humanity. In this sense, music-making is a touchstone for human rights, a constant reminder of the value of each person and of humanity as a whole. (p. 131)

Music can be used directly in conflict resolution and transformation work, as Bergh (2006) suggests, or it can impact change/transformation indirectly as Fromm proposes, simply by bringing people together in activities revolving around music; working to renew, create and strengthen bonds; accessing important emotions such as empathy and acknowledging and creating identity. Pete Seeger suggests the same:

I don't think there was any political movement in history that had as much singing as the civil rights movement had. And I think these pictures refute people who say that music is just an attempt to make life livable. It's true to a certain extent, that is one of the purposes of music, to help you survive your troubles, help distract you from your troubles. But some music helps you understand your troubles. And as you see here, some music can help you do 
something about your troubles. (as quoted in The Power of Song, directed by

Brown, 2007)

If oppression and violence are to be reduced and communities rebuilt after extreme tension, working to renew, create and strengthen bonds, accessing important emotions such as empathy and acknowledging and creating identity are essential.

Conflict resolution that incorporates music as a tool can be used in a variety of ways and in a range of locations, and can be aided by working in conjunction with music therapists or musicians coming from a community-engaged arts philosophy. There are already groups and individuals using music around the world to help heal their communities: in war zones, slums, prisons, schools, with the unemployed, - the examples and approaches are endless. It is important to note that the longer individuals and groups can be involved in musical activities, the more potential exists for bonds and understanding to develop and consequently reach a deeper level where lasting transformation can occur. Mary Parker Follett's (1924) notion of the "long view" is useful when considering the application of music in conflict resolution. In her book, Creative Experiences, she discusses the benefit of approaching a situation with the long view in mind, as opposed to the all-too-common desire for immediate gratification and a quick fix. This also works well with Zartman's (2003) concept of ripening. It is in this space created by the "long view" that I believe music can be most effective in its mediation of creating bonds and understanding between people. Music has the capacity to remind us of our universal condition as humans. One of the first steps in conflict resolution should always be to identify common goals that the 
participants can identify with, move toward, and affirm in attempting to come to a mutually acceptable compromise. Music can set up preconditions for the process of identifying a mutual set of values like little else can, and can act as a bridge between the undesirable conflict of the past and the potential of a future where destructive conflict is no longer so prominent.

Lederach (2005) explains, “The artistic process initially breaks beyond what can be rationally understood and then returns to a place of understanding that may analyze, think it through, and attach meaning to it. This is much like the process of reconciliation" (p. 160). The process of transformation takes time, and there is enormous potential to be creative with music as a "new mediator" (Ramos \& Ochoa, 2009) which can contribute to "learning the art" (Fromm, 1956) of peace. As Whitehead (2008) comments, "I believe that peace has to be more than the absence of war or conflict. Peace, to me, has to encompass the totality of human nature, experiences and emotions. Music is one way in which we, as humans, can connect. Music can be a catalyst to peaceful harmony on earth, although not all music is used for peaceful purposes. When used properly music can be the framework for constructive conflict transformation, which will result in a peaceful state (p. 78). The activities and relationships between music and conflict resolution should be explored more deeply to understand the benefits communities can and are already gaining from grassroots efforts to incorporate music into the lives of those who are suffering due to conflict. 


\section{Problems with Music as a Conflict Resolution/Transformation Tool}

It is important for those working in conflict settings to understand that individuals and communities might not always have the capacity to take on the healing work necessary, and the multiplicity of interests is likely to present a significant obstacle to collaboration and reconciliation (Cohen, 2008; Mattern, 1998). Collective identities are not going to be changed overnight and the application of music is not something that should be used without the same serious planning and consideration that goes into other resolution and transformation tactics (Bergh, 2006). Without thoughtful consideration of the situation, the use of music could inadvertently create distance and feelings of alienation. Cohen (2008) explains:

Glossing over music's particularities can lead us into ethically troubling situations when, for instance, we allow to dissipate the emotional affinities that musical experiences can facilitate, without exploring avenues for larger societal impact. An over-emphasis on the universal dimensions of musical experience also can obscure the very real power asymmetries that inscribe themselves onto musical encounters across differences. Unless engaged constructively, these power differences can perpetuate the underlying dynamics of the conflict that musical interventions may actually be intended to transform. Music is a powerful medium for expression, communication, healing, and transformation. As peace builders, we can access this potential when we embrace not only musics' universal appeal, but their particularities as well. (p. 38) 
To avoid potential harm, it is imperative to consider power relationships, historical perspectives and cultural identities associated with music in a particular situation. For example, the function of music as a means of hope, unity, and a tool for affirming identity and aiding in communication and resistance during apartheid-era South Africa certainly means different things to black South Africans and white Afrikaners. As Bergh (2006) states, because music is so important in identity formation and accesses our emotional selves, music is not necessarily without "baggage," even if it has never been heard before. People can have strong associations to specific pieces of music or genres of music that can recall memories or associations with the past; these can be extremely powerful and should not be minimized. Nussbaum (2003) explains, "Music may be universal in the sense that people widely separated by language and culture can learn to love the same music. It is not universal in the sense that this response is automatic and without effort" (p. 263). Music's use as a tool for conflict resolution requires the same care and consideration as any other tool, and if used inappropriately or without the care required, can further alienation or deepen divisions.

In the spirit of Mary Anderson's (2001) principle to “do no harm," Cohen (2008) has provided a valuable list of questions to help guide the incorporation of music in a conflict resolution or transformation situation. They are:

- Is it possible to extend the positive effects of musical encounters into political and social life? If so, how?

- What are the possibilities and limitations of focusing resources on children rather than adults? 
- Can arts projects be linked with other peace building efforts so that emotional, cognitive, and relational gains can be connected to political, economic, and ongoing cultural projects?

- What are the dynamics of power present among those involved in the project and among the various cultures and communities involved?

- How can these be acknowledged and addressed in a respectful way?

- What are the risks involved in transplanting a cultural form from one culture into another setting? What is gained and what is lost?

- Who benefits (politically, economically) from cultural forms when they are lifted out of context?

- How can we minimize the risk of reinforcing an inequitable status quo by creating short-term "good feelings" with no contribution to substantive or lasting change? (p. 37-38)

Music can have a very real and powerful effect on individuals and groups, but it is not an easy solution. It requires the same thoughtful and careful approaches of other peace building attempts in working to create or rebuild situations of respect, healthy communication, and understanding between individuals and communities.

\section{Reflections on the Process - Study Limitations}

It is my guess that there are numerous inspired and concerned people (from activists to musicians) making use of the power of music in war zones around the world; however, because of their circumstances and the political conditions of these 
regions, as well as my own limitations and constraints due to lack of resources, it was not possible for me to explore the full range of this topic. Consequently, I decided to focus on interviewing people in the Pacific Northwest area of the United States and thus, for the most part, my study reflects aspects of American culture and, furthermore, a generally more liberal section of the country.

In future studies of this nature, there are several recommendations I would make. In addition to interviewing the informants to discuss their ideas and experiences, it would be useful to observe their work with youth and other community groups and obtain insights from those participants about their involvement in music related activities. During the interview process, it would also be helpful to clarify definitions of words that might be assumed to have a common meaning. In this particular study, it would have been useful to define words, such as "empathy" and "activism." It also would have been interesting to do a pre-interview survey with the informants in order to expose some of my own assumptions. For example, I approached every informant because I had decided, in some way or another, that each was a musician-activist, and was surprised to learn that several of the informants did not think of themselves in this way. If I had known this before the interview, I could have prepared more thoughtful follow-up questions to explore the nature of identity and musical activity in conjunction with community engagement.

I would also amend several of the interview questions in order to be more informant-focused and specific, as opposed to the more philosophical and open-ended questions I used. For example, instead of asking questions that began with "what do 
you think," I would ask questions that began with "please describe a time when." Although the philosophical nature of some of the answers/responses were extremely interesting, I had wanted to learn more about the specific activities and experiences of the informants as musician-activists and that did not necessarily emerge from the "what do you think" nature of many of the questions.

\section{Recommendations for Future Research}

Conflict resolution practitioners have not studied the relationships between music and conflict resolution enough, not only because of the lack of awareness of the power of music, but also because it is a difficult topic. Both music and conflict resolution are multi-faceted and the possibilities for their partnership in creating a more peaceful world may be endless. More studies should be conducted, not only exploring musician-activists' ideas as this study has done, but also measuring the responses of participants/audience members of these musical activities. Longitudinal studies should be conducted in areas where music is already being used as a tool, such as with Brazil's AfroReggae Cultural Group, to establish the efficacy of such programs, thereby providing support and legitimacy so that social service agencies and funders understand the importance of these activities and allocate money to support them in their own communities.

\section{Conclusion}

This chapter has discussed my interpretations and the implications of this study, exploring how musician-activists perceive the role of music in community 
engagement in relation to the literature, as well as the study's limitations and suggestions for future research. It is my hope that this research will deepen the understanding conflict resolution practitioners have of music's power in people's lives, and highlight why this is important for consideration in the work of alleviating conflict. Albert Schweitzer (1975) explained how expansive music can be, and summed up what I hope this study will arouse for others, when he said, "Joy, sorrow, tears, lamentation, laughter - to all these music gives voice, but in such a way that we are transported from the world of unrest to a world of peace, and see reality in a new way, as if we were sitting by a mountain lake and contemplating hills and woods and clouds in the tranquil and fathomless water" (p. 34). As the themes "Music for Self" and "Music for Society" have shown, music and its possibilities are expansive, and the more this is recognized in partnership with efforts toward seeking peace the more likely peace will be. 


\section{REFERENCES}

Abi-Ezzi, K. (2008). Music as a discourse of resistance: The case of Gilad Atzmon. In O. Urbain, Music and conflict transformation: Harmonies and dissonances in geopolitics (pp. 93-103). New York: I.B. Tauris \& Co Ltd.

Anderson, M. (2001). Do no harm: Local capacities for peace project. Retrieved April 19, 2010, from Conflict sensitive approaches to development: Humanitarian assistance and peace building: Tools for peace and conflict impact assessment: http://www.conflictsensitivity.org/resource_pack/8_do_no_harm_local_capacit ies_for_peace_project_323.html

Augsburger, D. (1992). Conflict mediation aross cultures: Pathways and patterns.

Louisville: Westminster/John Knox Press.

Becker, J. (2001). Anthropological perspectives on music and emotion. In P. Juslin, \& J. A. Sloboda, Music and emotion (pp. 135-160). New York: Oxford University Press.

Bergh, A. (2006). I'd like to teach the world to sing: Music as a tool to reduce identity conflicts. American Sociologial Association 101st Annual Meeting (pp. 1-20). Montreal: Sociology of Culture: Musical Lifeworlds.

Bernard, H. R., \& Ryan, G. W. (2010). Analyzing qualitative data: Systemic approaches. Thousand Oaks, CA: Sage Publications, Inc.

Bicknell, J. (2009). Why Music Moves Us. New York: Palgrave Macmillan. 
Blacking, J. (1987). "A commonsense view of all music" : Reflections on Percy

Grainger's contribution to ethnomusicology and music education.

Cambridge/New York: Cambridge University Press.

Bonny, H., \& Savary, L. M. (1973). Music and your mind: Listening with a new consciousness. New York: Collins Associates Publishing, Inc.

Brown, D. (2004, December 25). Remembering a victory for human kindness: WWI's puzzling, poignant Christmas Truce. Retrieved February 1, 2010, from The Washington Post: http://www.washingtonpost.com/wp-dyn/articles/A252062004Dec24.html

Brown, J. (Director). (2007). Pete Seeger: The power of song [Motion Picture].

Burrowes, R. J. (1996). The strategy of nonviolent defense: A Gandhian approach. Albany: State University of New York Press.

Bush, R., \& Folger, J. (2005). The promise of mediation: The transformative approach to conflict. San Francisco: Jossey-Bass.

Centre for conflict resolution. (2000). Retrieved January 22, 2010, from History of conflict resolution: Unit 2:

http://www.brad.ac.uk/acad/confres/dislearn/unit2.html 
Charmaz, K. (2000). Grounded theory: Objectivist and constructivist methods. In N. K. Denzin, \& Y. Lincoln, Handbook of qualitative research (pp. 509-536). Thousand Oaks, CA: Sage Publications, Inc.

Charmaz, K. (2002). Qualitative interviewing and grounded theory analysis. In J. Gubrium, \& J. A. Holstein, Handbook of interview research: Context \& method (pp. 675-694). Thousand Oaks, CA: Sage Publications, Inc.

Coate, R., \& Rosati, J. (1988). The power of human needs in world society. New York: L. Rienner Publishers.

Cohen, C. (2008). Music: A universal language? In O. Urbain, Music and conflict transformation: Harmonies and dissonances in geopolitics (pp. 26-39). New York: I.B. Tauris \& Co Ltd.

Creswell, J. W. (2009). Research design: Qualitative, quantitative, and mixed methods approaches. Thousand Oaks, CA: Sage Publications, Inc.

Crosby, D., \& Bender, D. (2000). Stand and be counted: Making music, making history. New York: Harper Collins Publishers.

Darwin, C. (1874). The descent of man, and selection in relation to sex. New York: A.L. Burt.

David, G. (2004, June). Vamp 'til ready: Musings on music and emotion. The Tomkins Institute Newsletter , 2 (1), pp. 1-8. 
Davis, H. (2009, November 9). When art becomes critical practice: The village of arts and humanities. Retrieved March 20, 2010, from Politics and culture: http://www.politicsandculture.org/2009/11/09/when-art-becomes-criticalpractice-the-village-of-arts-and-humanities/

Deaux, K. (1993). Reconstructing Social Identity. Personality and Social Psychology Bulletin , 19 (1), 4-12.

DeNora, T. (1999). Music as a Technology of the Self. Poetics , 27 (1), 31-56.

Dixon, M. (2002). Music and human rights. In J. Sutton, Music, music therapy and trauma: International perspectives (pp. 119-132). London: Jessica Kingsley.

Dunn, B. (2008a, June 20). Transforming conflict through music. Cincinnati, Ohio: Doctoral dissertation, Union Institute \& University.

Dunn, D. (2008b). Research methods for social psychology. Oxford: Wiley-Blackwell.

Ehrenzweig, A. (1975). The psychoanalysis of artistic vision and hearing : An introduction to a theory of unconscious perception. London: Sheldon Press.

Eyerman, R., \& Jamison, A. (1998). Music and social movements. Cambridge, UK: Cambridge University Press.

Fawcett, S., Paine-Andrews, A., Francisco, V., Schultz, J., Richter, K. L., Williams, E., et al. (1995). Using Empowerment Theory in Collaborative Partnership for 
Community Health and Development. American Journal of Community Psychology , 23 (5), 677-697.

Fischlin, D. (2003). Rebel musics: Human rights, resistant sounds, and the politics of music making. In D. Fischlin, \& A. Heble, Rebel musics: Human rights, resistant sounds, and the politics of music making (pp. 10-43). Montreal: Black Rose Books.

Follett, M. P. (n.d.). Creative experience. Retrieved April 11, 2010, from Mary Parker Follett Foundation: http://www.follettfoundation.org/writings.htm

Frable, D. (1997). Gender, Racial, Ethnic, Sexual and Class Identities. Annual Review of Psychology , 48, 139-162.

Frankl, V. (2000). Man's search for ultimate meaning. New York: Perseus Publishing.

Freemuse: What is music censorship? (2001, January). Retrieved January 30, 2010, from Freemuse: Freedom of musical expression: http://www.freemuse.org/sw2338.asp

Frequently asked questions about music therapy. (1999). Retrieved January 27, 2010, from American Music Therapy Association: http://www.musictherapy.org/faqs.html\#WHERE_DO_MUSIC_THERAPIST _WORK 
Frith, S. (1987). Towards an aesthetic of popular music. In R. Leppert, \& S.

McClarey, Music and society: The politics of composition, performance and reception (pp. 133-150). Cambridge: Cambridge University Press.

Fromm, E. (1956). The art of loving. New York: Harper Collins Publishers Inc.

Gabriel, P. (2010). WOMAD: About. Retrieved January 30, 2010, from WOMAD.ORG: http://womad.org/about/

Galtung, J. (1990). Cultural Violence. Journal of Peace Research, 27 (3), 291-305.

Ghazzali, A. M. (1991). The alchemy of happiness (trans. C. Field \& Rev. E. Daniel). London: M.E. Sharpe.

Ginow-Hecht, J. (2009). Sound diplomacy: Music and emotions in transatlantic relations, 1850-1920. Chicago: The University of Chicago Press.

Gray, A. (2008). Music as a tool for reconciliation in South Africa. In O. Urbain, Music and conflict transformation: Harmonies and dissonances in geopolitics (pp. 63-77). New York: I.B. Tauris \& Co Ltd.

Grunig, L. (1992). Activism: How it limits the effectiveness of organizations and how excellent public relations departments respond. In J. (. Grunig, Excellence in public relations and communication management: Contributions to effective organizations (pp. 503-530). Hillsdale, NJ: Lawrence Erlbaum Associates. 
Hargreaves, D. J., MacDonald, R., \& Miell, D. (2005). How do people communicate using music? In D. J. Hargreaves, R. MacDonald, \& D. Miell, Musical communicaiton (pp. 1-26). Oxford: Oxford Univeristy Press.

History of music therapy. (2010). Retrieved January 27, 2010, from University Hospitals Health System: Music as Medicine: http://www.musicasmedicine.com/about/history.cfm

Jordanger, V. (2008). Healing cultural violence: "Collective vulnerability" through guided imagery with Music. In O. Urbain, Music and conflict transformation: Harmonies and dissonances in geopolitics (pp. 128-146). New York: I.B. Tauris \& Co Ltd.

Kagan, D. (1995). On the origins of war and the preservation of peace. New York: Anchor Books.

Kant, I. (1951). Critique of judgement. (J. Bernard, Trans.) New York: Hafner Press.

Kent, G. (2008). Unpeaceful music. In O. Urbain, Music and conflict transformation: Harmonies and dissonances in geopolitics (pp. 104-114). New York: I.B. Tauris \& Co Ltd.

Krumhansl, C. (2003). Cerebral Organization of Music-Related Functions Roundtable I: Dissecting the Perceptual Components of Music - Introduction. Annals of the New York Academy of Sciences , 999, 103. 
Lafreniere, B. (2000). Music through the dark. Honolulu: University of Hawai'i Press.

Langholtz, H. (1998). The evolving psychology of peacekeeping. In H. Langholtz, The psychology of peacekeeping (pp. 4-15). Westport, CT: Praeger.

Laurence, F. (2008). Music and empathy. In O. Urbain, Music and conflict transformation: Harmonies and dissonances in geopolitics (pp. 13-25). New York: I.B. Tauris \& Co Ltd.

Lederach, J.P. (1995). Preparing for peace: Conflict transformation across cultures. Syracuse: Syracuse University Press.

Lederach, J.P. (2003). The little book of conflict transformation. Intercourse, PA: Good Books.

Lederach, J. P. (2005). The moral imagination: The art and soul of building peace. Oxford: Oxford University Press.

Levitin, D. (2006). This is your brain on music: The science of a human obsession. New York: Penguin Group.

Levitin, D. (2008). The world in six songs: How the musical brain created human nature. New York: Penguin Group Inc.

Live 8: The story so far. (2010). Retrieved March 15, 2010, from Live 8: http://www.live8live.com/media/index.shtml\# 
Live Aid. (2010). Retrieved March 15, 2010, from bobgeldof.info:

http://www.bobgeldof.info/Charity/liveaid.html

Live Science. (2005, May 25). Retrieved January 26, 2010, from Health: Music during surgery reduces sedation needs:

http://www.livescience.com/health/050525_music_surgery.html

Longfellow, H. (2008). Quotation park. Retrieved January 25, 2010, from Longfellow, Henry Wadsworth (1807-1882), American poet: http://quotationpark.com/authors/LONGFELLOW,\%20Henry\%20Wadsworth. html

Lopéz-Vinader, M. (2008). Music therapy: Healing, growth, creating a culture of peace. In O. Urbain, Music and conflict transformation: Harmonies and dissonances in geopolitics (pp. 147-171). New York: I.B. Tauris \& Co Ltd.

Marks, M., \& Fischer, Z. (2002). The King's New Bodies: Simulating Consent in the Age of Celebrity. New Political Science, 24 (3), 371-394.

Maslow, A. (1943). A Thoery of Human Motivation. Psychological Review , 50, 370396.

Mattern, M. (1998). Acting in concert: Music, community, and political action. New Brunswick: Rutgers University Press. 
Merriam, S. \& Associates. (2002). Qualitative research in practice: Examples for discussion and analysis. San Francisco: Jossey-Bass.

Meyer, L. B. (1967). Music, the arts, and ideas. Chicago: The University of Chicago Press.

Miall, H. (2004). Conflict transformation: A multi-dimensional task. (M. Fischer, \& B. Schmelzle, Eds.) Retrieved January 25, 2010, from Berghof handbook for conflict transformation: http://www.shatil.org.il/files/miall_handbook_0.pdf

Naidus, B. (2009). Arts for change. Oakland, CA: New Village Press.

Nandorfy, M. (2003). The right to live in peace: Freedom and social justice in the songs of Violeta Parra and Victor Jara. In D. Fischlin, \& A. Heble, Rebel musics: Human rights, resistant sounds, and the politics of music making (pp. 172-209). Montreal: Black Rose Books.

Nussbaum, M. (2003). Upheavals of thought: The intelligence of emotions. Cambridge: Cambridge University Press.

Orris, M. (2003, April 10). The Badger Herald. Retrieved January 30, 2010, from Protest music a thing of the past: http://badgerherald.com/news/2003/04/10/protest_music_a_thin.php

Parkins, K. (2007, March). AfroReggae. Retrieved April 7, 2010, from The New York Times: http://home.clara.net/heureka/music/afroreggae.htm 
Perris, A. (1985). Music as propaganda: Art to persuade, art to control. Westport, CT: Greenwood Press.

Petersen, E. (2005, November 1). Voices: A world forum for music therapy. Retrieved January 27, 2010, from Music therapy and oncology at the National Institute of Cancer: http://www.voices.no/mainissues/mi40005000195.html

Pinnegar, S., \& Daynes, G. (2007). Locating narrative inquiry historically: Thematics in the turn to narrative. In D. J. Clandinin, Handbook of narrative inquiry: Mapping a methodology (pp. 3-34). Thousand Oaks, CA: Sage Publications, Inc.

Puterbaugh, P. (2004, February 15). Sounds of silence: Pop music today has no political edge. Greensboro (NC) News \& Record, p. H1.

Ramos, S., \& Ochoa, A. (2009). Music and human rights: The AfroReggae Cultural Group and the youth from the favelas as responses to violence in Brazil. In A. Weintraub, \& B. Yung, Music \& cultural rights (pp. 219-240). Champaign, IL: University of Illinois Press.

Reeves-Smith, T. L. (2007). Entertainers who lead: A phenomenological study of leadership and celebrity politics (doctoral dissertation, Gonzaga University, 2007). Digital Dissertations .

Retzinger, S., \& Scheff, T. (2000). Emotion, Alienation, and Narratives: Resolving Intractable Conflict. Mediation Quarterly, 71-85. 
Rosaldo, M. Z. (1984). Toward an anthropology of self and feeling. In R. Shweder, \& R. LeVine, Culture theory: Essays on mind, self, and emotion (pp. 137-157). Cambridge, UK: Cambridge University Press.

Sacks, O. (2007). Musicophilia: Tales of music and the brain. New York: Random House Inc.

Schulevitz, J. (2010, March 31). Making room for the Sabbath. (T. Gross, Interviewer) NPR. WHYY.

Schweitzer, A. (1975). Thoughts for our times. White Plains, NY: Peter Pauper Press.

Sharrock, D. (2008, June 7). Cellist of Sarajevo, Vedran Smailovic, is wounded by words. Retrieved February 8, 2010, from Times online: http://entertainment.timesonline.co.uk/tol/arts_and_entertainment/books/article 4083037.ece

Simmel, G. (1955). Conflict and the web of group-affiliations. New York: The Free Press.

Sites, P. (1973). Control: The basics of social order. New York: Dunellen Pub. Co.

Skyllstad, K. (2008). Managing conflicts through music: Educational perspectives. In O. Urbain, Music and conflict transformation: Harmonies and dissonances in geopolitics (pp. 172-186). New York: I.B. Tauris \& Co Ltd. 
Sloboda, J., \& O'Neill, S. (2001). Emotions in everyday listening to music. In P. Juslin, \& J. A. Sloboda, Music and emotions (pp. 415-430). New York: Oxford University Press.

Small, C. (1995, June 6). Musicking: A ritual in social space. Retrieved March 16, 2010, from Musicians United for Superior Education: http://www.musekids.org/musicking.html

Social movement. (2010). Retrieved April 11, 2010, from Encyclopedia Britannica: http://www.britannica.com/EBchecked/topic/551335/social-movement

Sousa, D. (2006a). How the Arts Develop the Young Brain. School Administrator, 63 (11), 26-31.

Sousa, D. (2006b). How the brain learns. Thousand Oaks, CA: Corwin Press.

Staub, E. (2003). The psychology of good and evil: Why children, adults, and groups help and harm others. Cambridge: Cambridge University Press.

Stein, E. (1989). On the problem of empathy. Washington, DC: ICS Publications.

Stokes, M. (1997). Ethnicity, identity and music: The musical construction of place. New York: Berg Publishers.

Storr, A. (1992). Music and the mind. New York: Ballantine Books.

Street, J. (2004). Celebrity Politicians: Popular Culture and Political Representation. British Journal of Politics \& International Relations , 6 (4), 435-452. 
Tame, D. (1984). The secret power of music. Rochester, VT: Destiny Books.

The universal declaration on human rights. (2010). Retrieved March 1, 2010, from The United Nations: http://www.un.org/en/documents/udhr/index.shtml\#a19

Thoreau, H. (2010). Henry David Thoreau Quotes. Retrieved April 11, 2010, from Quotes.net: http://www.quotes.net/quote/4767

Urbain, O. (2008). Introduction. In O. Urbain, Music and conflict transformation: Harmonies and dissonances in geopolitics (pp. 1-12). New York: I.B. Tauris \& Co Ltd.

van den Dungen, P. (2008). Foreword. In O. Urbain, Music and conflict transformation: Harmonies and dissonances in geopolitics (pp. xv-xvi). New York: I.B. Tauris \& Co Ltd.

Vinciguerra, T. (2005, December 25). The truce of Christmas, 1914. Retrieved February 1, 2010, from The New York Times: http://www.nytimes.com/2005/12/25/weekinreview/25word.ready.html?_r=1\& pagewanted $=$ all

Wallensteen, P. (2007). Understanding conflict resolution. Thousand Oaks, CA: Sage Publications Inc. (2nd Edition).

Weinberger, N. (2004). Music and the Brain. Scientific American , 291 (5). 
Weintraub, A. (2009). Introduction. In A. Weintraub, \& B. Yung, Music \& cultural rights (pp. 1-18). Champaign, IL: University of Illinois Press.

White Power MP3s. (2007). Retrieved January 31, 2010, from Tightrope: It's not illegal to be white...yet: http://www.tightrope.cc/mp3page.htm

White, B., \& Niles, Z. (Directors). (2005). Sierra Leone's Refugee All Stars [Motion Picture].

Whitehead, B. (2008). We shall overcome: The roles of music in the US Civil Rights movement. In O. Urbain, Music and conflict transformation: Harmonies and dissonances in geopolitics (pp. 78-92). New York: I.B. Tauris \& Co. Ltd.

Wilmot, W., \& Hocker, J. (2001). Interpersonal conflict. New York: McGraw-Hill (Sixth Edition).

Woodhouse, T. (1998). Peacekeeping and the psychology of conflict resolution. In H. Langholtz, The psychology of peacekeeping (pp. 153-166). Westport, CT: Praeger.

Zartman, W. I. (2003, September). Ripeness-promoting strategies. (G. Burgess, \& H. Burgess, Eds.) Retrieved February 11, 2010, from Beyond intractability: http://www.beyondintractability.org/essay/ripenesspromoting_strategies/?nid=1298 


\section{APPENDIX A: INTRODUCTORY EMAIL}

Dear

I am a graduate student at Portland State University in the Conflict Resolution Department and am currently working on a master's thesis about the role music can play in the world of activism and social/community engagement. I recently became aware of your work with and think you would be an interesting person to talk with about my thesis research.

I am writing to you because I am wondering if you would be willing to participate in an interview with me to explore this topic more in depth? My guess is the interview process will last approximately two hours (at the most) and I am more than happy to meet you in the most convenient place for you. I will attach my consent form and interview questions to this email so you can look them over and get a bit more information about what I am doing. If you have any questions for me, please let me know!

I would be honored to meet with you and talk to you about your experiences and ideas around this topic if you have time and are willing! Having the opportunity to talk to you about the activities you are involved in will be a great addition to my research exploring the relationship between music and conflict resolution.

Let me know if this is a possibility for you and then we can go from there! All the best to you, Mindy Johnston (503) 995-6502 


\section{APPENDIX B: INTERVIEW QUESTIONS}

\section{Music and Conflict Resolution: Exploring the Utilization of Music for Peaceful Engagement}

This interview is set up so you can answer the questions in any order you choose. There are two questions I would like to make sure you address, marked with a star. Other than those two questions, if there are questions you don't want to address, you can simply skip them. There are three categories of questions here, coded by color. These categories are personal stories (blue), application (green) and theory (pink).

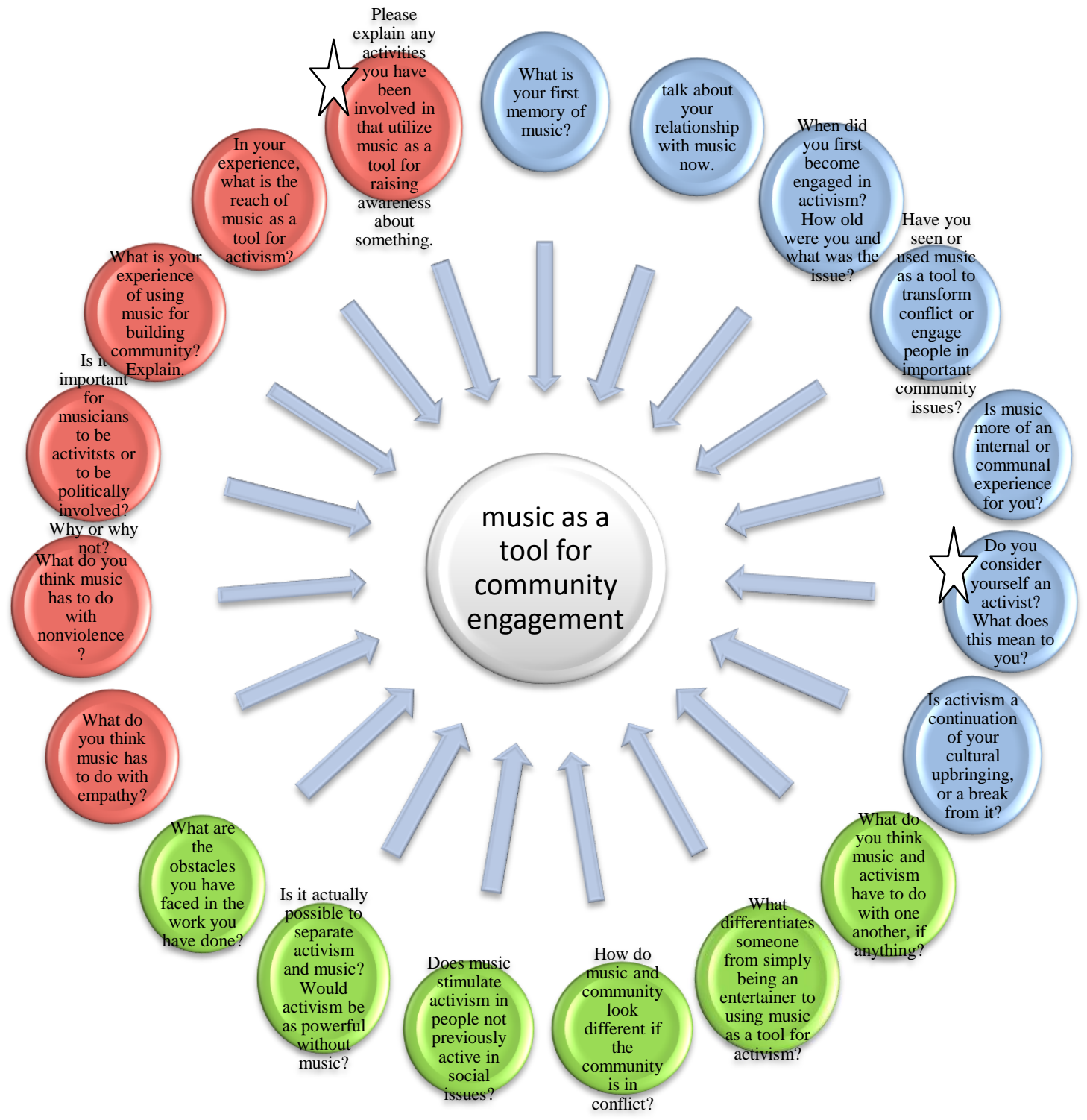




\section{APPENDIX C: INFORMED CONSENT}

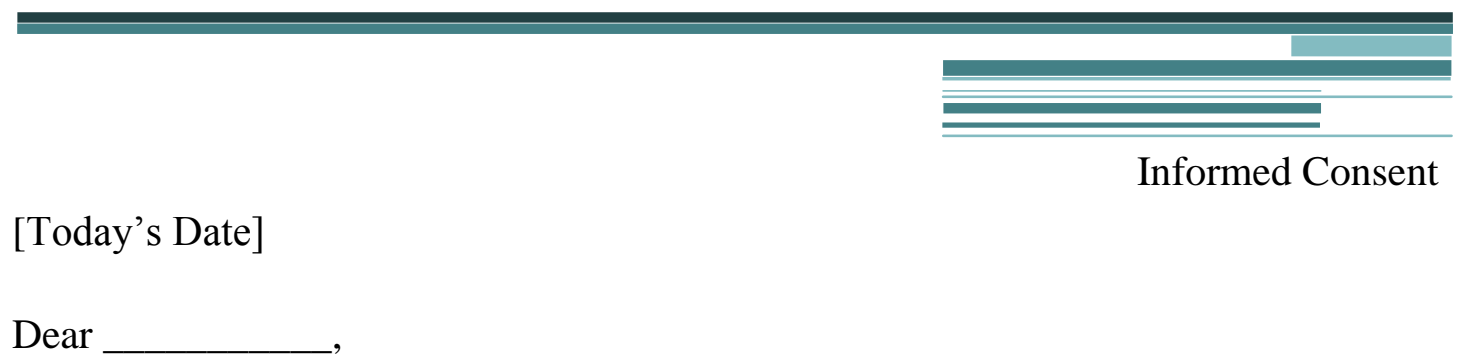

You are invited to participate in a research study conducted by Mindy Johnston, from Portland State University (PSU), Conflict Resolution Department. The researcher hopes to learn more about how music is being used as a tool for engagement in activism and to address conflict situations. This research is being completed for partial fulfillment for a master's degree in Conflict Resolution and is under the close supervision of Rachel Hardesty at Portland State University. You were selected as a possible participant in this study because of your experience using music to engage people in activism through your work with The researcher is interested in your opinions and attitudes about the role of music in engaging people in activism and potentially transforming conflict and feel you would be a valuable addition to this study.

If you decide to participate, you will be asked to participate in an interview with the researcher, lasting no more than two hours. The purpose of the interview will be to explore the activities you are currently involved in and to explore your opinions and thoughts related to the subject, music and conflict resolution. The researcher will record the interview, and would like to take photos of you at the time of the interview. While participating in this study it is possible that the topic will feel uncomfortable, as the researcher will ask you questions related to experiences of conflict in your life or the community in which you live, but in general there are no foreseeable risks to you by participating in this study. If you do feel uncomfortable by any of the questions, you may simply pass that question and move on to the next. You may not receive any direct benefit from taking part in this study, but the study may help to increase knowledge about the power of utilizing music in conflict and as a result get more people involved in activities like you are involved in, working to create change and a better world for all. 
Any information that is obtained in connection with this study and that can be linked to you or identify you will be kept confidential if that is your preference. If not, all ideas and statements that the researcher uses from the interview will be credited to you by name. None of the information the researcher gathers from the interview will be released to any other person or agency and will be used for the sole purpose of this study. Except for the data used in the thesis, all other transcripts and recordings from the interview will be stored in a locked filing cabinet and will be kept confidential.

Your participation is voluntary. You do not have to take part in this study, and if you decide not to it will not affect your relationship with the researcher or Portland State University. You may also withdraw from this study at any time without affecting your relationship with the researcher or PSU.

If you have concerns or problems about your participation in this study or your rights as a research subject, please contact the Human Subjects Research Review Committee, Office of Research and Sponsored Projects, 600 Unitus Bldg., Portland State University, (503) 725-4288/ 1-877-480-4400. If you have questions about the study itself, please contact Mindy Johnston at mindykayj@yahoo.com or (503)-995-6502.

Your signature indicates that you have read and understand the above information and agree to take part in this study. Please understand that you may withdraw your consent at any time without penalty, and that, by signing, you are not waiving any legal claims, rights or remedies. The researcher will provide you with a copy of this form for your own records.

Thank you for your consideration and potential participation in this study. Please sign and date below if you agree to participate in this study:

Signature

Date

Recording the Interview: With your permission, the interview will be recorded and later transcribed by the researcher. By signing below you are giving your permission for the interview to be recorded:

Signature

Date 
Photograph: With your permission, the researcher would like to take a photograph of you with your instrument or band. If you choose to remain anonymous, the photo can be cropped to maintain anonymity. By signing below you are giving your permission to be photographed:

Identity: Do you wish to remain anonymous in this study? $\square$ yes $\square$ no

If yes, your preferred pseudonym:

(If you do not want to create a pseudonym the researcher will create one for you.)

If you have agreed to have a photo taken and wish to remain anonymous, your photo will be cropped in a manner to keep your identity anonymous. 


\section{APPENDIX D: HUMAN SUBJECTS RESEARCH REVIEW APPLICATION}

I. Project Title and Prospectus: Music and Conflict Resolution: Exploring the Utilization of Music for Peaceful Engagement

I will explore the role of music in communities dealing with conflict, or in specific social movements, and how it can influence or transform conflict situations. The research will focus on the attitudes and beliefs of specific musician/activists and how they have utilized music to engage people in activism or to address a conflict they are facing in their community. This study is significant because music plays an important role in cultural identity, as well as providing meaning and direction in people's lives. The more we can broaden the scope of tools that are considered in the field of conflict resolution, the more potential there is that exists in finding common understanding between people and in finding resolution to negative conflicts.

I will utilize a qualitative research approach for this study. I have chosen this approach because it will allow me to focus on the participant's perspectives and stories, which is most appropriate for understanding this exploratory topic from a variety of angles. Qualitative research methodology is most suited for this thesis topic because it will allow me to explore this topic in-depth and gain an understanding for how different individuals view this relationship between music, activism and conflicts they experience. Qualitative research will invite participants to tell their stories about how they view the relationship between music and engagement in activism, and it is this space for telling and analyzing the individual stories in qualitative research that makes it the most appropriate choice for this thesis. I will utilize a narrative research strategy with the aim of giving a comprehensive analysis of how music has the potential to engage people in activism and potentially alter conflict. 


\section{Exemption Claim for Waiver of Review}

It is my understanding that I will be required to have an expedited review because my study will use methods that apply to points 6 (data from voice) and 7 (research employing interview) in this section.

\section{Subject Recruitment}

I would like to recruit a minimum of ten to fifteen subjects for this research study. I will be responsible for recruiting all participants. Musician/activists from or visiting Portland who have done work related to activism, or who have utilized music within a community dealing with conflict as a medium for building peace will be invited to participate in this research. I will also invite musician/activists from the Madison, Wisconsin and Chicago, Illinois area as I will be there in June and July 2009 and will be able to meet with people for in-person interviews. These subjects will be invited based on their engagement and activities related to this subject. In addition, they will range from hobby to professional musicians, and can vary in age, from teenagers to retirement. As much as possible, I would like a cross section of subjects from different nationalities, races, gender, age, socio-economic class and background experience.

\section{$\underline{\text { IV. Informed Consent }}$}

For each interview conducted, I will administer an informed consent to the potential participant, first clearly explaining the purpose of the research, the potential risks to the subject, the request to use photographs that I will take and the expected use of the data gathered. I will give each subject the opportunity to participate in the research anonymously and to create their own pseudonym. It is expected that I will have adult and minor (teenagers) subjects and will therefore obtain the appropriate informed consent form to be signed by each subject and the witnesses or guardians before collecting any data. Participants will have the option at any time of withdrawing from the study without any penalty. 


\section{$\underline{\text { V. First-Person Scenario }}$}

I received an email last week from Mindy Johnston, a student at Portland State University, describing her master's thesis and the research she hopes to conduct. Her email explained she is exploring the relationship of how music might be used in conflict resolution and engagement in activism. She asked to interview me because of my experiences in using music as a tool for engagement. Once I decided to participate in Mindy's research, she asked me when and where I would like to meet. I decided it would be fun for her to see my studio, so we met there the following week for the interview. She conducted the interview in a casual manner that lasted about two hours, taking notes and also utilizing a minidisc player to record our interview. Instead of asking the usual list of questions, Mindy had a diagram of the topics/questions she wanted to ask and let me go through the questions in the order I preferred. This gave me a chance to look over her questions, and respond thoughtfully - in whatever order I wanted. After the interview was finished we agreed that Mindy would provide me with a copy of the transcript of the interview, and I offered that if she had any further questions she could contact me. She also agreed that once her thesis is complete she will be in touch to see if I would like to have a copy of her finished thesis.

\section{Potential Risks and Safeguards}

There are no possible physical risks of this project. The subject matter could possibly be of a sensitive psychological nature when exploring past conflicts that impacted the subject's life and the role of the subject within a community, producing feelings of embarrassment, shyness or discomfort normally expected in such interviews. Some subjects might feel uneasy in recalling past events, or by telling stories of the past the subject might again feel the strain or emotion of the situation, particularly if the conflict is not completely resolved. Due to the potential delicate nature of the content related to conflict, whenever possible, the subjects will receive a copy of the interview questions before the actual interview takes place. The subject 
will have absolute freedom to skip any questions which might feel uncomfortable.

Despite the research not being absolutely void of any risks, the seriousness of potential harm to the subjects is very low.

\section{$\underline{\text { VII. Potential Benefits }}$}

The potential benefits of this study is that it will add to the body of literature related to the fields of conflict resolution and music, providing new information to both of these fields and as a result further legitimizing the utilization of music as a tool for peaceful activism and as a result potentially transform conflict situations and promote healing. There has not been enough extensive research done in either field about the relationship of music in conflict resolution. For each field, this research might provide more information about the benefits of utilizing music in conflict situations, and as a result have a positive impact on more people in the future, particularly in the very situations that can cause high levels of duress and that would benefit the most in having a healthy, nonviolent approach, which music can provide. This study will give participants the opportunity to voice their ideas, stories and opinions about this topic. Research has shown that reflection is an integrative function that can create mental modes (helping to create memory), making activities more effective in the future. In giving participants an opportunity to talk about this subject in a meaningful way, this study will provide a reciprocal exchange of ideas between the participant and the research being conducted. It will also bring attention to a larger audience in academia, giving validity and possible opportunity to future musician/activists.

\section{Records \& Distribution}

Results of interviews will be recorded in three ways: 1) hand written in a notebook, 2) typed on a laptop computer and 3) recorded on a Sony minidisc player. If a subject wishes to remain anonymous in the thesis manuscript, I will implement the utilization of a pseudonym to conceal his/her identity, which the participant can create 
if he/she wishes. There will be no group interviews or focus groups. During and after the course of the research, I will be the only person accessing the research data, and therefore there are no concerns about the identity of the subject being known to anyone else. It will be noted in the cover letter and in the consent form that I will be recording the interviews and transcriptions of these interviews can be made available to the subjects upon request. All materials related to this thesis (interviews, recordings, articles, notes and photographs) will be stored in a file cabinet in my home for the duration of three years after the research is completed. The digital files on the computer will be safeguarded by a login password only known to myself.

\section{$\underline{\text { IX. Appendix }}$}

- Introductory script 


\section{HSRRC Appendix: Introductory Script}

Hello, thank you again for taking time to meet with me today for this interview. I greatly appreciate the opportunity to meet with you and talk about your experience and knowledge related to my research study about music and conflict resolution. Today you will be provided with several questions pertaining to your experience and ideas related to music and activism.

I want to remind you that your presence here today is completely voluntary and if at any time you feel uncomfortable then we can stop the interview. If the interview process is stopped it will not disrupt our relationship or your relationship with the Conflict Resolution Department at Portland State University.

I have set up the interview questions in a format that allows you to choose which questions to answer and in whatever order you would like. If there are any questions that make you feel uncomfortable or that for whatever reason you do not want to respond to then you can simply pass over that question and move to another question in the circle that you would like to respond to.

I am very excited about my research and feel this is a great opportunity to expand the legitimacy between music and activism, as well as educating more people about this topic. Thank you again for taking part in my study. If you don't have any questions we can go ahead and begin.

After the interview has taken place I will thank the participant and make sure we have exchanged contact information if further questions and concerns arise in the future. 